\title{
Measuring and Decomposing of China's Agricultural Productivity and Environmental Efficiency
}

\author{
Dissertation \\ to attain the doctoral degree Dr.rer.pol \\ in the International Ph.D. Program for Agricultural Sciences in \\ Göttingen (IPAG) at the Faculty of Agricultural Sciences, \\ Georg-August-University Göttingen, Germany
}

\author{
submitted by Ma, Yuan \\ born in Inner Mongolia, China
}

Göttingen, November 2020 
$1^{\text {st }}$ Referee: Prof. Dr. Bernhard Brümmer

$2^{\text {nd }}$ Referee: Prof. Dr. Xiaohua Yu

$3^{\text {rd }}$ Referee: Prof. Dr. Meike Wollni

Date of disputation: February 12, 2021 


\section{Acknowledgements}

During the Ph.D. period, there are too many people, to whom I need to express my thanks. First, I would like to express my deep gratitude to my supervisor Prof. Dr. Bernhard Brümmer, who supervised the whole work in the past years and always provided helpful suggestions. No matter how complex or simple my questions were, Prof. Brümmer would shed light on the causes of my research issues and point out the possible solutions. Every time after discussion with Prof. Brümmer, I was inspired by the helpful advice and ready to devote myself to my research.

Moreover, I would like to extend my sincere thanks to Prof. Dr. Xiaohua Yu, who introduced me to Prof. Brümmer and provided me with research data. Additionally, I am grateful that Prof. Dr. Xiaohua Yu and Prof. Dr. Meike Wollni examined this dissertation and gave insightful comments on it. I am also thankful that Prof. Dr. Xiaohua Yu and Dr. Bernhard Dalheimer enlightened me as to the existing problems in my work at doctoral colloquium and provided insights into improving it.

Also, I would like to thank my colleagues in the chair group for their companionship, advice, assistance and all the happy hours in the past years. Many thanks to my friends in Germany, who made my time in Germany easier and happier. Besides, I am quite grateful that Chinese Scholarship Council provides me financial support, which allows me to focus on my research.

Last but not least, I would like to thank my parents. Thank you for trusting and supporting me all the time. 


\section{Summary}

China's agricultural productivity has achieved remarkable accomplishments in agricultural sector after China's accession to World Trade Organization (WTO). According to National Bureau of Statistics of China (NBSC), the total meat production in 2018 is $43 \%$ more than in 2000 , and the total cereal production in 2018 is $51 \%$ more than in $2000 .{ }^{1}$ However, the rapid development of agriculture is associated with environmental pollution. Since China's rice output has quadrupled compared to the level in $1949,{ }^{2}$ the rice production growth has serious repercussions on environment, which results in severe chemical fertilizer pollution. The amount of nitrogen fertilizer applied $\left(209 \mathrm{~kg} \mathrm{ha}^{-1}\right)$ during rice production in China is $90 \%$ higher than global average level (Chen et al., 2014), and the $\mathrm{N}$ taken by rice is only 30-35\% (Peng et al., 2009; Xu et al., 2012).

In general, this research focuses on two empirical issues: one is the trade effects on China's agricultural productivity, the other is measuring environmental efficiency and finding solutions for $\mathrm{N}$ pollution problem. First, we try to investigate the trade impacts on China's agricultural productivity change and answer following questions. How productivity changes after China's entry to WTO? Is there a substantial productivity growth behind yield growth? What's the main factor behind TFP change? Second, we focus on evaluating environmental performance within the framework of productivity analysis and tackling $\mathrm{N}$ pollution issue. We try to measure China's environmental efficiency and nitrogen use efficiency in particular to examine whether NUE is low, what factors lead to current NUE and what are the possible ways to abate $\mathrm{N}$ pollution.

To measure China's productivity change before and after China's entry to WTO and analyze trade impacts on agriculture, the Stochastic Frontier Analysis (SFA) method is

\footnotetext{
1 The figures are calculated according to China Statistical Yearbook.

2 The figure is calculated according to China Statistical Yearbook.
} 
adopted. For the measurement of environmental efficiency, both Data Envelopment Analysis (DEA) and SFA are applied to estimate environmental productivity. Furthermore, based on empirical researches, both agricultural and environmental TFP are decomposed into explicit components to explore the decisive factors accounted for productivity change.

In Chapter 2, we measure total factor productivity change in China's agricultural sector before and after China's entry to WTO, and obtain following conclusions. First, land, labor, intermediate input and capital could all lead to output growth. Second, China's productivity increases during the whole research period, and TFP growth rate rises slightly after China's entry to WTO. Third, the main contributors to TFP growth are not the same for the two subsamples. Before China's accession to WTO, productivity growth majorly owes to allocative effect of pork and other meat and the considerable technical progress, while allocative effect of crop and land and technical progress are contributing factors after China's accession to WTO. Fourth, the development of technology achieves steady and substantial progress during the research period. Fifth, export has significant positive effect on technical efficiency before China's entry to WTO, while import presents negative effect on technical efficiency after China's entry to WTO.

In Chapter 3, we measure and decompose China's environmental productivity when production technology exhibits VRS. Based on the empirical research on rice production, we obtain following findings. First, the annual INE scores experience a mild fluctuation in 2004-2010, and the average INE indicates there is large potential to reduce current $\mathrm{N}$ input by $39 \%$. Second, rice farmers in Hubei Province are already located at the most productive scale size. Third, RDTFP presents an annual decreasing rate owing to technical regress. Fourth, due to time lags and overestimation of inefficiency, the changing direction of TEC and TC are different. Fifth, rice farmers could decrease 19\% of the nitrogen emissions based on the technical-efficient point on the CRS frontier. Sixth, NASEC is found to be more strongly correlated with NTFPC. Seventh, the changing direction of NTFP is consistent with 


\section{RDTFP.}

In Chapter 4, we measure current TFP in rice production using SFA and analyze factors behind environmental productivity variation. After our empirical research on rice production, the main findings are as follows. First, increases in fertilizer $\mathrm{N}$ contents, land $\mathrm{N}$ contents, rice output, labor and intermediate input could all lead to N growth. Second, compared with fertilizer $\mathrm{N}$ contents, land $\mathrm{N}$ contents variation could lead to a larger rise in total $\mathrm{N}$. Third, due to the complementary relationship between fertilizer and quasi-fixed input, increases in labor and intermediate input can also lead to total $\mathrm{N}$ growth indirectly through fertilizer increase. Fourth, technical efficiency in rice production remains stable during 2004-2010. Fifth, TFP is decreasing at an average annual rate of $2 \%$, which is attributed to the negative impacts of the allocative effect of fertilizer nutrient, the effect of capital and technical regress. Sixth, the negative allocative effect of fertilizer $\mathrm{N}$ contents indicates that farmers use more fertilizer than they need. Seventh, due to the improvement of industrialization and low NUE, total $\mathrm{N}$ slightly increases at a rate of $1.6 \%$ every year.

The empirical findings provide several policy implications. First, encouraging technological innovation and developing an efficient fertilizer application approach may be a prior choice for promoting agricultural development and soil conservation in the future. Second, to become crop production allocative-efficient, government could cut subsidies and national support concerning crop production. Third, enacting more proposals and regulations on perfecting the land circulation market and protecting arable land from using for commercial purpose could help reduce land allocative inefficiency. Fourth, government's intervention and punishment on overuse of $\mathrm{N}$ fertilizer is necessary, due to the great potential of reducing $\mathrm{N}$ pollution by using less $\mathrm{N}$. Fifth, after satisfying the current minimum amount of $\mathrm{N}$ input to become technical-efficient and scale-efficient, policy makers could guide farmers to reallocate their input combination to become environmental-efficient, since it is an effective way to prevent $\mathrm{N}$ pollution. Sixth, using less fertilizer, integrating small fragmented land and using land efficiently are beneficial to eliminating nutrient allocative 
inefficiency and improving TFP. Seventh, developing sustainable agriculture instead of high energy consumption, high waste and low efficiency agriculture could help to prevent $\mathrm{N}$ pollution growing over the years. 


\section{Content}

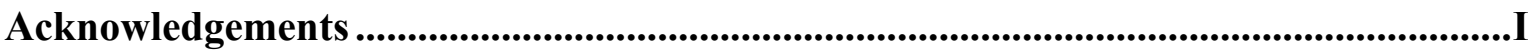

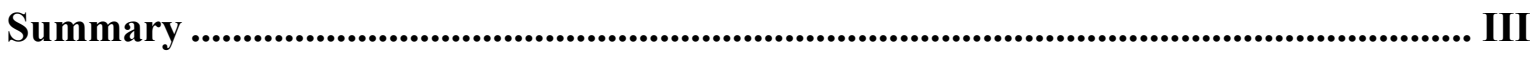

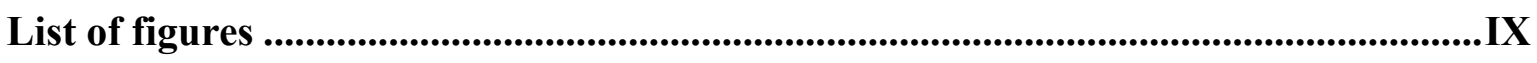

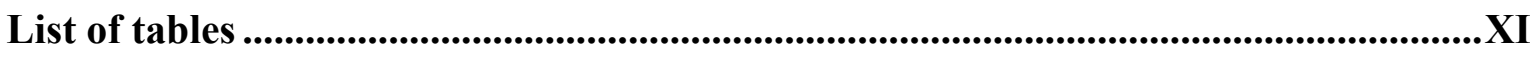

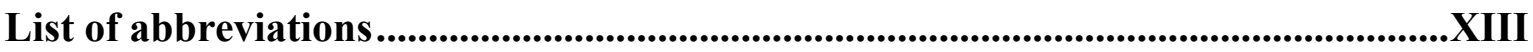

Chapter 1 Introduction .......................................................................................................... 1

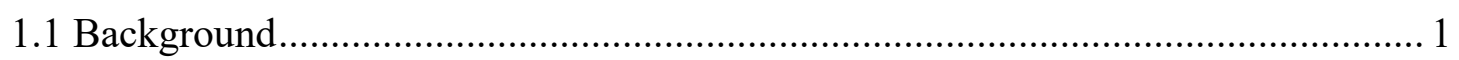

1.1.1 China's production situation of meat................................................... 1

1.1.2 China's production situation of cereal .................................................. 3

1.1.3 China's chemical fertilizer pollution ....................................................... 4

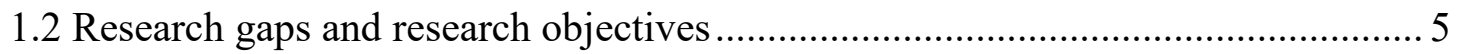

1.2.1 One-step estimation of technical efficiency determinants......................... 5

1.2.2 Measuring and decomposing environmental TFP using DEA ................... 6

1.2.3 Measuring and decomposing environmental TFP using SFA .................... 6

Chapter 2 China's trade development and agricultural productivity change................8 8

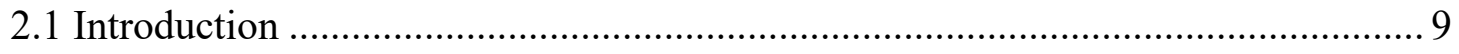

2.2 Agricultural trade development in China......................................................... 11

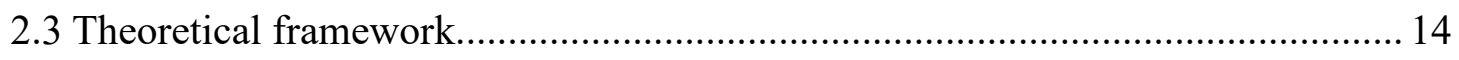

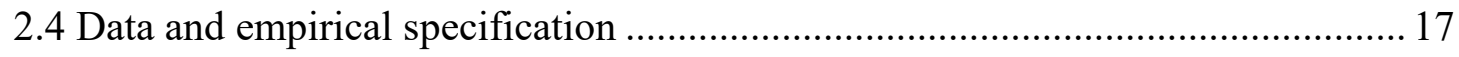

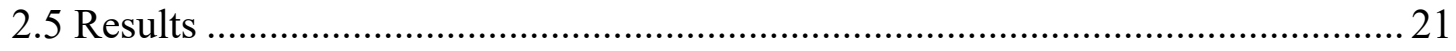

2.5.1 Parameter estimates and distance elasticities ......................................... 22

2.5.2 Technical efficiency and its determinants............................................. 23

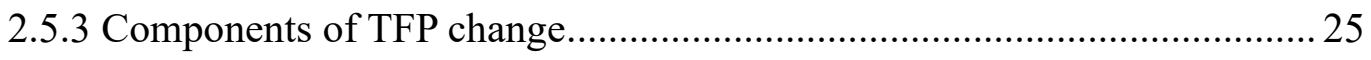

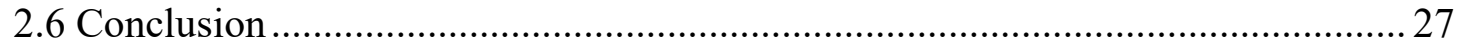

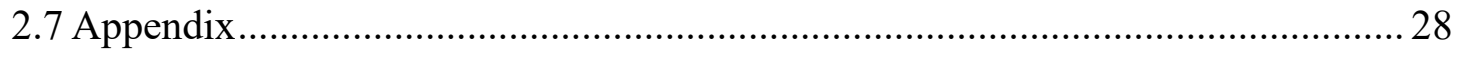


Chapter 3 Measurement of China's environmental related total factor productivity

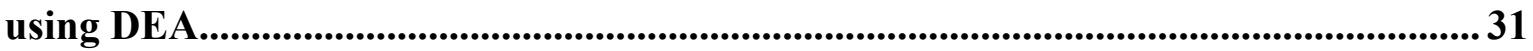

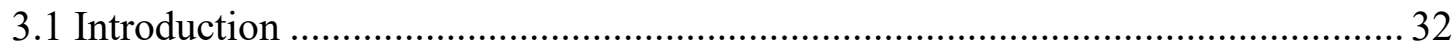

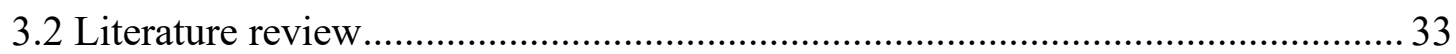

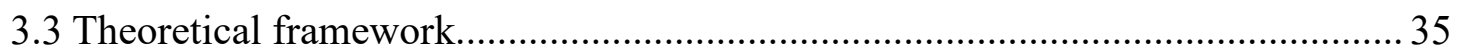

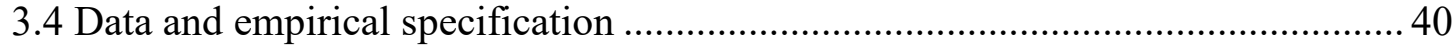

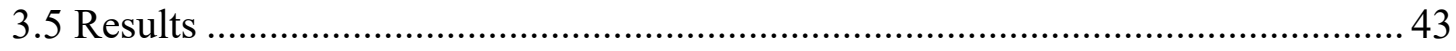

3.5.1 Efficiency levels of ITE, INASE, SE and INE..................................... 43

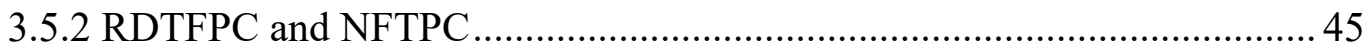

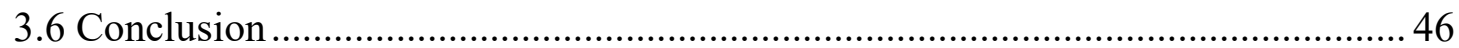

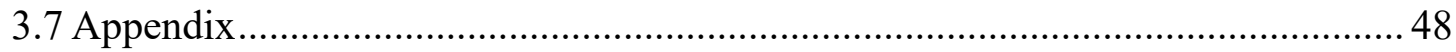

Chapter 4 Measurement of China's environmental related total factor productivity

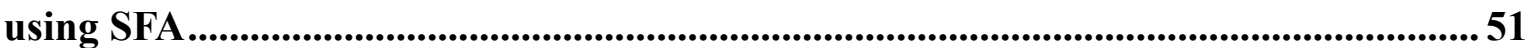

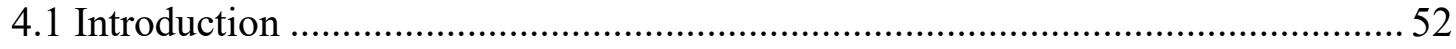

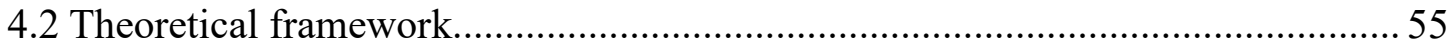

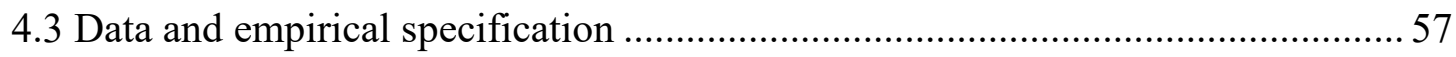

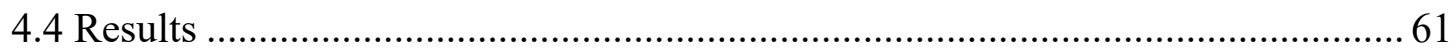

4.4.1 Parameter estimates and technical efficiency ........................................... 62

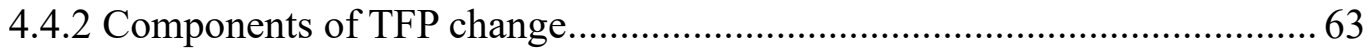

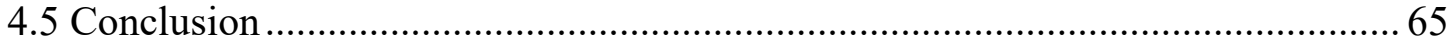

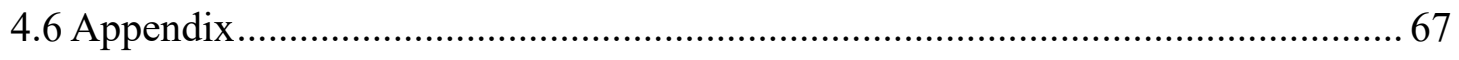

Chapter 5 General conclusion ................................................................................................. 70

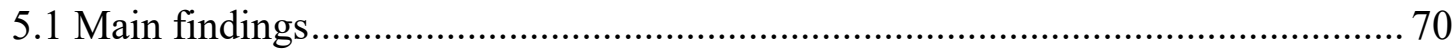

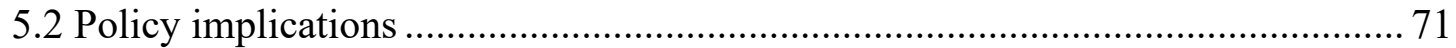

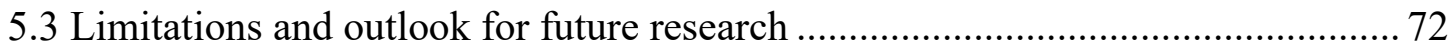

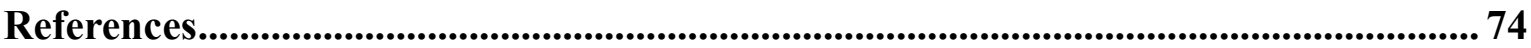




\section{List of figures}

Figure 1.1 Production of 5 main types of meat from 1995 to 2018 .................................. 2

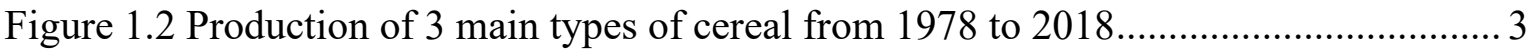

Figure 1.3 Application of 4 main types of fertilizer from 2000 to 2018 ............................ 4

Figure 2.1 China's annual agricultural trade amount (1994-2001) ................................... 13

Figure 2.2 China's annual agricultural trade amount (2002-2010) ................................. 14

Figure 3.1 INE components under VRS for the two-input and single-output case ............. 38

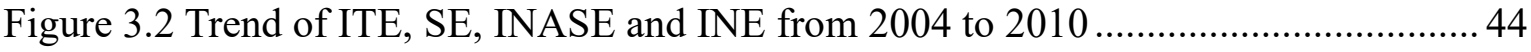

Figure 3.3 Trend of NTFPC, RDTFPC and their components from 2004 to 2009 ............ 46 


\section{List of tables}

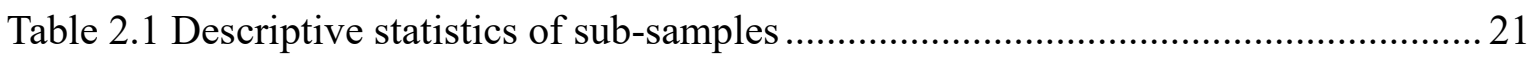

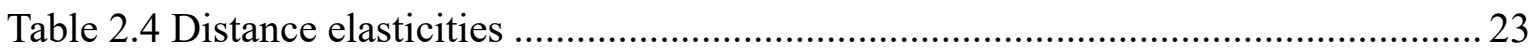

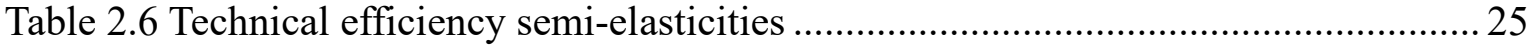

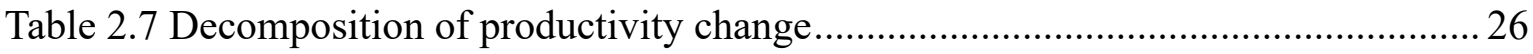

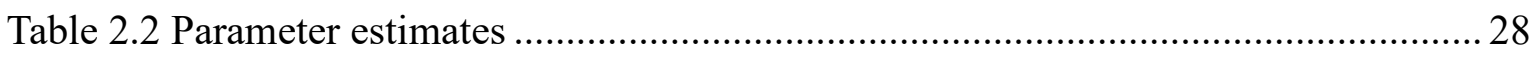

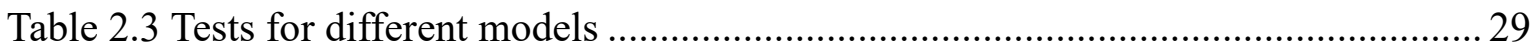

Table 2.5 Technical efficiency over the observation period .......................................... 30

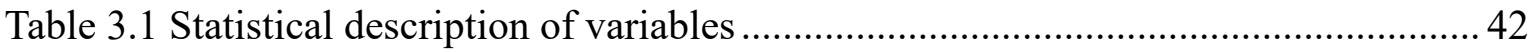

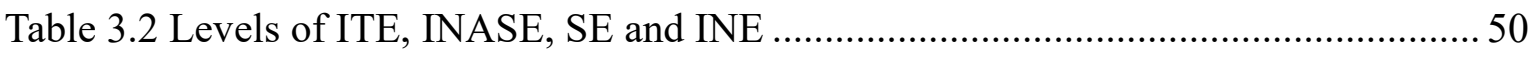

Table 3.3 Levels of TEC, TC, SEC, RDTFPC, NASEC and NTFPC …............................50

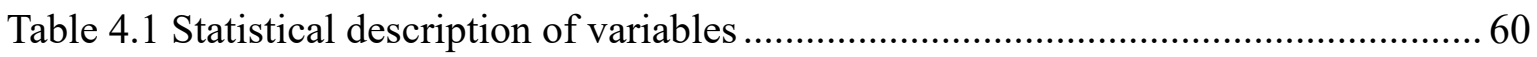

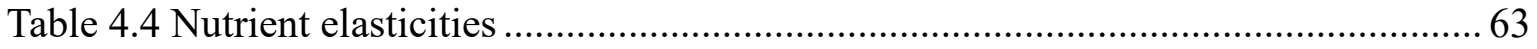

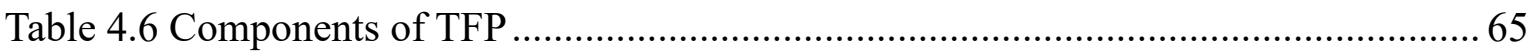

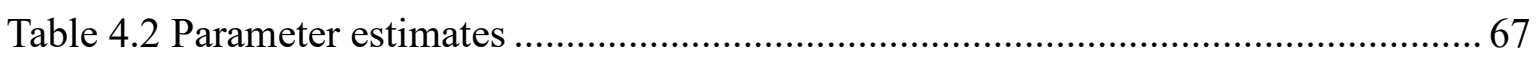

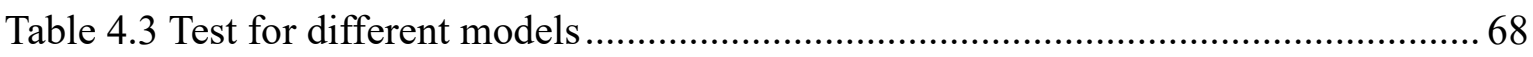

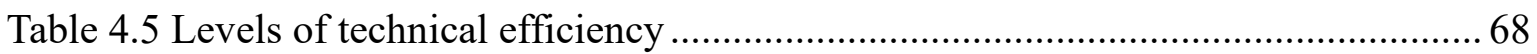

Table 4.7.1 OLS regression between fertilizer price and labor ........................................69

Table 4.7.2 OLS regression between fertilizer price and intermediate input ......................69

Table 4.7.3 OLS regression between fertilizer price and capital...................................... 69

Table 4.8 Instant changes of land N contents and fertilizer N contents .............................69 


\section{List of abbreviations}

\begin{tabular}{|c|c|}
\hline $\mathrm{AE}$ & Allocative Effect \\
\hline $\mathrm{AEC}$ & Allocative Efficiency Change \\
\hline $\mathrm{CD}$ & Cobb-Douglas \\
\hline $\mathrm{CNY}$ & China Yuan \\
\hline CPI & Consumer Price Index \\
\hline CRS & Constant Returns to Scale \\
\hline DEA & Data Envelopment Analysis \\
\hline DRS & Decreasing Returns to Scale \\
\hline EAPE & Environmentally Adjusted Production Efficiency \\
\hline FAO & Food and Agriculture Organization \\
\hline FEE & Frontier Eco-Efficiency \\
\hline GHG & Greenhouse Gas \\
\hline HRS & Household Responsibility System \\
\hline INAE & Input-Oriented Allocative Efficiency \\
\hline INASE & Input-Oriented Allocative Scale Efficiency \\
\hline INE & Input-Oriented Nutrient Efficiency \\
\hline IRS & Increasing Returns to Scale \\
\hline ITE & Input-Oriented Technical Efficiency \\
\hline K Fertilizer & Potash Fertilizer \\
\hline MBP & Material Balance Principle \\
\hline MPSS & Most Productive Scale Size \\
\hline $\mathrm{N}$ & Nitrogen \\
\hline NASEC & Nutrient Allocative Scale Efficiency Change \\
\hline NBSC & National Bureau of Statistics of China \\
\hline $\mathrm{NE}$ & Nutrient Efficiency \\
\hline NTFP & Nutrient-Oriented Total Factor Productivity \\
\hline NTFPC & Nutrient-Oriented Total Factor Productivity Change \\
\hline NUE & Nitrogen Use Efficiency \\
\hline P Fertilizer & Phosphate Fertilizer \\
\hline RDTFP & Malmquist Index introduced by Ray and Desli \\
\hline
\end{tabular}


RDTFPC

SE

SE

SEC

SFA

SNF

SNFF

TC

TE

TEC

TFP

TFPC

VRS

WTO
RD Malmquist TFP Change

Scale Effect in Chapter 2 \& Chapter 4

Scale Efficiency in Chapter 3

Scale Efficiency Change in Chapter 3

Stochastic Frontier Analysis

Stochastic Nutrient Frontier

Stochastic Nutrient Frontier Function

Technical Change

Technical Efficiency

Technical Efficiency Change

Total Factor Productivity

Total Factor Productivity Change

Variable Returns to Scale

World Trade Organization 


\section{Chapter 1 Introduction}

\subsection{Background}

China's agricultural productivity has achieved remarkable accomplishments in agricultural sector after China's accession to World Trade Organization (WTO). According to National Bureau of Statistics of China (NBSC) the total meat production in 2018 is $43 \%$ more than in 2000 , and the total cereal production in 2018 is $51 \%$ more than in $2000 .{ }^{1}$ Although we might have an intuitive awareness of yield growth, whether agricultural productivity increases is doubtful. Therefore, analyzing productivity change could provide empirical evidence that China's productivity has progressed in recent years.

The crop yield in recent decades has benefited substantially from fertilizer application, especially nitrogen (N) fertilizer (Cassman et al., 2003). Not surprisingly China's rice yield growth is associated with $\mathrm{N}$ fertilizer application increase. The amount of nitrogen fertilizer applied (209 $\left.\mathrm{kg} \mathrm{ha}^{-1}\right)$ during rice production in China is 90\% higher than global average level (Chen et al., 2014), and the $\mathrm{N}$ taken by rice is only 30-35\% (Peng et al., 2009; Xu et al., 2012). However, whether the $\mathrm{N}$ fertilizer application increase is caused by production demands or overuse should be figured out. Since $\mathrm{N}$ fertilizer is one of the main types of fertilizer applied by farmers and a prominent agricultural pollutant, measuring nitrogen use efficiency (NUE) and finding reasons behind low NUE could improve NUE and combat N related agricultural pollution to a large extent.

\subsubsection{China's production situation of meat}

There is no doubt that meat production experiences a large rise after China's entry to WTO. From 1995 to 2018, every category of meat presents an upward trend (see Figure 1.1).

\footnotetext{
1 The figures are calculated according to China Statistical Yearbook.
} 
Pork, beef, lamb, poultry \& egg, dairy products and aquatic products increase by $48 \%, 55 \%$, $136 \%, 87 \%, 372 \%$ and $157 \%$ respectively. ${ }^{1}$ The drastic rise of meat production reflects the increasing domestic consumption demand and the structural change of peoples' diet toward a more healthy and nutritious way. According to Burggraf et al. (2015), as people's income increases the expenditure share of carbohydrates decreases slightly, and the expenditure share of meat, fish, fruit and vegetables stays stable from 1997 to 2009. On the other hand, the meat production growth indicates the increasing export demand of labor-intensive products, such as pork, poultry \& egg, aquatic products, etc. According to FAO, the export values of pork, poultry \& egg, and aquatic products change by $1.85,-0.34$ and 8.70 times separately in 2018 compare to those in $2000,{ }^{2}$ though the export value of poultry \& egg drops slightly, it is still one of the main export goods.

Figure 1.1 Production of 5 main types of meat from 1995 to 2018

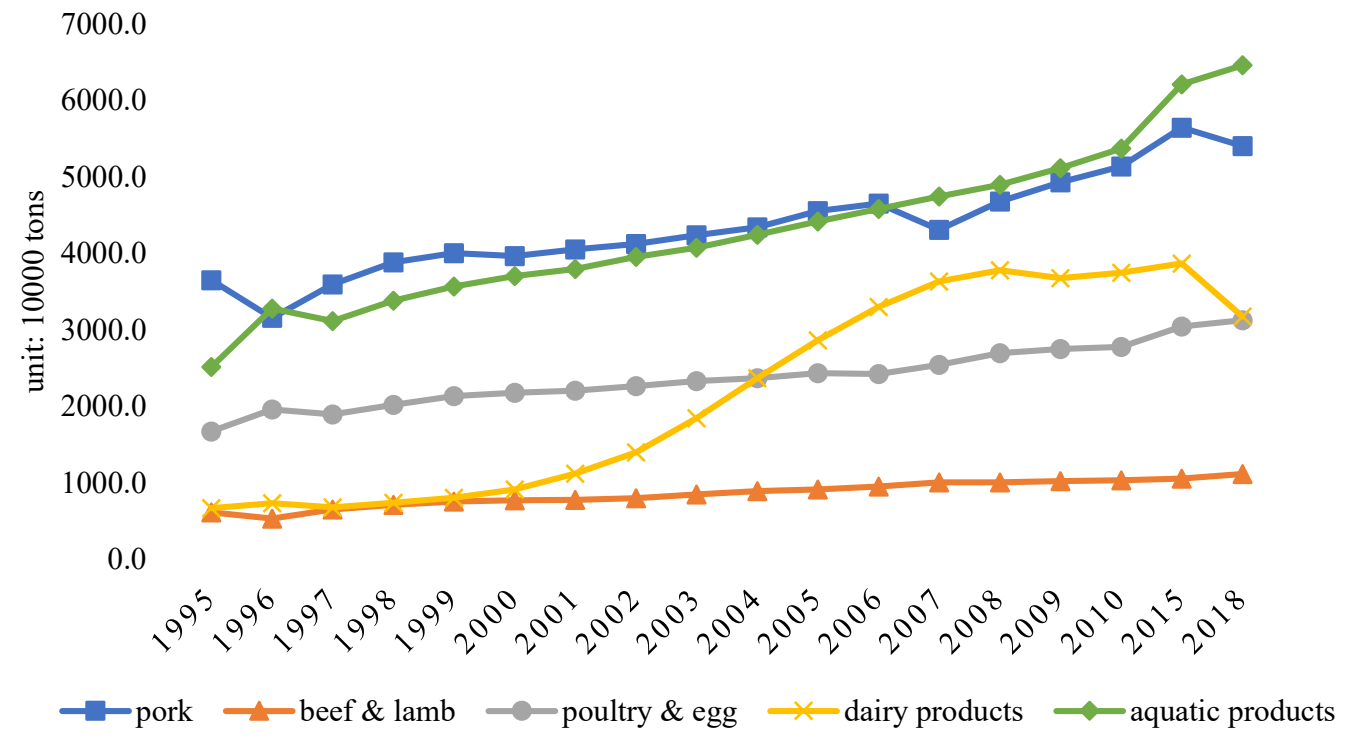

${ }^{\text {a }}$ Figure 1.1 is plotted according to China Statistical Yearbook.

\footnotetext{
1 The figures are calculated according to China Statistical Yearbook.

2 The figures are calculated according to China Statistical Yearbook.
} 


\subsubsection{China's production situation of cereal}

Since the implementation of reform and open policy, the three main types of cereal rise considerably. Rice, wheat and corn increase by 55\%, 144\% and 360\% separately (see Figure 1.2). After China's accession to WTO, land-intensive goods are the main imported products, the import values of rice and wheat have increased by 13.54 and 4.82 times respectively in 2018 compare to those in $2000{ }^{1}$ To satisfy the drastically increasing demand of corn, a large amount of corn is produced and imported since China's entry to WTO. From 2001 to 2009, corn import is below 100 thousand tons, while it sharply increases to 1.57 million tons in $2010 .^{2}$ Although the import value of corn in 2018 is 2248 times more than that of $2000,{ }^{3}$ there is still great potential for corn production and import growth in order to meet the growing domestic demand of industry and agriculture.

\section{Figure 1.2 Production of 3 main types of cereal from 1978 to 2018}

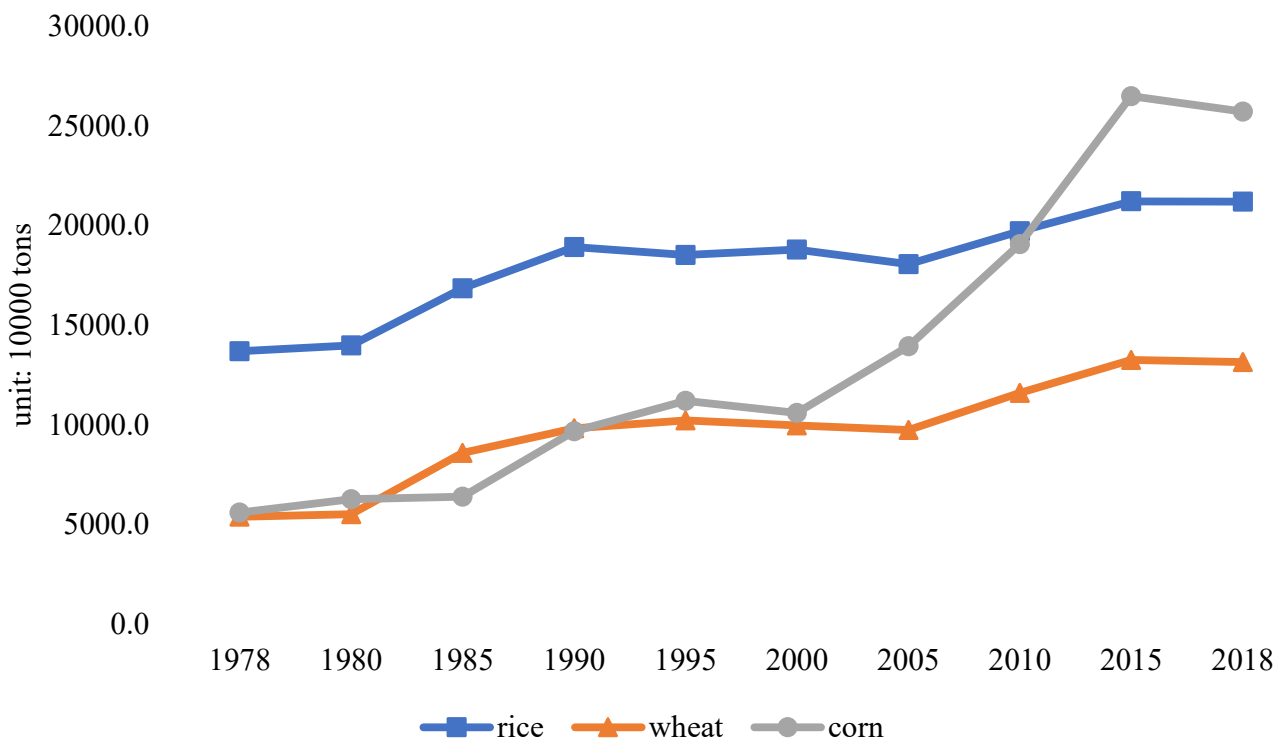

${ }^{\text {a }}$ Figure 1.2 is plotted according to China Statistical Yearbook.

\footnotetext{
1 The export value changes of rice and wheat are calculated according to China Statistical Yearbook.

2 The export value of corn is from UN Comtrade Database, see https:/comtrade.un.org/.

3 The export value change of corn is calculated according to UN Comtrade Database, see https://comtrade.un.org/.
} 


\subsubsection{China's chemical fertilizer pollution}

From 2000 to 2018, nitrogen (N) fertilizer, phosphate fertilizer (P fertilizer) and potash fertilizer ( $\mathrm{K}$ fertilizer) increase slightly, while compound fertilizer increases sharply (see Figure 1.3). The different increasing extent of fertilizer reflects a structural change of fertilizer application that compound fertilizer is more frequently used than single-nutrient fertilizer recently. Besides, the application amount of $\mathrm{N}$ fertilizer is the most, which is 1.8 times and 2.5 times more than the application amount of $\mathrm{P}$ fertilizer and $\mathrm{K}$ fertilizer. After nitrogen fertilizer has been applied to crop, $50-70 \%$ of the nitrogen contents in fertilizer are potentially lost to the environment (Cassman et al., 2002; Ladha et al., 2005), which results in various environmental damage, such as ozone depletion, eutrophication, biodiversity loss, etc.

\section{Figure 1.3 Application of 4 main types of fertilizer from 2000 to 2018}

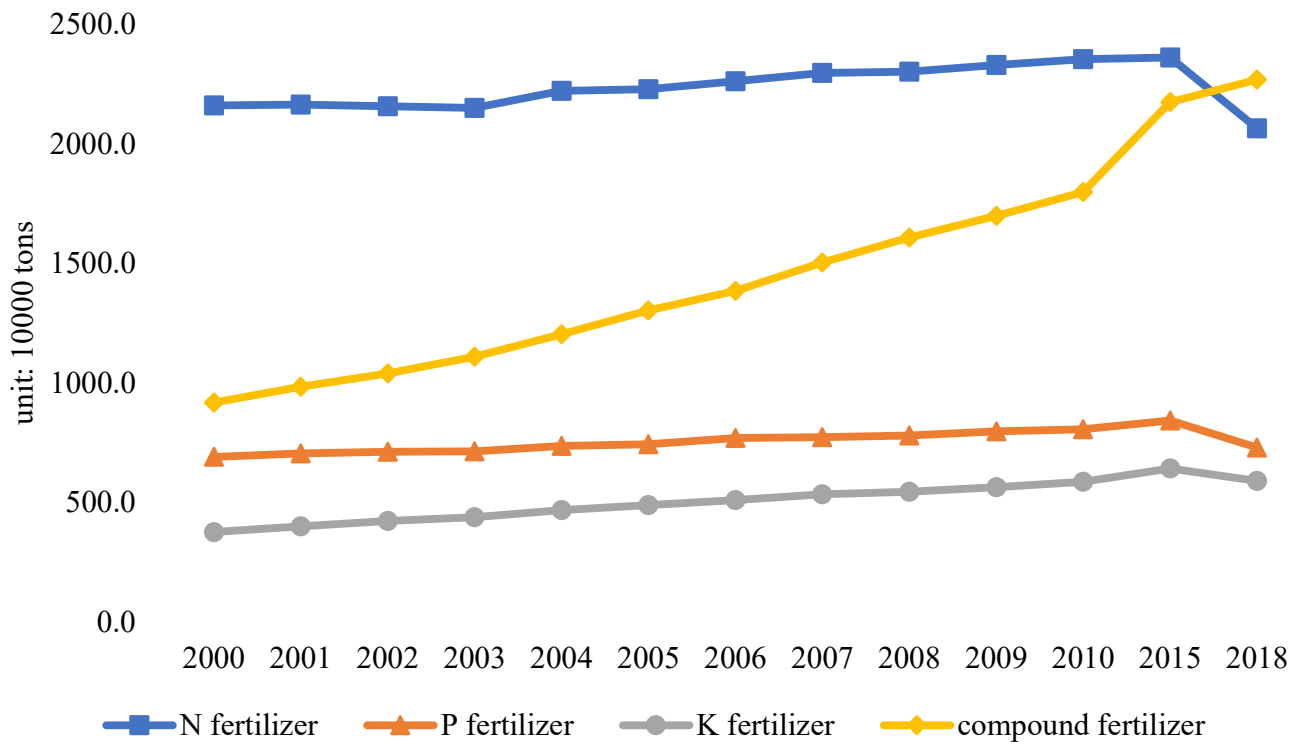

${ }^{a}$ Figure 1.3 is plotted according to China Statistical Yearbook. 


\subsection{Research gaps and research objectives}

In general, this research focuses on two empirical issues: one is the trade effects on China's agricultural productivity, the other is measuring environmental productivity and finding solutions for $\mathrm{N}$ pollution problem. First, we try to investigate the trade impacts on China's agricultural productivity change and answer following questions. How productivity changes after China's entry to WTO? Is there a substantial productivity growth behind yield growth? What's the main factor behind TFP change? Second, we focus on evaluating environmental performance within the framework of productivity analysis and tackling $\mathrm{N}$ pollution issue. We try to measure China's environmental productivity and nitrogen use efficiency in particular to examine whether NUE is low, what factors lead to current NUE and what are the possible ways to abate $\mathrm{N}$ pollution.

\subsubsection{One-step estimation of technical efficiency determinants}

Although there are some studies provide insights into the relationship between trade and China's productivity, less literature measures the trade effect on technical efficiency directly. We add trade index directly into the auxiliary regression of technical efficiency rather than adding it to production function or using the second stage analysis. ${ }^{1}$ Such specification is not only more reasonable, but also solves the issue of inconsistent data generation. Therefore, our first research objective is measuring the total factor productivity change in China's agricultural sector before and after China's entry to WTO, identifying the decisive factors behind TFP change and finding out the trade influence on technical efficiency.

\footnotetext{
1 The second stage analysis estimates the determinants of technical (in)efficiency in a separate regression after the estimation of production function.
} 


\subsubsection{Measuring and decomposing environmental TFP using DEA}

In order to measure environmental productivity, environmental indicators are usually treated as environmental-related inputs or detrimental outputs in production functions. One limitation of these approaches is that these methods are inconsistent with material balance principle. ${ }^{1}$ To solve the issue of MBP violation, Hoang and Coelli (2011) introduce a nutrient balance approach. However, this method is based on production technology under constant returns to scale. If the actual production technology exhibits variable returns to scale, Hoang and Coelli's (2011) nutrient-oriented total factor productivity index is biased and could further bias the decomposition components. To combat this drawback, we introduce an approach to decompose environmental-related productivity, when production technology exhibits VRS. Thus, the second research objective is estimating production technology under VRS, and further decomposing environmental efficiency and NTFP via DEA.

\subsubsection{Measuring and decomposing environmental TFP using SFA}

Another limitation of Hoang and Coelli's (2011) model is that the random error and inefficiency do not split within the framework of DEA, which could bias the result of decomposition components. To combat the problem of Hoang and Coelli's (2011) model, we estimate total factor productivity within the framework of SFA. To be specific, we estimate productivity within the stochastic nutrient frontier (SNF) and further decompose it into technical efficiency change (TEC), technical change (TC), allocative effect (AE), etc. based on the Divisia Index. To the best of our knowledge, the studies related to China's environmental productivity decomposition are still inadequate and preliminary. The third objective of this research is measuring current TFP in rice production, analyzing reasons

\footnotetext{
1 Material balance principle (MBP) regulates that the materials in inputs are transformed into desirable outputs and emissions that have potential to cause pollution.
} 
behind environmental efficiency variation and providing possible approaches, via which nitrogen use efficiency can be improved and $\mathrm{N}$ pollution can be reduced. 


\title{
Chapter 2 China's trade development and agricultural productivity change
}

\begin{abstract}
Since China joined the World Trade Organization (WTO) in 2001, more Chinese agricultural products are exported to various countries in the world at low tariff rates. However, its impacts on Chinese agricultural producers are ambiguous. This study is going to investigate the impacts of international trade on China's agricultural sector by analyzing agricultural productivity change before and after 2001. Furthermore, the total factor productivity (TFP) is decomposed into four basic components: technical efficiency change (TEC), technical change (TC), allocative effects (AE) and scale effect (SE) within a framework of multi-input multi-output distance function based on individual farm household data from Hubei Province since 1995 till 2010. Our findings indicate that export has significant positive effects on technical efficiency before China's accession to WTO, while import presents negative impacts on technical efficiency after China's accession to WTO. Besides, China's productivity increases during the whole research period, and TFP growth rate rises slightly after China's entry to WTO. Among all TFP components, the development of technology achieves steady and substantial progress.
\end{abstract}

Keywords: international trade, agricultural productivity, distance function 


\subsection{Introduction}

On 11 December 2001 China became the 143rd member of the World Trade Organization (WTO). In order to join WTO, Chinese government has committed to reducing tariffs, export subsidies, national support measures, etc. All the commitments mentioned above have profound impacts on Chinese agricultural development. Till 2010 China meets all WTO commitments cutting down agricultural tariffs by $72 \%$ and becomes one of the countries with the lowest agricultural tariff rate, which is $15.2 \%$ on average ( $\mathrm{Wu}$ and $\mathrm{Zhu}, 2014$ ). Although China's commitments to better open its market and integrate into the world economy bring benefits to worldwide trade partners, the effects of international trade on Chinese agricultural production and farmers are uncertain.

In the area of trade, many researchers develop models to figure out how trade is affected by trade barriers and whether firms decide to export or not. Although there are trade barriers between two identical countries under the framework of bilateral trade, trade could still happen, since consumers have different preferences for varieties (Krugman, 1980). Krugman (1980) provides justification to support the point that countries intend to export products, which comprise a relatively large share at domestic markets, especially in the case of transportation cost existence. Melitz (2003) extends Krugman's (1980) model by considering firm-level productivity differences and indicates how firms with different productivity could be affected by trade to enter or exit export market. Melitz (2003) thinks that trade only affects more productive farmers' decisions on entering or exiting the export market and the least productive farmers will exit market by force, when the whole industry is increasingly exposed to trade. Chaney (2008) adds firm heterogeneity and fixed cost of exporting into the model and thinks the effects of international trade include extensive margins and intensive margins. The high substitutional elasticities of trade goods could exaggerate the sensitivity of intensive margin to variations in trade barriers and weaken the sensitivity of the extensive margin. 
In the field of agriculture, a large number of scholars try to build connections between trade and agricultural production. Huang et al. (2009) think that trade liberalization narrows down the gap between domestic price and international price of agricultural goods in the 1980s and 1990s, which eliminates the domestic policy distortion and directly affects farmers' production. Fan and Agcaoili - Sombilla (1997) compare several studies and think China will keep importing bulk agricultural goods based on the almost consistent assumptions of increases in income and population. Nin Pratt et al. (2001) forecast the upward trend of livestock productivity and believe China could be a competitive market of meat export (especially non-ruminant products). Rae (2008) thinks the rural labor transfer trend and labor-intensive nature of China's meat production provide opportunities for international suppliers. Gong (2018) estimates the trade effect on China's agricultural productivity between 2004-2015 and thinks export could increase agricultural productivity effectively.

Furthermore, some recent studies focus on better explaining China's agricultural productivity change and finding the factors behind agricultural productivity change. Fan (1991) estimates the contribution of input growth, technological change, efficiency change and institutional change to China's agricultural productivity growth. Brümmer et al. (2006) examine China's policy reform effects by estimating grain productivity and dividing it into market related components and technological related components. Nin-Pratt et al. (2009) measure China's agricultural TFP, TE and TC and find that the productivity growth in China after 1979 stemmed from institution and policy changes. Zhang et al. (2011) calculate China's land efficiency and find that the impacts of land reallocation on technical efficiency rely on institutional settings and economic environment.

Although there are some studies provide insights into the relationship between trade and China's productivity, less literature measures the trade effect on technical efficiency directly. Therefore, this study is aimed at measuring the total factor productivity (TFP) change in China's agricultural sector, identifying the decisive factors behind TFP change and analyzing 
the role trade plays in technical efficiency change. In order to analyze the underlying reasons for TFP change, we decompose TFP into technical change (TC), technical efficiency change (TEC), allocative effects (AE) and scale effect (SE). The technical efficiency change (TEC) is examined particularly based on our function form and dataset. Additionally, we adopt a multi-input multi-output distance function to obtain the allocative effects (AE) for both inputs and outputs, which allows for technical inefficiency term and decomposition of TFP as well.

Different from current literature, our research extends the exploration of Chinese agricultural productivity in the following aspects. First, this research distinguishes from the existing literature by adding trade indices directly into the auxiliary regression of technical efficiency rather than production function or the second stage analysis. ${ }^{1}$ This specification is not only more reasonable, but also solves the issue of inconsistent data generation. Second, compared with deterministic method, the stochastic method has an explicit function form, which easily separates the effects of inefficiency and random noise. Third, the behavioral assumptions - such as profit maximization, cost minimization, etc. - are not necessary for a distance function, which is consistent with China's reality in 1990s, when the planning economy still dominated the market, and self-sufficiency was still the principal goal of agricultural production.

In the following section, we review the main phases of China's agricultural trade development. The theoretical framework, and data and empirical specification are introduced in section 2.3 and 2.4 respectively. After that, the empirical results are given and discussed in section 2.5, and the main conclusions are presented in the final section.

\subsection{Agricultural trade development in China}

China's agricultural trade experiences increase, fluctuation and steady phases

\footnotetext{
1 The second stage analysis estimates the determinants of technical (in)efficiency in a separate regression after the estimation of production function.
} 
successively since 1949, which can be roughly divide into slow development period, rapid development period, fluctuation period and open development period. The first period (1949-1978) witnessed China's shortage of agricultural products and the difficult situation of agricultural trade. At this time, only 60 countries developed trade relationship with China, which were East Europe, socialism countries in Asia, Africa, Latin America and some developing countries. From 1953 to 1978, China's agricultural export amount hovered around 2 billion dollars. Although the agricultural export value was small, it accounted for the biggest part of China's export value (70\%), which means agricultural trade made huge contribution to the whole trade and economy in the early period of China (Zhuang, 2011).

From the Third Plenary Session (1978) to $1993,{ }^{1}$ China's agricultural trade amount especially export amount - increased drastically, which was mainly attributed to the application of household responsibility system (HRS) and the growth of grain yields. According to Lin's (1988) estimation of productivity, household responsibility system (HRS) led to a $19.7 \%$ productivity jump and thus shifted the production frontier significantly to a higher level at the beginning of implementation of HRS institution (1979-1983). In 1979 China's agricultural export ranked 13th in the world, which was 3.32 billion dollars, while in 1993 China's ranking climbed to 5th and played a significant role on the world stage, which comprised 15.70 billion dollars of the world total agricultural export amount. ${ }^{2}$ Meanwhile, aquatic products, animal husbandry products and horticultural products became the major export products, which made up $60 \%$ of the total export value (Zhuang, 2011). As for agricultural import, the total import amount was only 3.05 billion dollars in 1978 and 3.43 billion dollars in $1993 .^{3}$ Till 1993, China's agricultural trade switched from trade deficit to trade surplus, soaring to 12.27 billion dollars of net export in 1993.

\footnotetext{
1 The Third Plenary Session refers to Chinese Eleventh Communist Party of China (CPC) Central Committee Third Plenary Session.

2 The export value of China comes from FAO website, see http://www.fao.org/statistics/zh/.

3 The import value of China comes from FAO website, see http://www.fao.org/statistics/zh/.
} 
The time from 1994 to 2001 witnessed fluctuations in agricultural import amount, while agricultural export amount kept stable (see Figure 2.1). The agricultural export value was 12.48 billion dollars in 1994, and grew slightly in the next 3 years, reaching a peak of 13.04 billion dollars in 1997. For agricultural import value, it started at 6.58 billion dollars in 1994 , following by a maximum of 11.56 billion dollars in 1995, and then experienced a mild downward trend till 2000. The large spring of agricultural import in 1995 owed to the import growth of daily necessities, among which the import amount of grain, edible oil, cotton and sugar increased by $120 \%, 14.6 \%, 47.5 \%$ and $90.3 \%$, respectively. ${ }^{1}$ With respect to the reduction of daily necessities - such as grain, edible oil, cotton, sugar, etc. - there was a moderate decrease of agricultural import from 1996 to 1999. Till 2001, China's agricultural export markets concentrated in Asia, which accounted for $72.3 \%$ of the total agricultural export, while agricultural import markets centralized in America, which represented 26.3\% of the total agricultural import. ${ }^{2}$

Figure 2.1 China's annual agricultural trade amount (1994-2001)

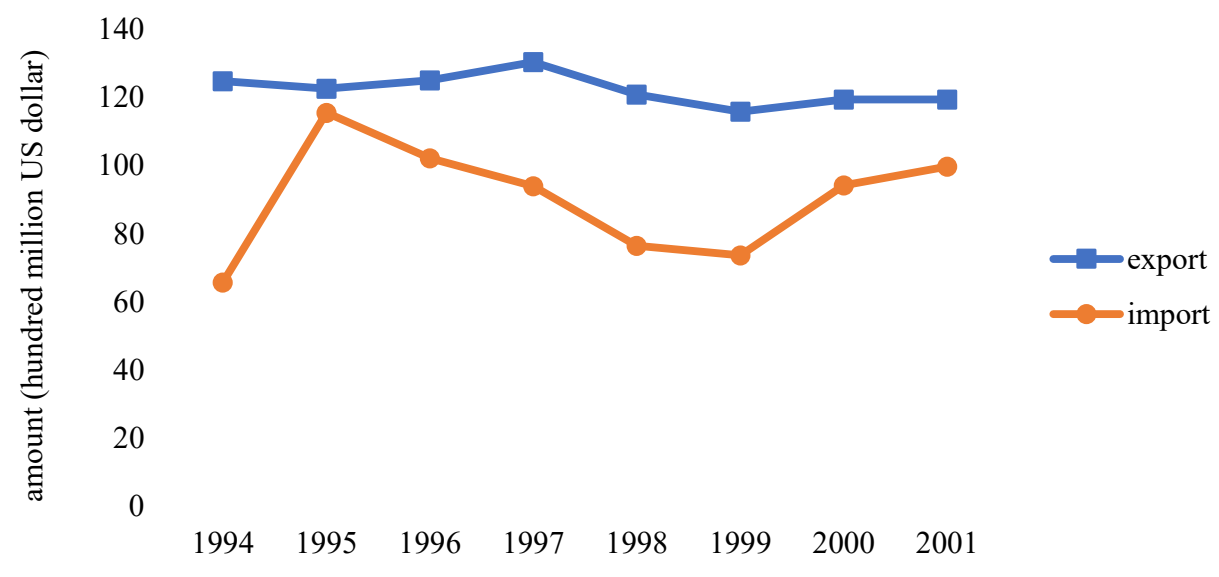

${ }^{\text {a }}$ Figure 2.1 is plotted according to China Agriculture Yearbook.

Since China's entry to WTO, agricultural trade moved to an open development period.

\footnotetext{
1 The data is reported by China Agriculture Yearbook.

2 The data is reported by China Agriculture Yearbook.
} 
From 2002 to 2010, both agricultural export and import had a significant upward trend, rising by 2.6 times and 6 times in export and import separately (see Figure 2.2). Due to the low export growing rate, China became a net importing country again in 2004. In 2010, China became one of the countries with the lowest agricultural tariff. For land-intensive crops such as wheat, rice, corn, etc. - the tariffs decreased by $62 \%, 61 \%$ and $60 \%$, respectively (Wu and Zhu, 2014). As for labor-intensive crops, all the tariffs decreased by about $60 \%$ (Wu and Zhu, 2014). Meanwhile, China focused on exporting labor-intensive goods and importing land-intensive goods, among which aquatic products, vegetable and fruit products, and poultry comprised more than $60 \%$ of the total export value, and vegetable oil, animal oil and cotton accounted for around $60 \%$ of the import value. ${ }^{1}$

Figure 2.2 China's annual agricultural trade amount (2002-2010)

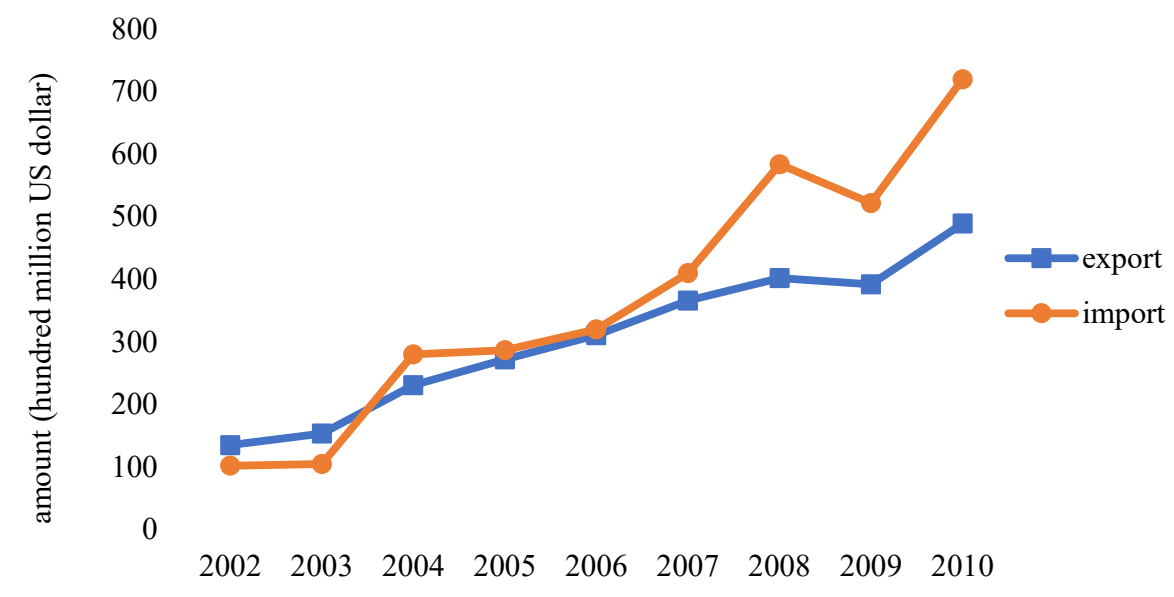

${ }^{\text {a }}$ Figure 2.2 is plotted according to China Agriculture Yearbook.

\subsection{Theoretical framework}

The research objective is to investigate how international trade affects China's agricultural productivity, particularly technical efficiency (TE), and further decompose total

\footnotetext{
1 The export and import share are calculated according to the data from Ministry of Commerce of the People's Republic of China (see http://www.mofcom.gov.cn/index.shtml).
} 
factor productivity (TFP) into explicit components. To describe the multiple-input multipleoutput production process, we adopt the output-oriented distance function. Considering the maximum proportional expansion of output vector when input vector is given based on production possibility set, the output distance function is then obtained (Färe, 1988; Shephard, 1970). It is denoted by $D_{o}^{t}\left(x_{t}, y_{t}\right)=\inf _{\phi}\left\{\phi>0: y^{t} / \phi \in P^{t}\left(x^{t}\right)\right\}$. It shows the maximum radial that output vector $y^{t}$ can be proportionally expanded, while input vector $x^{t}$ is given.

By using a specific expression of production function or production technology, productivity change can be decomposed in various ways. Generally, these decomposition approaches could be distinguished according to the productivity index they based on, where the frequently adopted indices are Malmquist Index and Divisia Index. Fuentes et al. (2001) calculate Malmquist TFP Index not based on non-parametric approaches, but on both parametric-deterministic and parametric-stochastic distance function. Balk (2001) proposes an encompassing index to capture productivity change, which contains technical change, technical efficiency change and scale efficiency change, finding that the Malmquist Index with scale efficiency change draws a quite different conclusion on productivity change. Orea (2002) develops a generalized Malmquist Productivity Index that includes the scale economies to TFP change rather than scale efficiency measure, and is superior to Balk's (2001) method according to the empirical study on Spanish savings banks.

On the other hand, there are also many empirical researches on TFP decomposition using Divisia Index and its extension variants. Kumbhakar and Lovell (2000) divide TFP change into technical change, technical efficiency change, scale effects and price relevant effects, and apply this method in both cost and profit functions. Brümmer et al. (2002) estimate and decompose TFP of dairy farms in Germany, the Netherlands, and Poland based on an outputoriented distance function. However, the allocative effect derived from this method just indicates whether allocative inefficiency exists or not. Its magnitude has nothing to do with the magnitude of allocative inefficiency. Karagiannis et al. (2004) decompose TFP based on an input-oriented distance function, and further include allocative efficiency. 
This research follows the method proposed by Brümmer et al. (2002) due to the characteristics of dataset and research goals. One of the advantages of using output distance function to measure technical efficiency is that there is an inverse relationship between output distance function and Farrell-type technical efficiency (Farrell, 1957), that is $D_{o}^{t}\left(x_{t}, y_{t}\right)=1 / T E_{o} \Leftrightarrow \ln D_{o}^{t}\left(x_{t}, y_{t}\right)+\ln T E_{o}=0$. By using an exponential non-negative error term $u$ instead of technical efficiency (TE) and differentiating, Equation (1) is obtained:

$$
\sum_{m=1}^{\mathrm{M}} \frac{\partial \ln D_{o}(.)}{\partial \ln y_{m}} \dot{y}_{m}+\sum_{k=1}^{K} \frac{\partial \ln D_{o}(.)}{\partial \ln x_{k}} \dot{x}_{k}+\frac{\partial \ln D_{o}(.)}{\partial t}+\frac{\partial u}{\partial t}=0,
$$

where a dot over the variable denotes the growth rate of the variable. Furthermore, we define $\partial \ln D_{o}(.) / \partial \ln y_{m}=\mu_{m}$ and $\partial \ln D_{o}(.) / \partial \ln x_{k}=-\lambda_{k} R T S$, where RTS is returns to scale. ${ }^{1}$ Then we involve a conventional Divisia index of TFP growth, which is defined as $\mathrm{T} \dot{\mathrm{FP}}=\sum_{m=1}^{M} R_{m} \dot{y}_{m}-\sum_{k=1}^{K} S_{k} \dot{x}_{k}$, where $R_{m}$ is the revenue share of output $y_{m}$, and $S_{k}$ is the cost share of input $x_{k}$. By combining Divisia index and Equation (1), the decomposition formula of TFP is obtained as Equation (2):

$$
\mathrm{TFP}=\sum_{m=1}^{M}\left(R_{m}-\mu_{m}\right) \dot{y}_{m}+\sum_{k=1}^{K}\left(\lambda_{k}-S_{k}\right) \dot{x}_{k}+(R T S-1) \sum_{k=1}^{K} \lambda_{k} \dot{x}_{k}-\frac{\partial \ln D_{o}(.)}{\partial t}-\frac{\partial u}{\partial t} .
$$

Here, $\sum_{m=1}^{M}\left(R_{m}-\mu_{m}\right) \dot{y}_{m}$ is output price effect, $\sum_{k=1}^{K}\left(S_{k}-\lambda_{k}\right) \dot{x}_{k}$ is input price effect, $\left([R T S-1] \sum_{k=1}^{K} \lambda_{k} \dot{x}_{k}\right)$ is SE, $\left(-\frac{\partial \ln D_{o}}{\partial t}\right)$ is TC, and $\left(-\frac{\partial u}{\partial t}\right)$ is TEC.

Moreover, we adopt the scaling model of Wang and Schmidt (2002) to analyze the specific factors contributing to technical efficiency change, and the specific model of $u$ is defined as Equation (3):

$$
u_{i}(z, \delta)=h(z, \delta) u_{i}^{*} .
$$

Here, the distribution for $u_{i}$ depends on $z$ (and possibly other parameters $\delta$ ). $h(z, \delta)=\exp \left(\delta^{\prime} z\right)$ is the scaling function, $u_{i}^{*} \sim N^{+}(0,1)$ is the basic distribution, and then $u_{i}$ follows $u_{i} \sim N^{+}\left(0, \sigma_{u_{i}}^{2}\right)$, where $\sigma_{u_{i}}=\exp \left(\delta^{\prime} z\right)$. As a special case of Wang and Schmidt's (2002)

\footnotetext{
1 Returns to scale (RTS) is defined as the same in Färe and Primont.
} 
model, $E\left(u_{i}\right)=h(z, \delta) E\left(u_{i}^{*}\right)=\exp \left(\delta^{\prime} z\right) E\left(u_{i}^{*}\right)$, and $\delta_{i}=\frac{\partial \ln E\left(u_{i}\right)}{\partial z_{i}}$, which means $z$ not only determines the variance of $u_{i}$, but also influences the mean of $u_{i}$.

\subsection{Data and empirical specification}

Based on our research objective and data availability, we adopt the individual farm household data from Hubei Province in 1995-2010 provided by China's Rural Fixed Observation Point Bureau. Owing to the inconsistent identity records after 2002, the whole dataset is naturally divided into two sub-samples. We first exclude farm households, whose family main business is not planting, husbandry and fishery. Then farm households inputting zero labor and producing zero pork in swine production are excluded. Finally, we select farm households that can be observed at least five years. After data cleaning, there are 3551 observations in the first sub-sample (1995-2002), and 1716 observations in the second subsample (2003-2010).

Due to the various categories of inputs and outputs in the dataset, we aggregate and split them into four inputs that are land, labor, intermediate input and capital, and three outputs that are pork, other meat and crop. The land variable is defined as the total sown area and grassland of each household measured by mu. ${ }^{1}$ The labor variable is represented by the total number of days each household devotes to agricultural activities. The intermediate input variable is an aggregation of purchases of seed, pesticide, diesel oil, plastic, etc., in yuan. The capital variable is given as the aggregation of purchases of machinery, agricultural building, etc., which reflects the input of long-term goods during production. ${ }^{2}$ Owing to the nature of long-term inputs, their values are depreciated using straight-line depreciation method and averagely added to the calculation of capital in yuan. ${ }^{3}$ To avoid inflation effects,

\footnotetext{
$11 \mathrm{mu}$ approximately equals 0.067 hectares.

${ }^{2}$ In this paper, capital does not reflect the economic notion of capital appropriately. Hence, the capital variable used in this study should be interpreted with caution.

${ }^{3}$ We assume the long-term inputs are depreciated averagely within ten years.
} 
intermediate input and capital are also adjusted by the CPI. ${ }^{1}$ First, we choose 1995 as the base year and transform the yearly CPI of 1995 to 2010 into the fixed-base CPI. Then, value of intermediate input and capital calculated in 1995 CNY are obtained by dividing the fixedbase CPI. As for outputs, pork is denoted by the total production from swine breeding industry, while the production from other animal husbandry - such as beef and lamb, ${ }^{2}$ poultry, egg, milk and aquatic products - account for other meat output. The crop output is defined as the total production from wheat, rice, maize, soybean, etc. All three types of outputs are calculated by kilograms and the statistical description of main variables is given in Table 2.1.

As for price information of outputs, we divide farmers' output sale value by output quantity. With regard to price information of inputs, average price of land and labor are obtained from Chinese Statistical Yearbook (1996-2011). For price of intermediate input and capital, we use the fixed-base CPI instead. All price variables for outputs (pork, other meat and crop) and inputs (land and labor) are deflated and calculated in 1995 CNY to avoid inflation effects.

The specific distance function is depicted by Equation (4):

$$
\begin{aligned}
\ln D_{i t}^{o}= & \alpha^{*}+\sum_{j=1}^{3} \beta_{j} \ln y_{j i t}+\sum_{k=1}^{4} \gamma_{k} \ln x_{k i t}+\frac{1}{2} \sum_{j=1}^{3} \sum_{k=1}^{4} \delta_{j k} \ln y_{j i t} \ln x_{k i t} \\
& +\frac{1}{2} \sum_{j=1}^{3} \sum_{k=1}^{3} \beta_{j k} \ln y_{j i t} \ln y_{k i t}+\frac{1}{2} \sum_{j=1}^{4} \sum_{k=1}^{4} \gamma_{j k} \ln x_{j i t} \ln x_{k i t}+\sum_{j=1}^{3} \beta_{T j} \ln y_{j i t} t . \\
& +\sum_{k=1}^{4} \gamma_{T k} \ln x_{k i t} t+\delta_{0} t+\frac{1}{2} \delta_{11} t^{2}+u_{i t}+\nu_{i t}
\end{aligned}
$$

To correctly estimate variables that contain zero observations, we adopt Battese's (1997) method. There are 1167 and 770 zero observations in output of other meat in sub-sample 1 and sub-sample 2, separately. To deal with them, other meat is defined as $y_{2}^{*}=\max \left\{y_{2}, D_{y 2}\right\}$ in Eq. (4), and $\alpha^{*}=\alpha_{0}+\left(\alpha_{1}-\alpha_{0}\right) * D_{y 2}$, where $D_{y 2}=0$ if $y_{2}>0$ and $D_{y 2}=1$ if

\footnotetext{
1 The CPI is from National Bureau of Statistics (see http://www.stats.gov.cn/).

2 Since beef and lamb is one category in the dataset, we will always denote and discuss them together.
} 
$y_{2}=0$. Additionally, output of crop also contains 143 zero observations in sub-sample 2 . Thus, crop is defined as $y_{3}^{*}=\max \left\{y_{3}, D_{y 3}\right\}$ in Eq. (4), and $\alpha^{*}=\alpha_{0}+\left(\alpha_{2}-\alpha_{0}\right)^{*} D_{y 3}$, where $D_{y 3}=0$ if $y_{3}>0$ and $D_{y 3}=1$ if $y_{3}=0 . \alpha, \gamma, \varphi$ and $\rho$ are parameters to be estimated.

By imposing linear homogeneity to the output distance function, we can convert the distance function to Equation (5), where $y_{1 i t}$ (pork) is on the righthand of the equation (Coelli and Perelman, 1999).

$$
\begin{aligned}
\ln y_{1 i t}= & -\left(\alpha^{*}+\sum_{j=2}^{3} \beta_{j} \ln \frac{y_{j i t}}{y_{1 i t}}+\sum_{k=1}^{4} \gamma_{k} \ln x_{k i t}+\frac{1}{2} \sum_{j=2}^{3} \sum_{k=1}^{4} \delta_{j k} \ln \frac{y_{j i t}}{y_{1 i t}} \ln x_{k i t}\right. \\
& +\frac{1}{2} \sum_{j=2}^{3} \sum_{k=2}^{3} \beta_{j k} \ln \frac{y_{j i t}}{y_{1 i t}} \ln \frac{y_{k i t}}{y_{1 i t}}+\frac{1}{2} \sum_{j=1}^{4} \sum_{k=1}^{4} \gamma_{j k} \ln x_{j i t} \ln x_{k i t}+\sum_{j=2}^{3} \beta_{T j} \ln \frac{y_{j i t}}{y_{1 i t}} t \\
& \left.+\sum_{k=1}^{4} \gamma_{T k} \ln x_{k i t} t+\delta_{0} t+\frac{1}{2} \delta_{11} t^{2}\right)-u_{i t}+\nu_{i t}
\end{aligned}
$$

Here, $y_{2 i t}$ denotes other meat output, and $y_{3 i t}$ denotes crop output. $x_{k i t}$ is a vector of input, which denotes land, labor, intermediate input and capital for $k=1,2,3,4 . t$ is a linear trend variable. $v_{i t}$ is i.i.d. $N\left(0, \sigma_{v}^{2}\right)$ and $u_{i t}$ is i.i.d. $N^{+}\left(0, \sigma_{u}^{2}\right)$. In the maximum likelihood estimation, all input and output variables are scaled by their sample mean.

Furthermore, the auxiliary regression on $u_{i t}$ is applied in our research to analyze factors contributing to technical efficiency change. To capture the trade effects on technical efficiency, we introduce trade index of Fleming et al. (2010) to our efficiency model and further extend it to export index $\left(E I_{i t}\right)$ and import index $\left(I I_{i t}\right)$. The trade indices are calculated as Equation (6) \& (7):

$$
\begin{aligned}
& E I_{i t}=\sum_{i=1}^{6} \theta_{i j t} \text { Exports }_{i t} / \text { Production }_{i t}, \\
& I I_{i t}=\sum_{i=1}^{6} \theta_{i j t} \text { Imports }_{i t} / \text { Production }_{i t},
\end{aligned}
$$

where $\theta_{i j t}$ denotes the output share of product $i$ in the total production of farmer $j$ in year $t$, and Exports $_{i t}$, Imports It $_{i t}$ and Production $_{i t}$ represent the export, import and production of $i$-th product at time $t$, respectively. The export index $\left(E I_{i t}\right)$ and import index 
$\left(I I_{i t}\right)$ build channels between individual farmer's output and international trade, so it could reflect how international trade affects individual farmer's production and technical efficiency. The specification function of $u_{i t}$ based on scaling model (Wang and Schmidt, 2002) is defined as Equation (8):

$$
\ln u_{i t}=\theta_{0}+\theta_{1} T N_{i t}+\theta_{2} M D_{i t}+\theta_{3} S U_{i t}+\theta_{4} C A_{i t}+\theta_{5} E I_{i t}+\theta_{6} I_{i t} .
$$

Here, $T N_{i t}$ denotes training times a farmer received annually. $M D_{i t}$ denotes machinery level, which is measured by total kilowatt of power of the machine owned by each farm household. $S U_{i t}$ denotes the total agricultural subsidies that farmers get from the government, which are measured in yuan. $C A_{i t}$ denotes disaster level, which is presented by the disaster area of the whole Hubei Province and measured by mu. $E I_{i t}$ and $I I_{i t}$ denotes the trade indices, which capture the export and import effects on technical efficiency. 
Table 2.1 Descriptive statistics of sub-samples

\begin{tabular}{|c|c|c|c|c|c|}
\hline Variable & Unit & Mean & Std.Dev. & Min & Max \\
\hline \multicolumn{6}{|c|}{ first sub-sample $(n=3551)$} \\
\hline pork & $\mathrm{kg}$ & 177.71 & 122.52 & 5 & 1353 \\
\hline other meat & $\mathrm{kg}$ & 41.68 & 106.13 & 0 & 1180 \\
\hline crop & $\mathrm{kg}$ & 3684.41 & 2227.77 & 0 & 17070 \\
\hline land & $\mathrm{mu}$ & 5.36 & 2.61 & 0 & 20.4 \\
\hline labor & day & 461.35 & 189.08 & 20 & 1485 \\
\hline intermediate input & yuan & 809.97 & 698.72 & 36.40 & 6415.18 \\
\hline capital & yuan & 166.80 & 231.12 & 0 & 2056.93 \\
\hline$T N$ & time & 0.05 & 0.25 & 0 & 2 \\
\hline$M D$ & kilowatt & 0.39 & 1.84 & 0 & 25 \\
\hline$S U$ & yuan & 30.73 & 352.87 & 0 & 15200 \\
\hline$C A$ & $\mathrm{mu}$ & 1722.25 & 291.41 & 1330 & 2030 \\
\hline$E I$ & / & 0.01 & 0.00 & 0.00 & 0.09 \\
\hline II & l & 0.02 & 0.01 & 0.00 & 0.04 \\
\hline \multicolumn{6}{|c|}{ second sub-sample $(n=1716)$} \\
\hline pork & $\mathrm{kg}$ & 238.45 & 190.22 & 7 & 4000 \\
\hline other meat & $\mathrm{kg}$ & 31.67 & 75.60 & 0 & 724 \\
\hline crop & $\mathrm{kg}$ & 2833.82 & 2945.46 & 0 & 26139 \\
\hline land & $\mathrm{mu}$ & 5.46 & 2.48 & 0 & 17.6 \\
\hline labor & day & 196.91 & 160.54 & 1 & 2179 \\
\hline intermediate input & yuan & 1333.13 & 771.14 & 416.10 & 6799.32 \\
\hline capital & yuan & 20.46 & 25.88 & 0 & 256.72 \\
\hline$T N$ & time & 1.61 & 0.84 & 0 & 8 \\
\hline$M D$ & kilowatt & 2.06 & 6.14 & 0 & 80 \\
\hline$S U$ & yuan & 545.96 & 1467.53 & 0 & 25307 \\
\hline$C A$ & $\mathrm{mu}$ & 1376.29 & 634.69 & 531.9 & 2658.7 \\
\hline$E I$ & 1 & 0.01 & 0.00 & 0.00 & 0.06 \\
\hline$I I$ & 1 & 0.03 & 0.02 & 0.00 & 0.06 \\
\hline
\end{tabular}

\subsection{Results}

This part focuses on the interpretation of estimation results and subsequent decomposition of total factor productivity. The determinants of technical efficiency change are investigated additionally to capture the trade impacts on technical efficiency. First, the 
result of parameter estimates and distance elasticities will be provided, as well as some necessary test results to guarantee the properties of output-oriented distance function. Then the estimation result of technical efficiency is presented. Finally, the components of TFP change are derived to show how different factors make up the productivity variation.

\subsubsection{Parameter estimates and distance elasticities}

Most parameter estimates in the model are statistically significant, and thus the result of our model is acceptable (see Table 2.2 in Appendix A). Additionally, the log likelihood values of different models (see Table 2.3 in Appendix A) indicate that it is appropriate to set inefficiency term and time trend variables in the model, and all the parameters of technical efficiency model should be included. Besides, pooled model, fixed-effects model (Greene, 2005) and random-effects model (Greene, 2005) are applied to both sub-samples, and we finally choose random-effects model (Greene, 2005). As for monotonicity of the outputoriented distance function, the $t$-test on elasticities shows that the monotonicity is achieved in all inputs and outputs in both sub-samples. By checking the sign of the diagonal elements of Hessian matrix, our model exhibits quasi-concavity in inputs in both subsamples.

Table 2.4 provides information about distance elasticities of inputs and outputs for two sub-samples. It is conspicuous that the growth in every input could increase output, and the absolute values of input distance elasticities reflect relative share of output rise caused by each input. During 1995-2002, land, labor, intermediate input and capital unevenly contribute to output growth, which are $19 \%, 22 \%, 23 \%$ and $3 \%$, respectively. Unlike the results from sub-sample 1 (see Table 2.4), the share of land and labor in output growth decreases slightly from 2003 to 2010, while the share of intermediate input in output growth increases to $37 \%$. As the quality of fodder has reached a higher level these days, increase in animal fodder could lead to a significant rise in total meat production. Meanwhile, since 
farmers' land tenure becomes longer and the integration of small fragmented land speeds up, the land put into production is fixed, and thus the positive effect of land on output growth dampens down. ${ }^{1}$ Following the trend of rural labor transfer, the structure of rural population changes much, and the shortage of young male labor leads to the problem of less efficient agricultural production. Hence, the output growth caused by increase in female and old labor also slows down.

Table 2.4 Distance elasticities

\begin{tabular}{lllllllll}
\hline & land & labor & $\begin{array}{l}\text { intermediate } \\
\text { input }\end{array}$ & capital & pork & other & crop \\
meat & & \\
\hline $1995-2002$ & -0.19 & -0.22 & -0.23 & -0.03 & 0.31 & 0.11 & 0.58 \\
$2003-2010$ & -0.14 & -0.16 & -0.37 & -0.03 & 0.32 & 0.18 & 0.50 \\
\hline
\end{tabular}

\subsubsection{Technical efficiency and its determinants}

Table 2.5 (see Appendix A) describes the degree of technical efficiency from 1995 to 2010, and the annual average technical efficiencies increase slightly overall. The average technical efficiency of sub-sample 1 is around 0.88 , while it is 0.92 for sub-sample 2 .

During the period 1995-2002, subsidies and export have significant positive effects on technical efficiency (see Table 2.6). ${ }^{2}$ During 1996-1998, grain protective price policy and subsidies for agricultural means of production were two main policies Chinese government implemented to support agriculture. Under the background of planning economy, these

\footnotetext{
1 In 1993, Chinese government extended the land tenure of individuals to 30 years, which used to be 15 years.

2 Although the coefficients of export and import indices are much larger than others for both sub-samples, they are not uncommon. The trade indices reflect the percentage change of technical efficiency related to the absolute trade indices change. Since trade indices change is within a very narrow range (0.001 to 0.094 in $E I$ and 0.002 to 0.041 in $I I$ for subsample 1, and 0.001 to 0.057 in $E I$ and 0.001 to 0.062 in $I I$ for sub-sample 2) and the mean values are small, if trade indices increase one, it could definitely cause a remarkable change in technical efficiency. Hence, to better interpret reality and compare trade effect with other factors on technical efficiency change, we could consider shrinking the coefficients of EI and $I I$ by 1000 times, and then see how technical efficiency changes if trade indices increase by 0.001 . To maintain consistency, all the trade semi-elasticities mentioned in the following sections refer to percentage change of technical efficiency when trade indices change 0.001 .
} 
subsidies protected farmers from market price disturbance and enabled them to afford basic agricultural machines and production materials, which ensured the stability of farmers' production and improved technical efficiency to some extent. Besides, export has a strong positive effect on technical efficiency due to the steady export value, while import effect remains obscure because of the fluctuated import value. As meat export increased, productive farmers left in export market, and less productive farmers were forced to exit the export market according to Melitz's (2003) model, which could shift the frontier to a higher level and improve the average technical efficiency.

In 2003-2010, technical efficiency semi-elasticities with respect to training times and subsidies present positive effect (see Table 2.6). Not surprisingly training times have a positive effect on technical efficiency. As increasing agricultural technological training activities have been organized in rural areas, farmers gain more access to learning new technologies, practices, experiences, management, etc., which could result in an improvement in technical efficiency. Moreover, Chinese government implements a series of polices to boost agricultural production since 2002 such as the direct subsidies for grain production (2004), the subsidies for superior seed varieties (2002), the subsidies for superior animal species (2005), the subsidies for agricultural machinery purchase (2004), the comprehensive subsidies for agriculture (2006), etc. There is no doubt that all subsidies mentioned above drive farmers to achieve a higher yield and lower technical inefficiency. Particularly, the implementation of agricultural machinery purchase subsidy directly stimulates farmers' purchase demand and promotes the level of agricultural mechanization.

Moreover, import and disaster areas have negative influences on technical efficiency (see Table 2.6). As annual disaster areas reached a peak in 2005, it irrefutably increased technical inefficiency in the following years. In addition, since China becomes a net importing country in the open development period, tremendous import of land-intensive agricultural products - such as grain, edible oil seeds, cotton, etc. - brings price uncertainty and risks to domestic market. Consequently, farmers need to adjust their production plan in anticipation of the 
demand of future market, and adapt to new production environment immediately, which lower farmers' managerial capability and technical efficiency to some extent. On the other hand, as importing products squeeze out some domestic products and the development of urbanization speeds up, a large amount of rural labor is transferring form agricultural industries to nonagricultural industries, and the remaining labor is usually female and old people having poor managerial capability, which reduce technical efficiency to a large extent.

Table 2.6 Technical efficiency semi-elasticities

\begin{tabular}{lllll}
\hline & $1995-2002$ & & $2003-2010$ & \\
& Mean & Std.Dev. & Mean & Std.Dev. \\
\hline$e_{T N}$ & -0.65 & $(0.45)$ & $-0.47^{* *}$ & $(0.21)$ \\
$e_{M D}$ & 0.03 & $(0.04)$ & -0.19 & $(0.16)$ \\
$e_{S U}$ & $-0.05^{* *}$ & $(0.02)$ & $-0.01^{* * *}$ & $(0.00)$ \\
$e_{C A}$ & $0.00^{* *}$ & $(0.00)$ & $0.00^{* * *}$ & $(0.00)$ \\
$e_{E I}$ & $-63.31^{* * *}$ & $(22.21)$ & 29.65 & $(52.38)$ \\
$e_{I I}$ & 5.41 & $(10.61)$ & $109.36^{* * *}$ & $(24.02)$ \\
\hline
\end{tabular}

\subsubsection{Components of TFP change}

Table 2.7 provides information about the results of TFP components of two sub-samples. The average growing rate of TFP is $5.5 \%$ per annum before 2003 , while it increases slightly with an annual rate at $8.2 \%$ after 2003 , which are both comprehensive outcomes of all relevant components. Actually, there are some differences between the main contributors to TFP change. In sub-sample 1, productivity growth majorly owes to the allocative effect of pork $(3.2 \%)$ and other meat $(2.1 \%)$ and the considerable technical progress $(2.2 \%)$. The positive allocative effects of pork and other meat indicate that the actual prices of pork and other meat are larger than shadow prices of pork and other meat, when instant changes of output for pork and other meat are positive, which means meat output rises as export demand of meat increases, and meat price also rises as domestic meat consumption increases. Therefore, reducing meat price or properly controlling meat export is beneficial to eliminating meat allocative inefficiency. 
Table 2.7 Decomposition of productivity change

\begin{tabular}{|c|c|c|c|c|}
\hline & Mean & Std. Dev. & Min & Max \\
\hline \multicolumn{5}{|l|}{ sample $1 n=2095$} \\
\hline allocative effect land & 0.002 & 0.119 & -1.588 & 1.834 \\
\hline allocative effect labor & -0.006 & 0.161 & -0.889 & 0.810 \\
\hline allocative effect intermediate input & -0.028 & 0.181 & -1.779 & 2.598 \\
\hline allocative effect capital & -0.010 & 0.120 & -1.142 & 1.796 \\
\hline allocative effect pork & 0.032 & 0.220 & -1.221 & 1.209 \\
\hline allocative effect other meat & 0.021 & 0.299 & -1.934 & 2.288 \\
\hline allocative effect crop & 0.015 & 0.176 & -0.911 & 1.107 \\
\hline scale effect & 0.007 & 0.109 & -0.770 & 0.864 \\
\hline $\mathrm{TC}$ & 0.022 & 0.022 & -0.039 & 0.088 \\
\hline TEC & 0.000 & 0.076 & -0.387 & 0.355 \\
\hline TFP & 0.055 & 0.476 & -3.623 & 3.597 \\
\hline \multicolumn{5}{|l|}{ sample $2 n=733$} \\
\hline allocative effect land & 0.020 & 0.651 & -1.763 & 17.372 \\
\hline allocative effect labor & 0.015 & 1.262 & -15.436 & 28.387 \\
\hline allocative effect intermediate input & -0.020 & 0.297 & -2.814 & 4.266 \\
\hline allocative effect capital & -0.002 & 0.333 & -6.996 & 4.288 \\
\hline allocative effect pork & -0.004 & 0.272 & -2.585 & 2.037 \\
\hline allocative effect other meat & 0.014 & 0.420 & -1.172 & 2.437 \\
\hline allocative effect crop & 0.097 & 0.380 & -1.034 & 1.992 \\
\hline scale effect & -0.065 & 1.432 & -36.945 & 6.902 \\
\hline $\mathrm{TC}$ & 0.029 & 0.056 & -0.116 & 0.198 \\
\hline TEC & -0.003 & 0.139 & -0.671 & 1.078 \\
\hline TFP & 0.082 & 0.721 & -2.926 & 4.007 \\
\hline
\end{tabular}

a The observations used to calculate TFP and its components are fewer than the observations used in regression, because of zero values of other meat and crop and the exclusion of first-year values when calculating instant changes of inputs and outputs.

As for sub-sample 2, the allocative effect of crop (9.7\%) and land (2\%) and technical progress $(2.9 \%)$ are the main contributors to TFP growth. Since the yield of grain in China is three times more than the yield five decades ago (Peng et al., 2015), farmers may place too much emphasis on crop output or the crop price is over protected, which means reducing crop related subsidies and support can lead to the achievement of crop allocative-efficient. As for allocative effect of land, the observed price of land is higher than the shadow land 
price owing to the increase in land price and decrease in land area, ${ }^{1}$ which implies controlling land prices and protecting arable land from using for commercial purpose could help reduce land allocative inefficiency. Furthermore, due to high-yield varieties, innovation of technology and equipment, implementation of agricultural machinery purchase subsidy, etc., the development of technology achieves steady and substantial progress in 1995-2010 and presents positive influence on TFP growth.

\subsection{Conclusion}

This research devotes to investigate the reasons for productivity growth before and after China's accession to WTO. After decomposing TFP, we can come to following conclusions. First, land, labor, and intermediate input evenly contribute to output growth before 2003. The share of land and labor in output growth decrease slightly after 2003, while the share of intermediate input in output growth increases to $37 \%$. Second, subsidies and export have significant positive effects on technical efficiency before China's entry to WTO. After 2003, subsidies and training times still present positive effects on technical efficiency, while natural disaster and import have negative effects on technical efficiency. Third, the average growing rate of TFP is $5.5 \%$ per annum before China joining WTO, and it increases slightly with an average annual rate at $8.2 \%$ after China joining WTO. Fourth, productivity growth majorly owes to the allocative effect of pork (3.2\%) and other meat $(2.1 \%)$ and the considerable technical progress $(2.2 \%)$ before 2003, while the allocative effect of crop (9.7\%) and land (2\%) and technical progress $(2.9 \%)$ become the main contributors to TFP growth after 2003. Fifth, due to high-yield varieties, innovation of technology and equipment, implementation of agricultural machinery purchase subsidy, etc., the development of technology achieves steady and substantial progress in 1995-2010.

\footnotetext{
1 The annual instant change of land is negative.
} 


\subsection{Appendix}

\section{Appendix A}

Table 2.2 Parameter estimates

\begin{tabular}{|c|c|c|c|c|c|}
\hline 1995-2002 & Estimates & $\mathrm{SE}$ & 2003-2010 & Estimates & SE \\
\hline$\gamma_{1}$ & $-0.21 * * *$ & $(0.02)$ & $\gamma_{1}$ & $-0.12^{* * *}$ & $(0.03)$ \\
\hline$\gamma_{2}$ & $-0.21 * * *$ & $(0.02)$ & $\gamma_{2}$ & $-0.20 * * *$ & $(0.02)$ \\
\hline$\gamma_{3}$ & $-0.20 * * *$ & $(0.01)$ & $\gamma_{3}$ & $-0.37 * * *$ & $(0.04)$ \\
\hline$\gamma_{4}$ & $-0.03 * * *$ & $(0.01)$ & $\gamma_{4}$ & $-0.05 * * *$ & $(0.01)$ \\
\hline$\beta_{2}$ & $0.10 * * *$ & $(0.01)$ & $\beta_{2}$ & $0.16^{* * *}$ & $(0.01)$ \\
\hline$\beta_{3}$ & $0.57 * * *$ & $(0.01)$ & $\beta_{3}$ & $0.52 * * *$ & $(0.02)$ \\
\hline$\beta_{22}$ & -0.00 & $(0.01)$ & $\beta_{22}$ & 0.00 & $(0.01)$ \\
\hline$\beta_{33}$ & 0.02 & $(0.02)$ & $\beta_{33}$ & $0.11 * * *$ & $(0.02)$ \\
\hline$\beta_{23}$ & $-0.03 * * *$ & $(0.01)$ & $\beta_{23}$ & $-0.03 *$ & $(0.02)$ \\
\hline$\gamma_{11}$ & -0.04 & $(0.03)$ & $\gamma_{11}$ & -0.05 & $(0.07)$ \\
\hline$\gamma_{12}$ & -0.04 & $(0.03)$ & $\gamma_{12}$ & $0.07 * *$ & $(0.03)$ \\
\hline$\gamma_{13}$ & $-0.06 * *$ & $(0.02)$ & $\gamma_{13}$ & 0.11 & $(0.07)$ \\
\hline$\gamma_{14}$ & 0.01 & $(0.01)$ & $\gamma_{14}$ & -0.02 & $(0.02)$ \\
\hline$\gamma_{22}$ & -0.06 & $(0.05)$ & $\gamma_{22}$ & $-0.07 * * *$ & $(0.02)$ \\
\hline$\gamma_{23}$ & -0.01 & $(0.03)$ & $\gamma_{23}$ & $-0.12 * * *$ & $(0.04)$ \\
\hline$\gamma_{24}$ & $0.04 * * *$ & $(0.01)$ & $\gamma_{24}$ & $-0.03 * *$ & $(0.01)$ \\
\hline$\gamma_{33}$ & $0.13^{* * *}$ & $(0.02)$ & $\gamma_{33}$ & $0.34 * * *$ & $(0.09)$ \\
\hline$\gamma_{34}$ & -0.01 & $(0.01)$ & $\gamma_{34}$ & -0.03 & $(0.03)$ \\
\hline$\gamma_{44}$ & 0.00 & $(0.01)$ & $\gamma_{44}$ & -0.00 & $(0.01)$ \\
\hline$\delta_{21}$ & -0.01 & $(0.01)$ & $\delta_{21}$ & 0.00 & $(0.03)$ \\
\hline$\delta_{22}$ & -0.00 & $(0.01)$ & $\delta_{22}$ & -0.01 & $(0.01)$ \\
\hline$\delta_{23}$ & 0.00 & $(0.01)$ & $\delta_{23}$ & -0.02 & $(0.03)$ \\
\hline$\delta_{24}$ & $-0.02 * * *$ & $(0.01)$ & $\delta_{24}$ & -0.01 & $(0.01)$ \\
\hline$\delta_{31}$ & $0.08 * * *$ & $(0.02)$ & $\delta_{31}$ & -0.03 & $(0.03)$ \\
\hline$\delta_{32}$ & $0.11 * * *$ & $(0.02)$ & $\delta_{32}$ & $0.04 * *$ & $(0.02)$ \\
\hline$\delta_{33}$ & $-0.12 * * *$ & $(0.02)$ & $\delta_{33}$ & $-0.18 * * *$ & $(0.04)$ \\
\hline$\delta_{34}$ & 0.01 & $(0.01)$ & $\delta_{34}$ & $0.03 * * *$ & $(0.01)$ \\
\hline$\beta_{T 2}$ & 0.00 & $(0.00)$ & $\beta_{T 2}$ & $0.02 * * *$ & $(0.01)$ \\
\hline$\beta_{T 3}$ & $-0.01 * * *$ & $(0.00)$ & $\beta_{\text {T3 }}$ & -0.01 & $(0.01)$ \\
\hline$\gamma_{T 1}$ & -0.01 & $(0.01)$ & $\gamma_{T 1}$ & 0.00 & $(0.01)$ \\
\hline$\gamma_{T 2}$ & 0.00 & $(0.01)$ & $\gamma_{T 2}$ & 0.00 & $(0.01)$ \\
\hline
\end{tabular}




\begin{tabular}{llllll}
\hline$\gamma_{T 3}$ & 0.01 & $(0.01)$ & $\gamma_{T 3}$ & -0.02 & $(0.02)$ \\
$\gamma_{T 4}$ & $0.01^{* * *}$ & $(0.00)$ & $\gamma_{T 4}$ & $0.01^{* * *}$ & $(0.00)$ \\
$\delta_{0}$ & $-0.02^{* * *}$ & $(0.00)$ & $\delta_{0}$ & $-0.03^{* * *}$ & $(0.01)$ \\
$\delta_{11}$ & 0.00 & $(0.00)$ & $\delta_{11}$ & $0.01^{* *}$ & $(0.01)$ \\
$\alpha_{0}$ & 0.03 & $(0.03)$ & $\alpha_{0}$ & $0.07^{* *}$ & $(0.03)$ \\
$\alpha_{1}$ & $-0.13^{* * *}$ & $(0.01)$ & $\alpha_{1}$ & -0.01 & $(0.02)$ \\
& & & $\alpha_{2}$ & -0.52 & $(0.34)$ \\
$\theta_{1}$ & -0.65 & $(0.45)$ & $\theta_{1}$ & $-0.47^{* *}$ & $(0.21)$ \\
$\theta_{2}$ & 0.03 & $(0.04)$ & $\theta_{2}$ & -0.19 & $(0.16)$ \\
$\theta_{3}$ & $-0.05^{* *}$ & $(0.02)$ & $\theta_{3}$ & $-0.01^{* * *}$ & $(0.00)$ \\
$\theta_{4}$ & $0.00^{* *}$ & $(0.00)$ & $\theta_{4}$ & $0.00^{* * *}$ & $(0.00)$ \\
$\theta_{5}$ & $-63.31^{* * *}$ & $(22.21)$ & $\theta_{5}$ & 29.65 & $(52.38)$ \\
$\theta_{6}$ & 5.41 & $(10.61)$ & $\theta_{6}$ & $109.36^{* * *}$ & $(24.02)$ \\
$\theta_{0}$ & $-3.95^{* * *}$ & $(0.66)$ & $\theta_{0}$ & $-7.76^{* * *}$ & $(1.43)$ \\
$\sigma_{v}$ & $-2.82^{* * *}$ & $(0.06)$ & $\sigma_{v}$ & $-2.75^{* * *}$ & $(0.05)$ \\
theta & $0.17^{* * *}$ & $(0.01)$ & theta & $0.18^{* * *}$ & $(0.01)$ \\
obs & 3432 & 3432 & obs & 1,440 & 1,440 \\
\hline
\end{tabular}

Table 2.3 Tests for different models

\begin{tabular}{lllll}
\hline model & $\begin{array}{l}\text { loglikelihood } \\
\text { value }\end{array}$ & $\begin{array}{l}\text { degree of } \\
\text { freedom }\end{array}$ & AIC & BIC \\
\hline sub-sample1 & -945.61 & 29 & 1949.23 & 2127.59 \\
$\mathrm{M}_{1}$ : OLS & -945.61 & 31 & 1953.23 & 2143.89 \\
$\mathrm{M}_{2}$ : inefficiency term & -885.79 & 39 & 1849.59 & 2089.46 \\
$\mathrm{M}_{3}$ : time trend variable & not convergent & & & \\
$\mathrm{M}_{4}$ : scaling model & not convergent & & & \\
$\mathrm{M}_{5}$ : Fixed Effect Model & -643.72 & 46 & 1379.45 & 1661.93 \\
$\mathrm{M}_{6}$ : Random Effect Model & & & & \\
& & & & \\
sub-sample2 & -476.49 & 30 & 1012.98 & 1171.49 \\
$\mathrm{M}_{1}$ : OLS & -462.67 & 32 & 989.34 & 1158.41 \\
$\mathrm{M}_{2}$ : inefficiency term & -438.92 & 40 & 957.83 & 1169.17 \\
$\mathrm{M}_{3}$ : time trend variable & -396.41 & 46 & 884.82 & 1127.36 \\
$\mathrm{M}_{4}$ : scaling model & 31.71 & 309 & 554.58 & 2183.53 \\
$\mathrm{M}_{5}$ : Fixed Effect Model & -291.64 & 47 & 677.28 & 925.08 \\
$\mathrm{M}_{6}$ : Random Effect Model & & &
\end{tabular}




\section{Table 2.5 Technical efficiency over the observation period}

\begin{tabular}{lcccccccc}
\hline \multicolumn{2}{l}{ first sub-sample } \\
1995 & 1996 & 1997 & 1998 & 1999 & 2000 & 2001 & 2002 & average \\
0.89 & 0.87 & 0.89 & 0.86 & 0.88 & 0.87 & 0.87 & 0.89 & 0.88 \\
\multicolumn{2}{l}{ second sub-sample } & & & & & & & \\
2003 & 2004 & 2005 & 2006 & 2007 & 2008 & 2009 & 2010 & average \\
$/$ & 0.94 & 0.91 & 0.91 & 0.90 & 0.87 & 0.97 & 0.94 & 0.92 \\
\hline
\end{tabular}




\title{
Chapter 3 Measurement of China's environmental related total factor productivity using DEA
}

\begin{abstract}
As agricultural development has made substantial and rapid progress over recent decades, the environmental side effects of agricultural activities are strongly debated nowadays. However, environmental performance is usually ignored by farmers, and the relationship between environmental effects and production activities remains obscure. This study extends the nutrient balance approach by incorporating production technology exhibiting variable returns to scale (VRS). We investigate the environmental performance of rice production in China's Hubei Province based on 259 observations of individual household data. Our findings indicate that the environmental efficiency in China's rice production is low (0.61), and an effective way of reducing $\mathrm{N}$ pollution is to reallocate input combination.
\end{abstract}

Keywords: nitrogen pollution, environmental efficiency, productivity decomposition 


\subsection{Introduction}

In recent years, crop yield has been continuously increasing to feed the growing population, partly due to the increasing input of fertilizers, particularly nitrogen $(\mathrm{N})$ fertilizers (Cassman et al., 2003). As one of the largest crop production and consumption countries, China has always been trying to improve its crop yield, particular rice yield. As hybrid rice technology has been successfully carried out, Chinese rice output has quadrupled compared with 1949 levels. ${ }^{1}$ In 2010, China's rice production reached 19.58 million tons, and rice yield accounted for $36 \%$ of the total cereal yield. ${ }^{2}$ China's rice yield would have to rise by $14 \%$ by 2030 to satisfy the food demand of the growing population (Cheng et al., 2007). However, high productivity also causes environmental issues, including greenhouse gases (GHG) emissions, land degradation, biodiversity loss, groundwater contamination, etc. To meet the challenge of high yield and less pollution, both developed and developing countries are trying to allocate resource efficiently and economically to achieve a balance between productivity growth and environmental sustainability.

At present, approximately $10-12 \%$ of global anthropogenic GHG and $60-80 \%$ of global anthropogenic $\mathrm{N}_{2} \mathrm{O}$ are associated with agriculture (Linquist et al., 2012; Turner et al., 2015). Among various agricultural pollution, nitrogen $(\mathrm{N})$ pollution is noteworthy. China produces $30 \%$ of global rice production, with approximately $7 \%$ of global nitrogen consumption (Peng et al., 2006). The amount of nitrogen fertilizer applied during rice production in China (209 $\mathrm{kg} \mathrm{ha}^{-1}$ ) is $90 \%$ higher than the global average level (Chen et al., 2014), while the nitrogen use efficiency (NUE) for rice is only 30-35\% (Peng et al., 2015; Xu et al., 2012). Ammonia volatilization, leaching, runoff loss and denitrification are the main reasons for low NUE (Bijay et al., 1995; Cho, 2003; Freney et al., 1990; Ponnamperuma, 1972). Since N pollution

\footnotetext{
1 The figure is calculated according to China Statistical Yearbook.

2 The data comes from China Statistical Yearbook (2011).
} 
could severely damage the environment, reducing total $\mathrm{N}$ input (mainly from fertilizer and land) and balancing fertilizer $\mathrm{N}$ against soil $\mathrm{N}$ hold strong importance for improving both the agricultural productivity and sustainability of the environment. Therefore, measuring productivity from an agricultural and environmental perspective rather than the agricultural perspective alone is a more comprehensive and objective way to evaluate agricultural performance, which illustrates the current situation of production as well as the potential $\mathrm{N}$ pollution.

In the following section, we review the literature in the field of environmental-related productivity to gain an overview of relevant academic progress and identify possible research gaps that need to be filled. The theoretical framework, data and empirical specification are introduced in sections three and four, respectively. Subsequently, the empirical results are detailed and discussed in section five. The conclusion and discussion are presented in the final section.

\subsection{Literature review}

It is not uncommon to find that existing studies use various approaches to incorporate environmental performance evaluations into productivity analyses. In order to measure environmental efficiency, environmental indicators are usually treated as environmentalrelated inputs or detrimental outputs in production functions. Picazo-Tadeo et al. (2012) use three environmental indicators and one economic indicator to unveil the economic and environmental performance of olive-growing farmers in Spain, finding that eco-inefficient management is widespread among olive farmers. Vlontzos et al. (2014) include environmental detrimental outputs in a non-radial data envelopment analysis (DEA), and find that countries with strict environmental protection standards - such as Germany, Austria and Sweden - are not definitely more efficient than other countries in respect of energy and the environment. Huang et al. (2014) evaluate the technical efficiency and environmental efficiency in China's Qinghai-Tibetan Plateau by incorporating an ecological variable into 
the production function, finding that there is an overuse of grassland in livestock grazing.

One limitation of the above approaches is that it is impossible to expand desirable outputs and contract undesirable outputs simultaneously. To overcome this shortcoming, production analyses that simultaneously enable increasing desirable output and reducing undesirable output are proposed and applied. Faere et al. (1989) relax the strong disposability restrictions to allow undesirable outputs to be freely disposable, and modify multi-output production technology to treat desirable outputs and undesirable outputs asymmetrically. Chung et al. (1997) propose a directional distance function with a new production index (MalmquistLuenberger Index) to combat the criticism of the joint production of good and bad outputs. Cuesta et al. (2009) introduce an environmental hyperbolic distance function to allow an extension of equal-proportional good outputs and reduction of bad outputs. Despite the progress made by the aforementioned models, these methods are inconsistent with the material balance principle (MBP), which regulates that the materials in inputs are transformed into desirable outputs and emissions that have potential to cause pollution.

To solve the issue of MBP violation, Hoang and Coelli (2011) introduce a nutrient balance approach that measures environmental-related productivity and conforms with MBP. Hoang and Coelli (2011) think that the pollution potential of agriculture can be denoted by the nutrient balance, which equals the total amount of nutrients in inputs minus the amount of nutrients in outputs, which can be denoted as follows:

$$
\mathrm{u}=\mathbf{a x}-\mathbf{b q},
$$

where $\mathrm{u}$ represents the nutrient balance. $\mathbf{q}$ and $\mathbf{x}$ denote the output and input vector, respectively. $\mathbf{a}$ and $\mathbf{b}$ are vectors representing the nutrient contents of inputs and outputs. Since some inputs like labor, capital, etc. might have zero nutrients, the vector a can contain zero values.

Subsequently, the authors propose a nutrient-oriented total factor productivity estimated within the framework of production technology exhibiting constant returns to scale (CRS). If the actual production technology approximately presents CRS, this method will not lead 
to a significant bias among productivity components. ${ }^{1}$ To adapt to the production technology exhibiting VRS, we extend the nutrient balance approach when production technology exhibits VRS and provide a way to decompose environmental-related total factor productivity (TFP) in this case. Compared with TFP decomposition under CRS, our method is more applicable to the long-term assessment of agricultural and environmental performance.

Although some studies offer insights into the effects of agricultural activities on the environment, our research can be distinguished in several respects. The main contribution of this paper is that we extend the nutrient-oriented TFP of Hoang and Coelli's (2011) by incorporating production technology exhibiting variable returns to scale, and decompose the nutrient-oriented TFP under VRS. Additionally, conservation of ecological environment and resources is a critical issue to be aware of and resolve at present. To the best of our knowledge, studies related to China's environmental efficiency and environmental-related productivity are still inadequate and preliminary. This research measures current productivity from an agricultural and environmental perspective rather than the agricultural perspective alone, which illustrates the potential of improvements of agricultural productivity and environmental sustainability. Furthermore, we adopt the DEA method to measure environmental-related productivity, in which prerequisites for behavioral assumptions and production function specifications are not necessarily needed, and thus it is more flexible and adaptable.

\subsection{Theoretical framework}

According to Hoang and Coelli's (2011) model, undesirable outputs are defined as the nutrient balance (Coelli et al., 2007). When outputs are given, the nutrient balance is the minimum when the total amount of nutrients in inputs $\left(\mathrm{NC}=\mathbf{a}^{\prime} \mathbf{x}\right)$ is minimum. In an input-

\footnotetext{
1 The Malmquist index used to capture TFP change should fulfill the CRS condition, otherwise it is biased. Based on the traditional Malmquist index, Hoang and Coelli’s (2011) nutrient-oriented TFP is also limitted to the CRS condition.
} 
oriented production measurement, this approach solves the optimization issue in Eq. (2)

$$
\mathrm{NC}(\mathbf{q}, \mathbf{a})=\min _{x}\left\{\mathbf{a}^{\prime} \mathbf{x} \mid\langle\mathbf{x}, \mathbf{q}\rangle \in T\right\}
$$

Here, $\mathbf{q}$ and $\mathbf{x}$ denote the output vector and input vector separately. $\mathbf{a}$ is a vector that represents the nutrient contents of inputs. $T$ is the production possibility set, which is defined as Eq. (3)

$$
T=\{(\mathbf{q}, \mathbf{x}): \mathbf{x} \text { can produce } \mathbf{q}\} \text {. }
$$

Input-oriented technical efficiency (ITE) is defined as Eq. (4)

$$
\operatorname{ITE}(\mathbf{q}, \mathbf{x})=\min _{\theta}\{\theta \mid\langle\theta \mathbf{x}, \mathbf{q}\rangle \in T\},
$$

Here, $\theta$ is a scalar ranging from zero to one.

After combing the solutions of Eq. (2) and Eq. (4), the input-oriented nutrient efficiency (INE) decomposition function can be obtained, and we extend Hoang and Coelli's (2011) INE definition regarding VRS, which is larger than the INE under CRS. The new INE decomposition formula is as follows:

$$
\begin{aligned}
\mathrm{INE} & =\frac{\mathrm{NC}_{\mathrm{INE}}^{\mathrm{V}}}{\mathrm{NC}}=\frac{\mathbf{a}^{\prime} \mathbf{x}_{\mathrm{INE}}^{\mathrm{V}}}{\mathbf{a}^{\prime} \mathbf{x}}=\frac{\mathbf{a}^{\prime} \mathbf{x}_{\mathrm{ITE}}^{\mathrm{V}}}{\mathbf{a}^{\prime} \mathbf{x}} \times \frac{\mathbf{a}^{\prime} \mathbf{x}_{\mathrm{INE}}^{\mathrm{V}}}{\mathbf{a}^{\prime} \mathbf{x}_{\mathrm{ITE}}^{\mathrm{V}}}=\frac{\mathrm{NC}_{\mathrm{ITE}}^{\mathrm{V}}}{\mathrm{NC}} \times \frac{\mathrm{NC}_{\mathrm{INE}}^{\mathrm{V}}}{\mathrm{NC}_{\mathrm{ITE}}^{\mathrm{V}}} \\
& =\frac{\mathbf{a}^{\prime} \mathbf{x}_{\mathrm{ITE}}^{\mathrm{V}}}{\mathbf{a}^{\prime} \mathbf{x}} \times \frac{\mathbf{a}^{\prime} \mathbf{x}_{\mathrm{INE}}^{\mathrm{V}}}{\mathbf{a}^{\prime} \mathbf{x}_{\mathrm{ITE}}^{\mathrm{C}}} \times \frac{\mathbf{a}^{\prime} \mathbf{x}_{\mathrm{ITE}}^{\mathrm{C}}}{\mathbf{a}^{\prime} \mathbf{x}_{\mathrm{ITE}}^{\mathrm{V}}}=\frac{\mathrm{NC}_{\mathrm{ITE}}^{\mathrm{V}}}{\mathrm{NC}} \times \frac{\mathrm{NC}_{\mathrm{INE}}^{\mathrm{V}}}{\mathrm{NC}_{\mathrm{ITE}}^{\mathrm{C}}} \times \frac{\mathrm{NC}_{\mathrm{ITE}}^{\mathrm{C}}}{\mathrm{NC}_{\mathrm{ITE}}^{\mathrm{V}}}, \\
& =\mathrm{ITE} \times \mathrm{INASE} \times \mathrm{SE}
\end{aligned}
$$

where the superscripts $\mathrm{V}$ and $\mathrm{C}$ represent VRS and CRS, respectively. $\mathrm{NC}_{\mathrm{INE}}^{\mathrm{V}}$ is the solution to Eq. (2), and $\mathbf{x}_{\mathrm{INE}}^{\mathrm{V}}$ is the input vector when the nutrient amount is minimized, i.e. $\mathrm{NC}_{\mathrm{INE}}^{\mathrm{V}}=\mathbf{a}^{\prime} \mathbf{x}_{\mathrm{INE}}^{\mathrm{V}} \cdot \mathrm{NC}_{\mathrm{ITE}}^{\mathrm{V}}$ is the solution to Eq. (4), and $\mathbf{x}_{\mathrm{ITE}}^{\mathrm{V}}$ is the input vector when the goal maximizing proportional contraction of input quantities given output quantities is achieved, i.e. $\mathrm{NC}_{\mathrm{ITE}}^{\mathrm{V}}=\mathbf{a}^{\prime} \mathbf{x}_{\mathrm{ITE}}^{\mathrm{V}}$. From Eq. (5), it is clear that INE is decomposed into ITE and inputoriented allocative efficiency (INAE) all estimated under VRS. If we further decompose INAE, we can obtain a scale efficiency (SE) and an input-oriented allocative scale efficiency (INASE) estimated against production technology exhibiting CRS. The INASE is not pure allocative efficiency, because it also contains a scale inefficiency of INE estimated under 
$\mathrm{CRS}$ and VRS. More specifically, $\mathrm{INE}=\frac{\mathrm{NC}_{\mathrm{INE}}^{\mathrm{V}}}{\mathrm{NC}}=\frac{\mathbf{a}^{\prime} \mathbf{x}_{\mathrm{INE}}^{\mathrm{V}}}{\mathbf{a}^{\prime} \mathbf{x}}, \quad \mathrm{ITE}=\theta=\frac{\mathrm{NC}_{\mathrm{ITE}}^{\mathrm{V}}}{\mathrm{NC}}=\frac{\mathbf{a}^{\prime} \mathbf{x}_{\mathrm{ITE}}^{\mathrm{V}}}{\mathbf{a}^{\prime} \mathbf{x}}$, $\mathrm{INASE}=\frac{\mathrm{NC}_{\mathrm{INE}}^{\mathrm{V}}}{\mathrm{NC}_{\mathrm{ITE}}^{\mathrm{C}}}=\frac{\mathbf{a}^{\prime} \mathbf{x}_{\mathrm{INE}}^{\mathrm{V}}}{\mathbf{a}^{\prime} \mathbf{x}_{\mathrm{ITE}}^{\mathrm{C}}}$, and $\mathrm{SE}=\frac{\mathbf{a}^{\prime} \mathbf{x}_{\mathrm{ITE}}^{\mathrm{C}}}{\mathbf{a}^{\prime} \mathbf{x}_{\mathrm{ITE}}^{\mathrm{V}}}=\frac{\mathrm{NC}_{\mathrm{ITE}}^{\mathrm{C}}}{\mathrm{NC}_{\mathrm{ITE}}^{\mathrm{V}}}$.

Figure 3.1 illustrates INE components under VRS for the two-input and single-output case. The $\mathrm{x}-, \mathrm{y}-$ and $\mathrm{z}$-axis denote input $\mathrm{x}_{1}, \mathrm{x}_{2}$ and output $\mathrm{y}$, respectively. We focus on observed point Obs, of which corresponding points on the CRS frontier GAB and VRS frontier CAEFBD are point $\mathrm{X}_{\mathrm{CRS}}$ and point $\mathrm{X}_{\mathrm{VRS}}$, separately. The corresponding points of Obs, $X_{V R S}$ and $X_{C R S}$ on the iso-nutrient line OP, O'P' and O"P" are $Q$, Q' and $Q^{\prime \prime}$. The corresponding allocative efficient point of Obs is $\mathrm{X}_{\mathrm{AE}, \mathrm{VRS}}$, and the projection point of $\mathrm{X}_{\mathrm{AE}, \mathrm{VRS}}$ on the iso-nutrient line is $\mathrm{R}$. The difference between nutrients of point $\mathrm{R}$ and nutrients of point Obs represents input-oriented nutrient inefficiency under VRS. The difference between nutrients of point Q' and nutrients of point Obs represents inputoriented technical inefficiency under VRS. The difference between nutrients of point $\mathrm{R}$ and nutrients of point Q' represents input-oriented nutrient allocative inefficiency under VRS. The difference between nutrients of point $\mathrm{R}$ and nutrients of point $\mathrm{Q}^{\prime}$ represents inputoriented nutrient allocative scale inefficiency. The difference between nutrients of point Q" and nutrients of point Q' represents scale inefficiency. 


\section{Figure 3.1 INE components under VRS for the two-input and single-output case ${ }^{1}$}

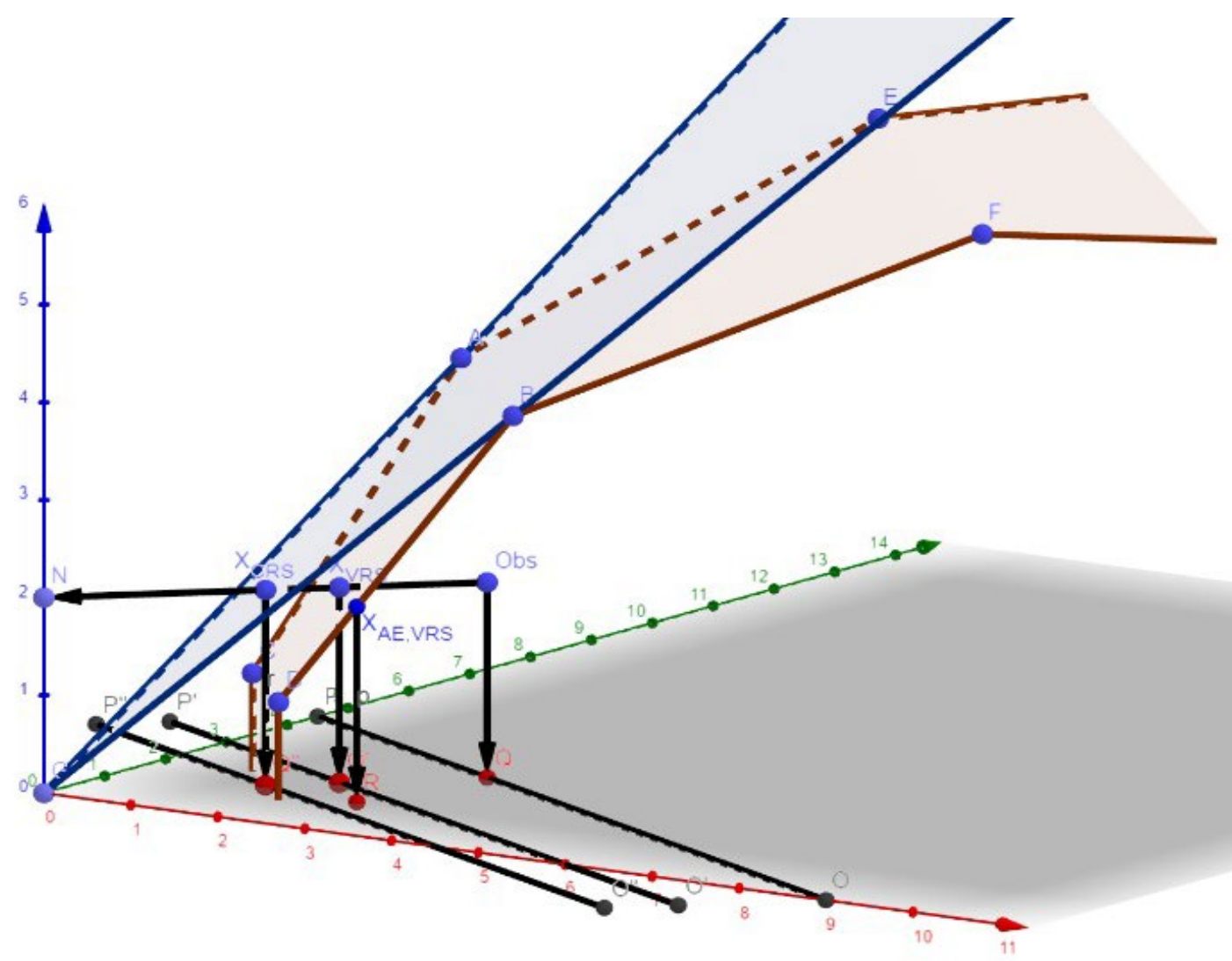

To capture the temporary dynamic change of productivity and production technology, we adopt the RD Malmquist index introduced by Ray and Desli (1997). The input-oriented RD Malmquist indices of period $t$ and $t+1$ are defined as follows:

$$
\begin{aligned}
& R D_{I}^{t}\left(x^{t}, y^{t}, x^{t+1}, y^{t+1}\right)= M_{I}^{t}\left(x^{t}, y^{t}, x^{t+1}, y^{t+1}\right) * E_{I}^{t}\left(x^{t}, y^{t}, x^{t+1}, y^{t+1}\right) \\
&= D_{I}^{t}\left(x^{t+1}, y^{t+1}\right) / D_{I}^{t}\left(x^{t}, y^{t}\right) *\left[S E_{I}^{t}\left(x^{t+1}, y^{t+1}\right) / S E_{I}^{t}\left(x^{t}, y^{t}\right)\right] \\
&= {\left[D_{I}^{t}\left(x^{t+1}, y^{t+1}\right) / D_{I}^{t+1}\left(x^{t+1}, y^{t+1}\right)\right]\left[D_{I}^{t+1}\left(x^{t+1}, y^{t+1}\right) / D_{I}^{t}\left(x^{t}, y^{t}\right)\right], } \\
& *\left\{\left(D_{I C}^{t}\left(x^{t+1}, y^{t+1}\right) / D_{I}^{t}\left(x^{t+1}, y^{t+1}\right)\right) /\left(D_{I C}^{t}\left(x^{t}, y^{t}\right) / D_{I}^{t}\left(x^{t}, y^{t}\right)\right)\right\} \\
& R D_{I}^{t+1}\left(x^{t}, y^{t}, x^{t+1}, y^{t+1}\right)=M_{I}^{t+1}\left(x^{t}, y^{t}, x^{t+1}, y^{t+1}\right) * E_{I}^{t+1}\left(x^{t}, y^{t}, x^{t+1}, y^{t+1}\right) \\
&=D_{I}^{t+1}\left(x^{t+1}, y^{t+1}\right) / D_{I}^{t+1}\left(x^{t}, y^{t}\right) *\left[S E_{I}^{t+1}\left(x^{t+1}, y^{t+1}\right) / S E_{I}^{t+1}\left(x^{t}, y^{t}\right)\right] \\
&= {\left[D_{I}^{t}\left(x^{t}, y^{t}\right) / D_{I}^{t+1}\left(x^{t}, y^{t}\right)\right]\left[D_{I}^{t+1}\left(x^{t+1}, y^{t+1}\right) / D_{I}^{t}\left(x^{t}, y^{t}\right)\right] } \\
& *\left\{\left(D_{I C}^{t+1}\left(x^{t+1}, y^{t+1}\right) / D_{I}^{t+1}\left(x^{t+1}, y^{t+1}\right)\right) /\left(D_{I C}^{t+1}\left(x^{t}, y^{t}\right) / D_{I}^{t+1}\left(x^{t}, y^{t}\right)\right)\right\}
\end{aligned}
$$

\footnotetext{
1 The setting and software used to draw Figure 3.1 can be found in Appendix A.
} 
Here, $t$ denotes period 1, 2, 3..n. $R D_{I}^{t}\left(x^{t}, y^{t}, x^{t+1}, y^{t+1}\right)$ and $R D_{I}^{t+1}\left(x^{t}, y^{t}, x^{t+1}, y^{t+1}\right)$ are the RD Malmquist indices of period $t$ and $t+1 . M_{I}^{t}\left(x^{t}, y^{t}, x^{t+1}, y^{t+1}\right)$ and $M_{I}^{t+1}\left(x^{t}, y^{t}, x^{t+1}, y^{t+1}\right)$ are CCD Malmquist indices (Caves et al., 1982) of period $t$ and $t+1 . E_{I}^{t}\left(x^{t}, y^{t}, x^{t+1}, y^{t+1}\right)$ and $E_{I}^{t+1}\left(x^{t}, y^{t}, x^{t+1}, y^{t+1}\right)$ are Malmquist scale indices of period $t$ and $t+1 . E_{I}^{t}\left(x^{t}, y^{t}, x^{t+1}, y^{t+1}\right)$ is defined as the ratio of a pair of input-oriented scale efficiencies relative to period $t$, and $E_{I}^{t+1}\left(x^{t}, y^{t}, x^{t+1}, y^{t+1}\right)$ is defined in the same way. $S E_{I}^{t}\left(x^{t+1}, y^{t+1}\right)$ represents the SE of observations of period $t+1$ against technology of period $t$, and $S E_{I}^{t}\left(x^{t}, y^{t}\right), S E_{I}^{t+1}\left(x^{t+1}, y^{t+1}\right)$ and $S E_{I}^{t+1}\left(x^{t}, y^{t}\right)$ are defined in the same way. $D_{I}(\cdot)$ and $D_{I C}(\cdot)$ are the input-oriented distance function measured within the framework of VRS and CRS, separately. For instance, $D_{I}^{t}\left(x^{t+1}, y^{t+1}\right)$ is an input-oriented distance function, where observations of time $t+1$ are used to measure the maximum proportional contraction of inputs when outputs are given against technology $t$, which also equals the reciprocal of Farrell (1957) ITE, i.e. $\operatorname{ITE}^{t, t+1}=1 / D_{I}^{t}\left(x^{t+1}, y^{t+1}\right)$.

The input-oriented RD Malmquist TFP change (RDTFPC) is the geometric mean of Eq. (6) and Eq. (7), and it is specified as Eq. (8)

$$
\begin{aligned}
\text { RDTFPC } & =R D_{I}^{G}\left(x^{t}, y^{t}, x^{t+1}, y^{t+1}\right) \\
& =M_{I}^{G}\left(x^{t}, y^{t}, x^{t+1}, y^{t+1}\right) \times E_{I}^{G}\left(x^{t}, y^{t}, x^{t+1}, y^{t+1}\right) \\
& =\left(\frac{\mathrm{ITE}^{t, t+1}}{\operatorname{ITE}^{t, t}} \times \frac{\mathrm{ITE}^{t+1, t+1}}{\mathrm{ITE}^{t+1, t}}\right)^{1 / 2} \times\left(\frac{\mathrm{SE}^{t, t+1}}{\mathrm{SE}^{t, t}} \times \frac{\mathrm{SE}^{t+1, t+1}}{\mathrm{SE}^{t+1, t}}\right)^{1 / 2}=\mathrm{TC} \times \mathrm{TEC} \times \mathrm{SEC}
\end{aligned}
$$

where $R D_{I}^{G}\left(x^{t}, y^{t}, x^{t+1}, y^{t+1}\right), M_{I}^{G}\left(x^{t}, y^{t}, x^{t+1}, y^{t+1}\right)$ and $E_{I}^{G}\left(x^{t}, y^{t}, x^{t+1}, y^{t+1}\right)$ are the geometric mean of adjacent-period input-oriented RD Malmquist indices, the geometric mean of adjacent-period input-oriented CCD Malmquist indices and the geometric mean of adjacentperiod input-oriented Malmquist scale indices.

Similarly, the nutrient-oriented Malmquist TFP change (NTFPC) is defined as the geometric mean of nutrient-oriented TFP indices of period $t$ and period $t+1$, and it is specified as follows:

$$
\mathrm{NTFPC}=\left[M_{\mathrm{NTFP}}^{t} \times M_{\mathrm{NTFP}}^{t+1}\right]^{1 / 2}=\left[\frac{\mathrm{INE}^{t, t+1}}{\mathrm{INE}^{t, t}} \times \frac{\mathrm{INE}^{t+1, t+1}}{\mathrm{INE}^{t+1, t}}\right]^{1 / 2} .
$$


Here, $\mathbb{N N E}^{t, t+1}$ represents the INE score, which measures a firm's nutrient performance in period $t$ against the technology in period $t_{t+1}$. In the same way, $\operatorname{INE}^{t, t}, \operatorname{INE}^{t+1, t+1}$, and $\operatorname{INE}^{t+1, t}$ can be obtained. $\mathrm{M}_{\mathrm{NTFP}}^{t}$ is a nutrient-oriented Malmquist total factor productivity (NTFP) of period $t$, i.e. $M_{\mathrm{NTFP}}^{t}=\frac{\mathrm{INE}^{t, t+t}}{\mathrm{INE}^{t, t}}$, and $M_{\mathrm{NTFP}}^{t+1}$ is defined in the same way. Considering Eq. (5) and Eq. (9) together, the nutrient-oriented Malmquist TFP change (NTFPC) can be further rewritten as follows:

$$
\mathrm{NTFPC}=\mathrm{RDTFPC} \times\left[\frac{\mathrm{INASE} \mathrm{INE}^{t, t+1}}{\mathrm{INASE}^{t, t}} \times \frac{\mathrm{INASE}^{t+1, t+1}}{\mathrm{INASE}^{t+1, t}}\right]^{1 / 2}=\mathrm{TC} \times \mathrm{TEC} \times \mathrm{SEC} \times \mathrm{NASEC} .
$$

Here, technical change (TC) captures the shift of the production frontier. Technical efficiency change (TEC) accounts for the ITE change. Scale efficiency change (SEC) measures the SE change between different technologies. Nutrient allocative scale efficiency change (NASEC) measures the INASE change.

\subsection{Data and empirical specification}

Based on our research objective and data availability, we adopt the individual farm household data from Hubei Province in 2004-2010 provided by China's Rural Fixed Observation Point Bureau. We first exclude farm households whose family main business is not planting. Subsequently, farm households inputting zero land or labor in rice production are excluded. Finally, we select farm households that can be observed for all seven years. After data cleaning, there are 37 farm households (259 observations in total) engaged in rice plantation each year in our balanced panel, which are still widely distributed in household aspects (such as producer age, gender, education background, etc.) and input aspects (see Table 1), rather than being concentrated in a small range. The reduction of the overall dataset to a balanced panel would definitely be a waste of data information. Nevertheless, to fulfill the subsequent calculation of different productivity components, this is inevitable since the discrete data would not be involved in calculating different indices or providing extra 
information. Besides, the attempt to compile missing data and then transform the unbalanced panel to a balanced panel may cause more potential problems and reduce the authenticity and validity of the data.

Due to various categories of inputs and outputs in the dataset, we aggregate and split them into five inputs, namely land, labor, intermediate input, capital and fertilizer, and one output, the total production of rice. The land variable is defined as the total sown area of each household measured by mu. ${ }^{1}$ The labor variable is defined as the total number of days that each household devotes to rice plantation activities. The intermediate input variable is an aggregation of purchases of seed, pesticide, diesel oil, plastic, etc., in yuan. The capital variable is given as the aggregation of purchases of machinery, agricultural assets, etc., which reflects the input of long-term goods during production. ${ }^{2}$ Due to the nature of longterm inputs, their values are depreciated using the straight-line depreciation method and averagely added to the calculation of capital in yuan. ${ }^{3}$ To avoid inflation effects, intermediate input and capital are also adjusted by CPI. ${ }^{4}$ First, we choose 2004 as the base year, and transform the yearly CPI of 2004 to 2010 into the fixed-base CPI. Subsequently, the value of intermediate input and capital calculated in 2004 CNY are obtained by dividing the fixed-base CPI. The fertilizer variable is the total fertilizers - which mainly include urea, ammonium phosphate and ammonium bicarbonate - applied in rice production in one year, calculated by kilogram. As for outputs, the rice output is defined as the total production of rice, measured by kilogram. The statistical description of variables is presented in Table 3.1.

\footnotetext{
$11 \mathrm{mu}$ approximately equals 0.067 hectares.

${ }^{2}$ In this paper, capital does not reflect the economic notion of capital appropriately. Hence, the capital variable used in this study should be interpreted with caution.

3 We assume the long-term inputs are depreciated averagely within ten years.

${ }^{4}$ CPI is from National Bureau of Statistics (see http://www.stats.gov.cn/).
} 
Table 3.1 Statistical description of variables

\begin{tabular}{|c|c|c|c|c|c|}
\hline Variable & Unit & Mean & Std. Dev. & Min & Max \\
\hline \multicolumn{6}{|c|}{ sample observation $n=259$} \\
\hline land & $\mathrm{mu}$ & 3.27 & 3.64 & 0.3 & 50 \\
\hline labor & day & 95.76 & 72.03 & 2 & 310 \\
\hline intermediate input & yuan & 421.81 & 331.09 & 24.01 & 1897 \\
\hline capital & yuan & 4.69 & 19.75 & 0 & 221.5 \\
\hline fertilizer & $\mathrm{kg}$ & 294.20 & 751.05 & 0 & 12020 \\
\hline rice output & $\mathrm{kg}$ & 1345.94 & 978.90 & 1.5 & 6600 \\
\hline land $N$ & $\mathrm{~g} / \mathrm{mu}$ & 22364.97 & 5018.62 & 0 & 31045.55 \\
\hline fertilizer $N$ & $\mathrm{~g} / \mathrm{kg}$ & 131.98 & 110.18 & 0 & 515.7 \\
\hline
\end{tabular}

Among the five inputs, labor, intermediate input and capital are assumed to have zero nitrogen contents. The $\mathrm{N}$ content in land is the total grams of available nitrogen (alkali hydrolysable nitrogen) in tillage layer per mu, which is usually inorganic nitrogen (nitrate nitrogen and ammonium nitrogen) and easily hydrolyzed organic nitrogen (amino acids, ammonium and easily hydrolyzed proteins). The nitrogen supply capacity of paddy soil in Hubei Province is represented by the nitrogen capacity of paddy soil in the observation spot in the adjacent Hunan Province from 2004 to 2010 according to the Soil Science Database, ${ }^{1}$ because both provinces have a long history of planting rice, and they are similar in paddy soil share, size and nutrient composition. ${ }^{2}$ Since the effects of different soil layers for rice root to absorb nutrients have a wide range, we choose a 20 -centimeter tillage layer for calculating soil mass. Taking soil fertility heterogeneity into consideration, we use the ratio of harvest area to sow area to adjust the nitrogen supply capacity of different plots.

The $\mathrm{N}$ contents in fertilizer is the ratio of the total grams of nitrogen coming from all types of fertilizers applied to rice to the amount of total fertilizers applied to rice. After calculating the total nitrogen contained in different types of fertilizers and the share of fertilizer applied to rice among total fertilizer application, the total nitrogen contained in

\footnotetext{
${ }^{1}$ See http://vdb3.soil.csdb.cn/.

2 See http://vdb3.soil.csdb.cn/.
} 
fertilizer applied to rice can be obtained. Despite the possible existing bias that types of fertilizer applied may vary from crop to crop, our estimation of nitrogen in fertilizer applied to rice remains reliable and referable, because rice is the main crop that farmers in Hubei Province grow.

Based on the characteristics of our dataset and our research goal, we adopt DEA to estimate efficiency scores for several reasons. First, the specific production function forms are not required in DEA. Second, the flexible specification of different production technology is very convenient for our subsequent calculation of relevant indices. Third, DEA does not require behavioral assumptions such as profit maximization, cost minimization, etc., and it is more adaptable to our data. Nevertheless, the use of DEA also has some limitations. For instance, it does not take account of data noise, and the estimated frontier may be influenced by several extreme values. There is no doubt that every method has its own advantages and disadvantages. Hence, there are opportunities for future research to improve methods and empirical applications.

\subsection{Results}

This section interprets the estimation results of the production frontier and the calculation results of RDTFPC and NTFPC. First, the ITE, INASE, SE and INE are given. Subsequently, RDTFPC, NTFPC and their components are presented and compared to reflect how productivity changes after considering environmental factors.

\subsubsection{Efficiency levels of ITE, INASE, SE and INE}

Table 3.2 (see Appendix B) provides a statistical description of levels of ITE, INASE, SE and INE in 2004-2010. ${ }^{1}$ The average INE score (0.61) suggests that farmers could reduce $\mathrm{N}$ emissions by $39 \%$, which shows the strong possibility of reducing environmental

\footnotetext{
1 Since distributions of INE components are skewed, we choose medians to show the calculation results of ITE, INASE, SE and INE.
} 
pollution in rural areas. During the research period, the annual INE experienced a mild fluctuation, aside from a decline in 2009 (see Figure 3.2). The INE (0.29) in 2009 is much lower compared with in other observed years, which is a comprehensive outcome of low INASE and SE. On the one hand, the mean of rice yield reaches the maximum in 2009, which represents an increase in total inputs. This can lead to a low INASE, because the N input is larger than expected. On the other hand, due to the large difference between the production frontier estimated under CRS and VRS, the SE in 2009 is also lower than that in the previous year, which means that farmers can reduce more inputs by moving to the most productive scale size (MPSS).

Among the components of INE, it is obvious that INASE is the main factor that lowers the INE score. The average INASE (0.81) indicates that rice farmers could reduce nitrogen emissions by $19 \%$ based on the technical-efficient point on the CRS frontier. INASE suggests that after satisfying the current minimum amount of fertilizer application to become technical- and scale-efficient, farmers could further reduce the amount of fertilizer application to become environmental-efficient. The average ITE score (0.94) indicates that farmers in Hubei Province could save 6\% total inputs to yield the current rice production. Besides, the average SE score (0.94) implies that farmers are almost located at the MPSS.

Figure 3.2 Trend of ITE, SE, INASE and INE from 2004 to 2010

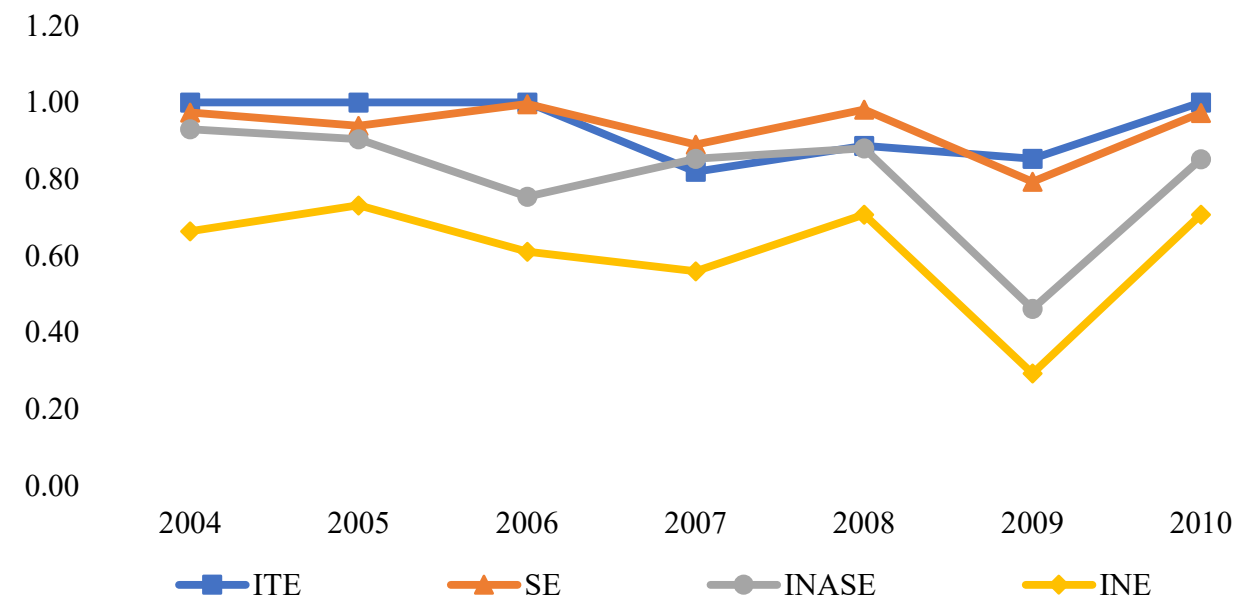




\subsubsection{RDTFPC and NFTPC}

Table 3.3 (see Appendix B) provides information about the changes in RDTFP and NTFP. ${ }^{1}$ RDTFPC is decomposed into TEC, TC and SEC, while NTFPC is decomposed into all former components plus NASEC. On average, RDTFP presents a decreasing trend at a rate of $6 \%$ owing to technical regress (0.96). In 2004-2009, the annual RDTFPC slightly fluctuates, aside from a significant low point in 2004 due to technical regress and an SE decrease (see Figure 3.3). From 2004 to 2005, the disaster areas in Hubei Province increased by $66 \%$ and peaked at $2,580,000$ hectares in 2005 . In this situation, farmers have to reduce their input and scale size to reduce disaster damage, which could lead to a low SE and low productivity. During most observed years, the movements of TC and TEC are towards different directions, which result from two factors. First, there may be time lags in response to the technical progress, i.e. the effects of adoption of new farming practices, experience, technology, management, etc. take time to make a difference in farmers' production and improvement of technical efficiency. Second, the random error and data noise may cause an overestimation problem of inefficiency, which could show a different trend between TEC and TC. As for SEC (0.98), it keeps stably near one and indicates that the adjustment of scale size will not lead to higher productivity since farmers are already located at the MPSS.

\footnotetext{
1 Since distributions of RDTFPC and NTFPC components are skewed, we choose medians to show the calculation results of TEC, TC, SEC, RDTFPC, NASEC and NTFPC.
} 
Figure 3.3 Trend of NTFPC, RDTFPC and their components from 2004 to 2009

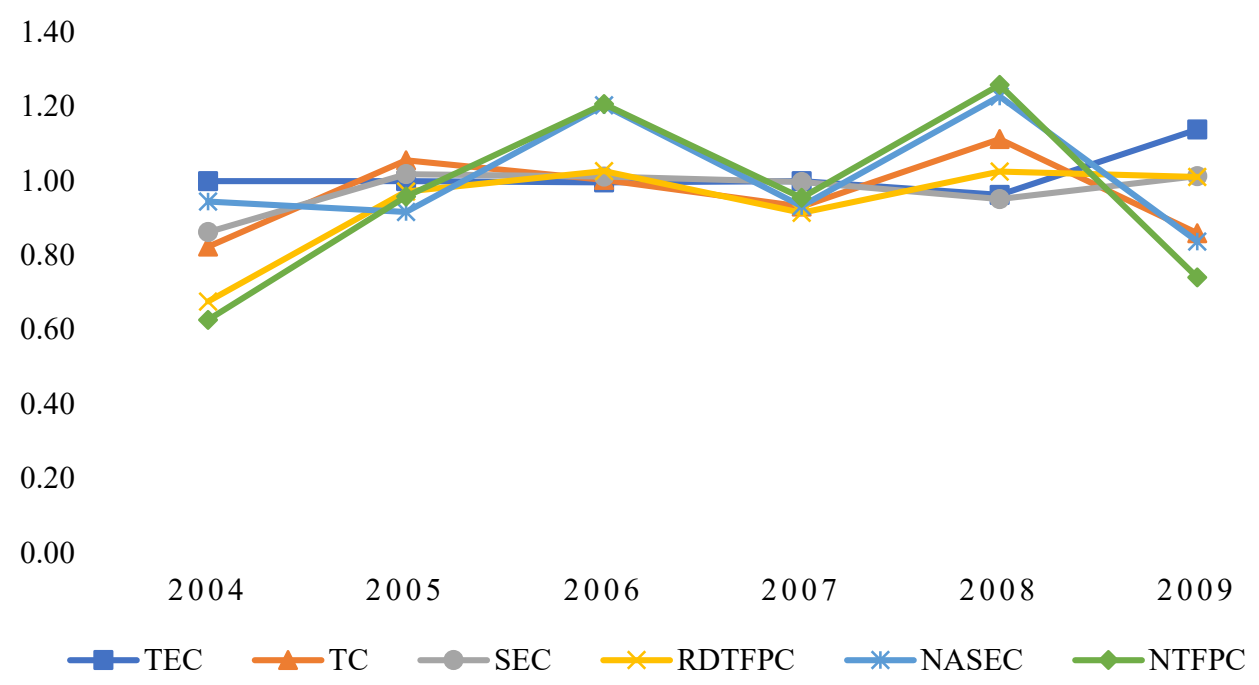

In terms of average NTFPC (0.96), it changes in line with the trend of RDTFPC and NASEC. From 2004 to 2009, NASEC is found to be more strongly correlated with NTFPC. It indicates that the most effective way to prevent $\mathrm{N}$ pollution and protect the ecosystem is to reallocate input combination. Moreover, the changing direction of NTFP is consistent with RDTFP in general, which implies that the movement of environmental-related TFP is not necessarily the contrary of agricultural TFP.

\subsection{Conclusion}

The main contribution of this paper is to extend the nutrient balance approach by incorporating production technology exhibiting VRS. After decomposing RDTFPC and NTFPC, we could derive the following conclusions. First, the annual INE experienced a mild fluctuation during 2004-2010, aside from a drop in 2009. Second, rice farmers in Hubei Province are already located at the MPSS. Third, average RDTFPC presents an annual decreasing rate of $6 \%$ owning to technical regress $(0.96)$. Fourth, due to time lags and an overestimation of inefficiency, the changing directions of TEC and TC are different. 
Since N pollution could cause problems such as global warming, ozone depletion, eutrophication, acidification, biodiversity loss, etc., the attempt to improve NUE when agricultural production goals have been achieved is critical to abating $\mathrm{N}$ pollution. This empirical research also yields several important findings related to environment conservation. First, the average INE indicates that there is strong potential to reduce current $\mathrm{N}$ input by $39 \%$. Second, INASE is the main factor that lowers the INE score, which indicates that rice farmers could reduce nitrogen emissions by $19 \%$ based on the technicalefficient point on the CRS frontier. Third, NASEC is found to be more strongly correlated with NTFPC, which indicates that the most effective way to prevent $\mathrm{N}$ pollution and protect the ecosystem is to reallocate input combination. Fourth, the changing direction of NTFP is consistent with RDTFP in general, which implies that the movement of environmental TFP is not necessarily the contrary of agricultural TFP. 


\subsection{Appendix}

\section{Appendix A}

Figure 3.1 INE components under VRS for the two-input and single-output case

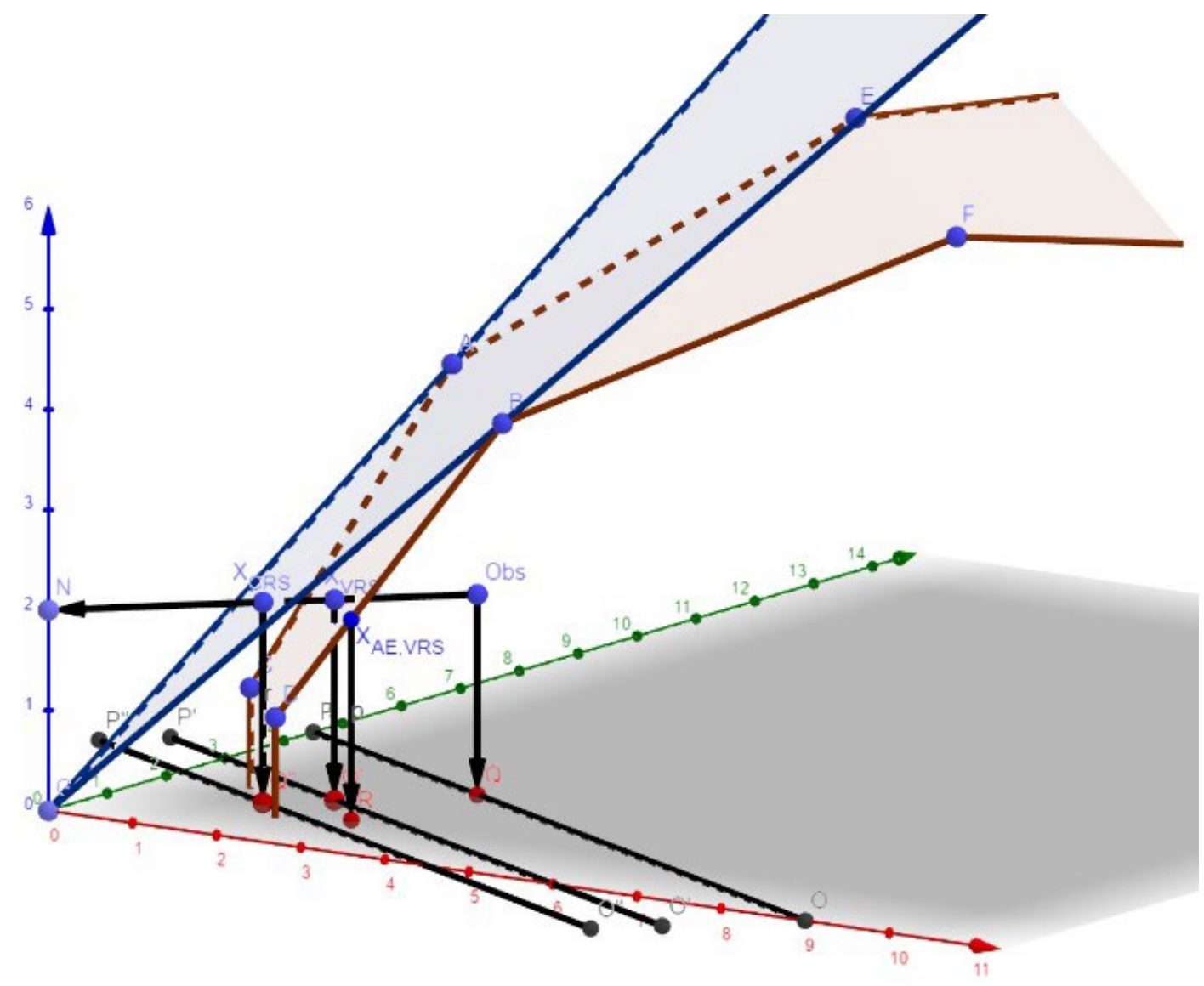

We use seven observations A $(2,4,4)$, B $(4,2,4)$, C $(1,2,1)$, D $(2,1,1)$, E $(4,8,6)$, F $(8,4,6)$, and Obs $(3,3,2)$ to draw Figure 1 in GeoGebra. $x-, y-$ and $z$-axis denote input $\mathrm{x}_{1}$, input $\mathrm{x}_{2}$ and output $\mathrm{y}$ respectively. We assume the nutrient contents of input 1 and 2 are $\mathrm{w}_{1}$ and $\mathrm{w}_{2}$, where $\mathrm{w}_{1}=1$ and $\mathrm{w}_{2}=2$. First, we draw the CRS frontier $\mathrm{GAB}$ and VRS frontier CAEFBD. Second, we do DEA based on the seven points in Ox under CRS and VRS to obtain the ITE scores, and then calculate the coordinates of point $\mathrm{X}_{\mathrm{VRS}}$ and point $\mathrm{X}_{\mathrm{CRS}}$. Third, we calculate the nutrients of point Obs, point $\mathrm{X}_{\mathrm{VRS}}$ and point $\mathrm{X}_{\mathrm{CRS}}$, and draw 
the corresponding iso-nutrient $(\mathrm{N})$ line OP, O'P' and O"P". Fourth, we calculate the nutrients of observation $\mathrm{A}, \mathrm{B}, \mathrm{C}, \mathrm{D}, \mathrm{E}, \mathrm{F}$, and then estimate the nutrient minimization frontier under VRS in Ox to obtain the coordinates of point $\mathrm{X}_{\mathrm{AE}, \mathrm{VRS}}$. 


\section{Appendix B}

Table 3.2 Levels of ITE, INASE, SE and INE

\begin{tabular}{lllll}
\hline & ITE & SE & INASE & INE \\
\hline 2004 & 1.00 & 0.97 & 0.93 & 0.66 \\
2005 & 1.00 & 0.94 & 0.90 & 0.73 \\
2006 & 1.00 & 1.00 & 0.75 & 0.61 \\
2007 & 0.82 & 0.89 & 0.85 & 0.56 \\
2008 & 0.89 & 0.98 & 0.88 & 0.71 \\
2009 & 0.85 & 0.79 & 0.46 & 0.29 \\
2010 & 1.00 & 0.97 & 0.85 & 0.71 \\
average & 0.94 & 0.94 & 0.81 & 0.61 \\
\hline
\end{tabular}

a Since distributions of INE components are skewed, we choose medians to show the calculation results of ITE, INASE, SE and INE.

Table 3.3 Levels of TEC, TC, SEC, RDTFPC, NASEC and NTFPC

\begin{tabular}{lllllll}
\hline & TEC & TC & SEC & RDTFPC & NASEC & NTFPC \\
\hline 2004 & 1.00 & 0.82 & 0.86 & 0.68 & 0.94 & 0.63 \\
2005 & 1.00 & 1.06 & 1.02 & 0.97 & 0.92 & 0.96 \\
2006 & 1.00 & 1.00 & 1.01 & 1.03 & 1.20 & 1.21 \\
2007 & 1.00 & 0.93 & 1.00 & 0.92 & 0.93 & 0.95 \\
2008 & 0.96 & 1.11 & 0.95 & 1.03 & 1.23 & 1.26 \\
2009 & 1.14 & 0.86 & 1.01 & 1.01 & 0.84 & 0.74 \\
average & 1.02 & 0.96 & 0.98 & 0.94 & 1.01 & 0.96 \\
\hline
\end{tabular}

a Since distributions of RDTFPC and NTFPC components are skewed, we choose medians to show the calculation results of TEC, TC, SEC, RDTFPC, NASEC and NTFPC. 


\title{
Chapter 4 Measurement of China's environmental related total factor productivity using SFA
}

\begin{abstract}
Rice yield has significantly increased over recent decades along with the increasing input of nitrogen $(\mathrm{N})$ fertilizer. Nevertheless, excess and improper $\mathrm{N}$ fertilizer application could cause a range of environmental issues and damage ecosystems. The long-term consequences of agricultural pollution are often neglected by farmers. Our research evaluates farmers' environmental performance and finds that appropriate allocating input combination could improve farmers' productivity and reduce $\mathrm{N}$ pollution. The main contribution of this paper is that we estimate total factor productivity (TFP) within the framework of the stochastic nutrient frontier (SNF) and further decompose it based on the Divisia Index using individual farm household data from Hubei Province from 2004 to 2010. Our findings indicate that the average decreasing rate of TFP is $2 \%$, which is a comprehensive outcome of all relevant components. Among TFP components, the allocative effect of fertilizer nutrient has a strong negative effect on TFP change, which indicates farmers use more chemical fertilizer than they need. Thus, using less fertilizer and increasing nitrogen use efficiency (NUE) are beneficial to eliminating nutrient allocative inefficiency and improving TFP.
\end{abstract}

Keywords: rice production, stochastic nutrient frontier, TFP decomposition 


\subsection{Introduction}

In 2010, China's rice production reached 19.58 million tons, and rice yield comprised $36 \%$ of the total cereal yield. ${ }^{1}$ Regarding the nationwide adoption of hybrid varieties and semi-dwarf varieties, rice yield has increased from $2.0 \mathrm{t} \mathrm{ha}^{-1}$ in the $1960 \mathrm{~s}$ to $6.89 \mathrm{t} \mathrm{ha}^{-1}$ in 2010 (Cheng et al., 2007). Increasing rates of fertilizer application - especially nitrogen (N) fertilizer - have substantially contributed to crop yield growth in recent years (Cassman et al., 2003). As a staple food in China, rice provides $40 \%$ of the total calorie intake of Chinese people, and the demand for rice is still increasing, requiring 14\% more rice yield by 2030 to nourish the growing population (Cheng et al., 2007). There is no doubt that the increase in rice yield will lead to an increase in the input of $\mathrm{N}$ fertilizer. However, the amount of nitrogen fertilizer applied (209 $\left.\mathrm{kg} \mathrm{ha}^{-1}\right)$ during rice production in China is $90 \%$ higher than the global average level (Chen et al., 2014), and the $\mathrm{N}$ taken by rice is only $30-35 \%$ (Peng et al., 2015; $\mathrm{Xu}$ et al., 2012). In this case, increased $\mathrm{N}$ fertilizer application could definitely add to the environmental burden of agricultural pollution.

In fact, $50-70 \%$ of nitrogen content in fertilizer is potentially lost to the environment (Cassman et al., 2002; Ladha et al., 2005). $\mathrm{N}$ losses could cause enormous environmental damage. Around $10-12 \%$ of global anthropogenic greenhouse gases (GHG) and $60-80 \%$ of global anthropogenic $\left(\mathrm{N}_{2} \mathrm{O}\right)$ are associated with agricultural production (Linquist et al., 2012; Turner et al., 2015). The volatilization and denitrification of $\mathrm{N}$ fertilizer can lead to the formation of GHG such as $\mathrm{N}_{2} \mathrm{O}, \mathrm{NO}$, and $\mathrm{NH}_{3}$. The deposition of nitrates and ammonia in soil and groundwater could cause acidification, eutrophication and biodiversity loss (Reeves et al., 2002; Vitousek et al., 1997). Finally, drinking groundwater with an excess nitrate content could damage human health and result in respiratory diseases, such as methemoglobinemia in infants and low vitamin A levels in the liver (Bohlool et al., 1992; Phupaibul et al., 2002).

\footnotetext{
1 The data comes from China Statistic Yearbook (2011).
} 
Considering the enormous negative impacts of the overuse of $\mathrm{N}$ fertilizer, evaluating agricultural and environmental performance in the meantime is crucial to reduce $\mathrm{N}$ pollution and achieve environmental sustainability. In the field of incorporating environmental efficiency in measuring productivity, conventional empirical attempts can be divided into the two categories. First, environmentally-adjusted production efficiency (EAPE) is adopted to capture environmental efficiency (Faere et al., 1989; Iram et al., 2020; Piot-Lepetit and Le Moing, 2007; Reinhard et al., 1999; Reinhard et al., 2000). EAPE adds environmental indicators as environmentally-detrimental inputs or undesirable outputs to production function to estimate relevant environmental efficiency. Second, the frontier formed by multiple environmental, economic, or social factors is measured and then the frontier ecoefficiency (FEE) is applied in a more extensive range (Callens and Tyteca, 1999; Kuosmanen and Kortelainen, 2005; Picazo-Tadeo et al., 2012; Picazo-Tadeo et al., 2011).

However, there are some obvious weaknesses in these methods. Murty et al. (2012) believe that models that treat pollution as a freely disposable input or weakly disposable output may lead to an inappropriate interpretation of trade-offs among inputs and outputs. Besides, these methods are not in line with material balance principle (MBP), and these methods' violation of MBP has also been proven by Coelli et al. (2007). The MBP approach provides a new perspective to model production technologies incorporating pollution problems, which does not involve extra environmentally-detrimental inputs or outputs, but analyzes the pollution potential of existing inputs and outputs based on the material transformation and flow perspective.

The MBP indicates that the nutrients contained in inputs not only go into desirable outputs, but also undesirable outputs (pollution) (Coelli et al., 2007; Reinhard et al., 2000). Since agricultural production is a component of the ecosystem, the MBP is applied to agricultural sector, and thus we need to adhere to the MBP when considering the transformation of substance from inputs to outputs. Measuring environmental efficiency 
incorporating the MBP has two benefits: first, it can reduce the costs of pollution abatement; ${ }^{1}$ and second, the method holds when the MBP is applicable (Coelli et al., 2007). After noticing the MBP, Hoang and Coelli (2011) introduce their nutrient-oriented total factor productivity (NTFP) and decompose it into technical efficiency change (TEC), technical change (TC) and allocative efficiency change (AEC) based on the Malmquist Index. One limitation of Hoang and Coelli's (2011) model is that the random error and inefficiency do not split within the framework of the DEA, which could bias the results of decomposition components.

To combat the problem of Hoang and Coelli's (2011) model, we estimate total factor productivity (TFP) within the framework of the stochastic nutrient frontier (SNF) and further decompose it into technical efficiency change (TEC), technical change (TC), allocative effect (AE), etc. based on the Divisia Index. There are three advantages of measuring TFP within the framework of the stochastic nutrient frontier: first, it splits random errors and inefficiency and avoids the estimation bias of the frontier caused by extreme observations; and second, it fulfills the MBP condition, and the benefits of environmental efficiency based on MBP is also available for our method; and third, we decompose TFP into TEC, TC, AE, etc. based on the Divisia Index in a similar manner to Bauer's (1990) cost efficiency decomposition, because measuring environmental efficiency within SNF can be viewed as a counterpart of measuring cost efficiency under SFA. To the best of our knowledge, studies related to China's environmental productivity decomposition are still inadequate and preliminary. This paper measures current TFP in rice production and decomposes it, which not only illustrates the potential of improving agricultural productivity but also analyzes the reasons behind environmental efficiency variation and provides possible approaches via which nitrogen use efficiency (NUE) can be improved and N pollution can be reduced.

In the following section, we will illustrate the theoretical framework, before the data and empirical specification will be introduced in section three. Subsequently, the empirical

\footnotetext{
${ }^{1}$ Compared with the ex-post cost of pollution abatement, the ex-ante regulation on environmentally-detrimental inputs could lead to a lower cost of pollution abatement. 
results are given and discussed in section four. Finally, the main conclusions are presented in the last section.

\subsection{Theoretical framework}

Hoang and Coelli (2011) suggest that the pollution potential of agriculture can be denoted by the nutrient balance, which equals the total amount of nutrients in inputs minus the amount of nutrients in outputs, denoted as follows:

$$
\mathrm{u}=\mathbf{a x}-\mathbf{b q},
$$

where $\mathrm{u}$ represents the nutrient balance, $\mathbf{q}$ and $\mathbf{x}$ denote the output vector and input vector, and $\mathbf{a}$ and $\mathbf{b}$ are the vectors that represent the nutrient contents of inputs and outputs. Since some inputs like labor, capital, etc. might have zero nutrients, the vector a could contain zero values. In the context of studying $\mathrm{N}$ transformation in rice production, the nutrient balance equals $\mathrm{N}$ that enters the rice production in inputs (e.g. land and fertilizer) minus $\mathrm{N}$ that leaves the rice production in good outputs (e.g. rice). Thus, the above linear relation between the nutrient balance and inputs and outputs holds in our empirical research, because we only evaluate the nitrogen transformation.

According to Hoang and Coelli's (2011) model, undesirable outputs are defined as the nutrient balance (Coelli et al., 2007). When outputs are given, the nutrient balance reaches the minimum when the total amount of nutrients in inputs is minimized. Considering the crop production process, the nutrient frontier is decided by the output and the nutrients contained in each input, and then the nutrient frontier function can be denoted by Eq. (2):

$$
\mathrm{NC}^{*}=\mathrm{f}(\mathbf{q}, \mathbf{a}, \mathbf{t}) .
$$

Here, $\mathrm{NC}^{*}$ is the minimum nutrients that input into the production process given the output vector $q$ and nutrient content vector of input a at time $t$. If we use $\mathrm{NC}=\mathrm{f}$ to denote the observed nutrients, following Hoang and Coelli's (2011) idea, the nutrient efficiency (NE) can be defined as Eq. (3): 


$$
\mathrm{NE}=\frac{\mathrm{NC}}{\mathrm{NC}}=\frac{\mathrm{f}(\mathbf{q}, \mathbf{a}, \mathbf{t})}{\mathrm{f}} \text {. }
$$

Since the nutrient frontier function can be viewed as a counterpart of a cost frontier function, total factor productivity estimated within the nutrient frontier framework could be decomposed in the same way as the single-output and multiple-input case of the cost function approach introduced by Bauer (1990). By taking the natural logarithm and differentiating Eq. (3), the following equation can be yielded:

$$
\dot{\mathrm{NE}}=\varepsilon_{\mathrm{fq}}(\mathbf{q}, \mathbf{a}, \mathbf{t}) \dot{\mathrm{q}}+\sum_{\mathrm{i}} \frac{\partial \ln \mathrm{f}(\mathbf{q}, \mathbf{a}, \mathbf{t})}{\partial \mathrm{a}_{\mathrm{i}}} \frac{\mathrm{a}_{\mathrm{i}}}{\mathrm{f}(\mathbf{q}, \mathbf{a}, \mathbf{t})} \dot{\mathrm{a}}_{\mathrm{i}}+\frac{\partial \ln \mathrm{f}(\mathbf{q}, \mathbf{a}, \mathbf{t})}{\partial \mathrm{t}}-\dot{\mathrm{f}} .
$$

Here, $\quad \varepsilon_{\mathrm{fq}}(\mathbf{q}, \mathbf{a}, \mathbf{t})=\frac{\partial \ln \mathrm{f}(\mathbf{q}, \mathbf{a}, \mathbf{t})}{\partial \ln \mathrm{q}}=\frac{1}{\mathrm{RTS}} \cdot{ }^{1}$ After combing Eq. (4) and the Divisia Index $\mathrm{TF} \dot{\mathrm{F}}=\dot{\mathrm{q}}-\sum_{\mathrm{i}} \frac{\mathrm{a}_{\mathrm{i}} \mathrm{x}_{\mathrm{i}}}{\mathrm{f}} \dot{\mathrm{x}}_{\mathrm{i}}$, the TFP can be decomposed as Eq. (5):

$$
\mathrm{TFP}=\left[1-\varepsilon_{\mathrm{fq}}(\mathbf{q}, \mathbf{a}, \mathbf{t})\right] \dot{\mathrm{q}}+\dot{\mathrm{N} E}-\frac{\partial \ln \mathrm{f}(\mathbf{q}, \mathbf{a}, \mathbf{t})}{\partial \mathrm{t}}-\sum_{\mathrm{i}} \frac{\partial \ln \mathrm{f}(\mathbf{q}, \mathbf{a}, \mathbf{t})}{\partial \mathrm{a}_{\mathrm{i}}} \frac{\mathrm{a}_{\mathrm{i}}}{\mathrm{f}(\mathbf{q}, \mathbf{a}, \mathbf{t})} \dot{\mathrm{a}}_{\mathrm{i}}-\sum_{\mathrm{i}} \frac{\mathrm{a}_{\mathrm{i}} \mathrm{x}_{\mathrm{i}}}{\mathrm{f}} \dot{\mathrm{x}}_{\mathrm{i}}+\dot{\mathrm{f}}
$$

Furthermore, by using $\dot{\mathrm{f}}=\sum_{\mathrm{i}} \frac{\mathrm{a}_{\mathrm{i}} \mathrm{x}_{\mathrm{i}}}{\mathrm{f}} \dot{\mathrm{x}}_{\mathrm{i}}+\sum_{\mathrm{i}} \frac{\mathrm{a}_{\mathrm{i}} \mathrm{x}_{\mathrm{i}}}{\mathrm{f}} \dot{\mathrm{a}}_{\mathrm{i}}$, Eq. (5) can be simplified as:

$$
\dot{\mathrm{T} P}=\left[1-\varepsilon_{\mathrm{fq}}(\mathbf{q}, \mathbf{a}, \mathbf{t})\right] \dot{\mathrm{q}}+\dot{\mathrm{N} E}-\frac{\partial \ln \mathrm{f}(\mathbf{q}, \mathbf{a}, \mathbf{t})}{\partial \mathrm{t}}+\sum_{\mathrm{i}}\left[\mathrm{s}_{\mathrm{i}}-\mathrm{s}_{\mathrm{i}}(\mathbf{q}, \mathbf{a}, \mathbf{t})\right] \dot{\mathrm{a}}_{\mathrm{i}} .
$$

Here, $s_{i}$ and $s_{i}(\mathbf{q}, \mathbf{a}, \mathbf{t})$ represent the observed nutrient share and efficient nutrient share separately, i.e. $\quad \mathrm{s}_{\mathrm{i}}=\sum_{\mathrm{i}} \frac{\mathrm{a}_{\mathrm{i}} \mathrm{x}_{\mathrm{i}}}{\mathrm{f}} \quad$ and $\quad \mathrm{s}_{\mathrm{i}}(\mathbf{q}, \mathbf{a}, \mathbf{t})=\frac{\partial \ln \mathrm{f}(\mathbf{q}, \mathbf{a}, \mathbf{t})}{\partial \mathrm{a}_{\mathrm{i}}} \frac{\mathrm{a}_{\mathrm{i}}}{\mathrm{f}(\mathbf{q}, \mathbf{a}, \mathbf{t})}=\frac{\mathrm{a}_{\mathrm{i}} \mathrm{x}_{\mathrm{i}}(\mathbf{q}, \mathbf{a}, \mathbf{t})}{\mathrm{f}(\mathbf{q}, \mathbf{a}, \mathbf{t})} \cdot\left[1-\varepsilon_{\mathrm{fq}}(\mathbf{q}, \mathbf{a}, \mathbf{t})\right] \dot{\mathrm{q}}$ is the scale effect. $\quad \dot{N} E$ is the technical efficiency change, ${ }^{2}-\frac{\partial \ln f(\mathbf{q}, \mathbf{a}, \mathbf{t})}{\partial \mathrm{t}}$ is technical change and $\sum_{\mathrm{i}}\left[\mathrm{s}_{\mathrm{i}}-\mathrm{s}_{\mathrm{i}}(\mathbf{q}, \mathbf{a}, \mathbf{t})\right] \dot{\mathrm{a}}_{\mathrm{i}}$ is the allocative effect of nutrients, which could reflect the presence of nutrient allocative inefficiency, i.e. if nutrient allocative inefficiency exists, $\mathrm{s}_{\mathrm{i}} \neq \mathrm{s}_{\mathrm{i}}(\mathbf{q}, \mathbf{a}, \mathbf{t})$, and vice versa. If there are quasi-fixed inputs $\mathbf{z}$, then the nutrient function can be written as $\mathrm{f}(\mathbf{q}, \mathbf{a}, \mathbf{z}, \mathbf{t})$, and there will be an extra component $-\sum_{\mathrm{i}} \frac{\partial \ln f(\mathbf{q}, \mathbf{a}, \mathbf{z}, \mathbf{t})}{\partial \ln \mathrm{z}_{\mathrm{i}}} \dot{\mathrm{z}}_{\mathrm{i}}$ in Eq. (6), which is as follows:

\footnotetext{
1 RTS refers to returns to scale.

2 Note that the technical efficiency change is not the pure technical efficiency change, which can be further decomposed into pure technical efficiency change and allocative efficiency change. 


$$
\mathrm{TF} P=\left[1-\varepsilon_{\mathrm{fq}}(\mathbf{q}, \mathbf{a}, \mathbf{z}, \mathbf{t})\right] \dot{\mathrm{q}}+\dot{\mathrm{N}} \mathrm{E}-\frac{\partial \ln \mathrm{f}(\mathbf{q}, \mathbf{a}, \mathbf{z}, \mathbf{t})}{\partial \mathrm{t}}+\sum_{\mathrm{i}}\left[\mathrm{s}_{\mathrm{i}}-\mathrm{s}_{\mathrm{i}}(\mathbf{q}, \mathbf{a}, \mathbf{z}, \mathbf{t})\right] \dot{\mathrm{a}}_{\mathrm{i}}-\sum_{\mathrm{i}} \frac{\partial \ln \mathrm{f}(\mathbf{q}, \mathbf{a}, \mathbf{z}, \mathbf{t})}{\partial \ln \mathrm{z}_{\mathrm{i}}} \dot{\mathrm{z}}_{\mathrm{i}}
$$

From Eq. (7), the advantages of estimating a nutrient frontier, rather than other frontiers are obvious. First, compared with a fertilizer frontier only considering non-zero-nitrogen input, a nutrient frontier that also involves zero-nitrogen input (quasi-fixed input) may be more appropriate in productivity analysis, since the quasi-fixed input could limit the use of non-zero-nitrogen input and impact on productivity. Second, due to the nature of the production function, estimating the production frontier usually encounters endogeneity problems. However, most explanatory variables (nutrient content variables and quasi-fixed inputs) can be viewed as exogeneous variables. ${ }^{1}$ Third, the total factor productivity obtained based on the nutrient frontier contains the information about the actual nutrient share and efficient nutrient share, which enables evaluating environmental performance. If nutrient allocative inefficiency exists, there are chances for farmers to re-allocate their input combination to achieve environmental-efficient.

\subsection{Data and empirical specification}

Based on our research objective and data availability, we adopt the individual farm household data from Hubei Province in 2004-2010 provided by China's Rural Fixed Observation Point Bureau. We first exclude farm households, whose family main business is not planting. Subsequently, farm households inputting zero land or labor in rice production are excluded. Finally, we select farm households that can be observed over at least four years to alleviate the inconsistency of the variance of technical efficiency. ${ }^{2}$ After data cleaning, there are 1,837 farm households engaged in rice plantation in our unbalanced panel.

Due to the various categories of inputs and outputs in the dataset, we aggregate and split

\footnotetext{
1 The nutrient content variables are decided by the type and quality of fertilizer and land, and the quasi-fixed variables indirectly influence the amount of total nutrient.

2 Since some farmers can only be observed one year, we choose farmers can be observed at least four years to form our research data set to balance between farmers' observed years and the sample size.
} 
them into five inputs, namely land, labor, intermediate input, capital and fertilizer, and one output which is the total production of rice. ${ }^{1}$ The land variable is defined as the total sown area of each household measured by mu. ${ }^{2}$ The labor variable is defined as the total number of days that each household devotes to rice plantation activities. The intermediate input variable is an aggregation of purchases of seed, pesticide, diesel oil, plastic, etc., in yuan. The capital variable is given as the aggregation of purchases of machinery, agricultural assets, etc., which reflects the input of long-term goods during production. ${ }^{3}$ Due to the nature of long-term inputs, their values are depreciated using straight-line depreciation method and averagely added to the calculation of capital in yuan. ${ }^{4}$ To avoid inflation effects, intermediate input and capital are also adjusted by the CPI. ${ }^{5}$ First, we chose 2004 as the base year, and transformed the yearly CPI of 2004 to 2010 into a fixed-base CPI. Subsequently, values of intermediate input and capital calculated in 2004 CNY were obtained by dividing the fixed-base CPI. The fertilizer variable is the total fertilizers - which mainly include urea, ammonium phosphate and ammonium bicarbonate - applied in rice production in one year, calculated by kilogram. As for outputs, the rice output is defined as the total production of rice measured in kilograms. The statistical description of variables is presented in Table 4.1 .

Among five inputs, labor, intermediate input and capital are assumed to have zero nitrogen contents. The nitrogen contents in land are the total grams of available nitrogen

\footnotetext{
1 All of the inputs and outputs - such as land, labor, intermediate input, fertilizer and capital - refer to the inputs and outputs in the process of rice production based on the fourth section (farm households' production and operation status) of the original questionnaire, which includes the specific input and output situation of each crop.

21 mu equals approximately 0.067 hectares.

${ }^{3}$ In this paper, capital does not reflect the economic notion of capital appropriately. Hence, the capital variable used in this study should be interpreted with caution.

${ }^{4}$ We assume that the long-term inputs are depreciated averagely within ten years.

5 The CPI is from the National Bureau of Statistics (see http://www.stats.gov.cn/). Compared with other price indices and finance indices, the CPI may not be the best choice to reflect the true value change of intermediate input and capital. However, it is a good choice to reflect the true price change of farmers' production related inputs with regard to our research framework. 
(alkali hydrolysable nitrogen) in tillage layer per mu, which is usually inorganic nitrogen (nitrate nitrogen and ammonium nitrogen) and easily hydrolyzed organic nitrogen (amino acids, ammonium and easily hydrolyzed proteins). The nitrogen supply capacity of paddy soil in Hubei Province is represented by the nitrogen capacity of paddy soil in the observation spot in the adjacent Hunan Province from 2004 to 2010 according to the Soil Science Database, ${ }^{1}$ because the two provinces both have a long history of planting rice, and they are similar in paddy soil share, size and nutrient composition. ${ }^{2}$ Since the effects of different soil layers for rice root to absorb nutrients have a wide range, we chose a 20-centimeter tillage layer for the calculation of soil mass. Taking soil fertility heterogeneity into consideration, we use the ratio of the harvest area to sown area to adjust the nitrogen supply capacity of different plots.

The $\mathrm{N}$ contents in fertilizer is the ratio of the total grams of nitrogen coming from all types of fertilizers applied to rice to the total amount of fertilizers applied to rice. After calculating the total nitrogen contained in different types of fertilizers and the share of fertilizer applied to rice among total fertilizer application, the total nitrogen contained in fertilizer applied to rice can be obtained. Despite the possible existing bias that types of fertilizer applied may vary from crop to crop, our estimation of nitrogen in fertilizer applied to rice is still reliable and referable, because the main crop farmers in Hubei Province grow is rice. ${ }^{3}$

\footnotetext{
${ }^{1}$ See http://vdb3.soil.csdb.cn/.

2 See http://vdb3.soil.csdb.cn/.

3 The data set only has the amount of different fertilizers (urea, ammonium phosphate and ammonium bicarbonate) at the household level. According to the crop sown area data, where the sown areas for other crops are nearly zero, rice can be viewed as the main crop that farmers grow.
} 
Table 4.2 Statistical description of variables

\begin{tabular}{llllll}
\hline Variable & Unit & Mean & Std.Dev. & Min & Max \\
\hline observation $n=1837$ & & & & & \\
rice output & $\mathrm{kg}$ & 1831.84 & 1737.39 & 0 & 9989 \\
land & $\mathrm{mu}$ & 3.35 & 2.42 & 0.2 & 15 \\
labor & $\mathrm{day}$ & 58.97 & 46.98 & 1 & 378 \\
intermediate input & yuan & 602.95 & 873.12 & 4.39 & 19056.24 \\
capital & yuan & 4.15 & 11.69 & 0 & 133 \\
fertilizer & $\mathrm{kg}$ & 317.20 & 276.15 & 4 & 2689 \\
land $N$ contents & $\mathrm{g} / \mathrm{mu}$ & 22063.53 & 4223.91 & 0 & 70272.35 \\
fertilizer $N$ contents & $\mathrm{g} / \mathrm{kg}$ & 139.44 & 76.50 & 0 & 515.7 \\
\hline
\end{tabular}

a The land $\mathrm{N}$ contents multiplied by the land adding the fertilizer $\mathrm{N}$ contents multiplied by the fertilizer equals the total nitrogen input by each farm household. Here, the land $\mathrm{N}$ contents and fertilizer $\mathrm{N}$ contents should be measured at the level of rice production unit within the farm. However, considering the limitation of data, we only have the average level of the land $\mathrm{N}$ contents variable. Thus, we use the ratio of harvest area to sown area to adjust the nitrogen supply capacity for different farm households to make the variable more adaptable to our research framework.

${ }^{\mathrm{b}}$ There are four observations that have zero rice output.

${ }^{c}$ There are thirteen observations have the zero values in land $\mathrm{N}$ contents.

d There are 102 observations that have zero values and fifteen observations have missing values in fertilizer $\mathrm{N}$ contents. These observations may use other fertilizers, e.g. organic fertilizer and manure, from which it is difficult to calculate the nitrogen contents.

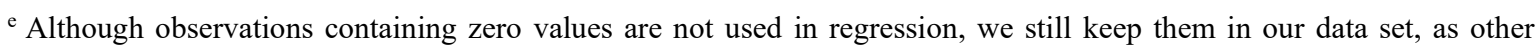
information about these observations could be used in the calculation of instant changes later.

As Reinhard et al. (2000) and Hoang and Nguyen (2013) have proposed, labor, capital and intermediate input are considered as quasi-fixed inputs, while land and fertilizer are variable inputs. The stochastic nutrient frontier function (SNFF) (Hoang and Nguyen, 2013) can be written as Eq. (8):

$$
n c_{i t}=f\left(q_{l i t}, a_{m i t}, z_{n i t} ; \beta\right) \exp \left\{v_{i t}+u_{i t}\right\},
$$

which should be non-decreasing in $q_{\text {lit }}$ and $a_{\text {mit }}$, and fulfill the concavity and linear homogeneity in $a_{m i t}$. Here, $n c_{i t}$ is the total nutrients contained in inputs at observation $i$ and time $t . q_{l i t} a_{m i t}$ and $z_{\text {nit }}$ refer to output $l$, nutrient contents in input $m$, quasi-fixed input $n$ at observation $i$ and time $t$, respectively. $\beta$ refers to unknown parameters to be estimated. $v_{i t}$ is assumed to be i.i.d. $N\left(0, \sigma_{v}\right) . u_{i t}$ is assumed to be i.i.d. $N^{+}\left(0, \sigma_{u}\right)$. 
After comparing Cobb-Douglas (CD) and translog functional forms for Eq. (8) (see Table 4.3 in Appendix A), the translog function is adopted to carry out the empirical model. The specific translog nutrient frontier function (the subscripts for farm $i$ and time $t$ are omitted for simplicity) is as Eq. (9):

$$
\begin{aligned}
\ln n c= & \beta^{*}+\sum_{n=1}^{2} \beta_{n} \ln a_{n}+\gamma_{1} \ln q+\sum_{m=1}^{3} \varphi_{m} \ln z_{m}+\frac{1}{2}\left(\sum_{n=1}^{2} \beta_{n n} \ln a_{n}^{2}+\gamma_{11} \ln q^{2}+\sum_{n=1}^{3} \sum_{m=1}^{3} \varphi_{n m} \ln z_{n} \ln z_{m}\right) \\
& +\beta_{12} \ln a_{1} \ln a_{2}+\sum_{n=1}^{2} \beta_{q n} \ln a_{n} \ln q+\sum_{n=1}^{2} \sum_{m=1}^{3} \rho_{n m} \ln a_{n} \ln z_{m}+\sum_{m=1}^{3} \varphi_{q m} \ln q \ln z_{m}+\theta t+\theta_{11} t^{2}+u+v
\end{aligned} .
$$

Here, $n c$ is the total nutrients and $q$ is the output vector. $a_{n}$ refers to nutrient contents in the land and fertilizer for $n=1,2 . z_{m}$ is quasi-fixed input vector, which denotes labor, intermediate input and capital for $m=1,2,3$. To correctly estimate variables that contain zero values, we adopt Battese's (1997) method to deal with the capital variable, which includes 748 zero values. Capital is defined as $z_{3}^{*}=\max \left\{z_{3}, D_{z 3}\right\}$, where $D_{z 3}=0$ if $z_{3}>0$, and $D_{z 3}=1$ if $z_{3}=0$. Thus, $\beta^{*}=\beta_{0}+\left(\alpha_{0}-\beta_{0}\right) * D_{z 3}$ in Eq. (9). $\alpha, \beta, \gamma, \varphi$ and $\rho$ are parameters to be estimated.

After imposing linear homogeneity in nutrient contents, the translog nutrient frontier function in Eq. (9) can be rewritten as Eq. (10):

$$
\begin{aligned}
\ln y= & \beta^{*}+\beta_{1} w+\gamma_{1} \ln q+\sum_{m=1}^{3} \varphi_{m} \ln z_{m}+\frac{1}{2}\left(\beta_{11} w^{2}+\gamma_{11} \ln q^{2}+\sum_{n=1}^{3} \sum_{m=1}^{3} \varphi_{n m} \ln z_{n} \ln z_{m}\right) \\
& +\beta_{q n} w \ln q+\sum_{m=1}^{3} \rho_{n m} w \ln z+\sum_{m=1}^{3} \varphi_{q m} \ln q \ln z_{m}+\theta t+\theta_{11} t^{2}+u+v
\end{aligned} .
$$

Here, $\ln y=\ln n c-\ln a_{1}$ and $w=\ln a_{2}-\ln a_{1}$. In the maximum likelihood estimation, all input, output and nutrient content variables are scaled by their sample mean.

\subsection{Results}

This part focuses on interpreting estimation results and the subsequent decomposition of total factor productivity. First, the results of the parameter estimates and levels of technical efficiency will be presented. Most parameter estimates in the model are statistically significant, and thus the results of our model are acceptable (see Table 4.2 in Appendix A). 
Additionally, the log likelihood values of different models (see Table 4.3 in Appendix A) indicate that it is appropriate to set time trend variables and an inefficiency term in the model. Subsequently, the components of TFP change are presented to show how different factors constitute TFP variation.

\subsubsection{Parameter estimates and technical efficiency}

Table 4.4 shows that increases in fertilizer $\mathrm{N}$ contents, land $\mathrm{N}$ contents, rice output, labor, and intermediate input could all lead to nitrogen growth, and the absolute values of nutrient elasticities reflect the relative share of N growth caused by each term. During 2004-2010, N contents in fertilizer and land contribute to $\mathrm{N}$ growth unevenly at $33 \%$ and $67 \%$, separately. This indicates that since the type and amount of fertilizer applied to a plot and the fertilizer taken by plants are limited, a percent increase in fertilizer $\mathrm{N}$ contents could only lead to about one-third of $\mathrm{N}$ growth. Unlike fertilizer $\mathrm{N}$ contents, our sample shows that land $\mathrm{N}$ contents significantly vary from plot to plot, which means that the fertile land can lead to an enormous rise in $\mathrm{N}$ growth. The nutrient elasticity of rice output (0.59) suggests that a $1 \%$ rice output growth may lead to $59 \% \mathrm{~N}$ growth. For nutrient elasticities of quasi-fixed input, rises in labor and intermediate input also contribute to $\mathrm{N}$ growth due to the complementary relationships among inputs (see Tables 4.7.1 and 4.7.2 in Appendix B). ${ }^{1}$ Therefore, increases in labor and intermediate input can also lead to total $\mathrm{N}$ growth indirectly through a fertilizer increase. The impact of capital on $\mathrm{N}$ growth is uncertain, because it takes a long time to appear.

\footnotetext{
${ }^{1}$ Since the prices of quasi-fixed input are price indices that do not reflect the price changes faced by individuals, we estimate the relationships between fertilizer price faced by individuals (can be calculated from the data set) and different quasi-fixed inputs used in per land unit using the OLS model. Although the coefficients are not statistically significant, the signs of these coefficients can still give us a preliminary view about the relationship between fertilizer price and different quasi-fixed inputs. 
Table 4.4 Nutrient elasticities

\begin{tabular}{lllll}
\hline & Obs & Mean & Std.Err. & [95\% Conf.Interval] \\
\hline $\mathrm{N}$ in fertilizer & 1707 & 0.330 & 0.003 & $0.325,0.335$ \\
$\mathrm{~N}$ in land & 1707 & 0.670 & 0.003 & $0.665,0.675$ \\
rice output & 1707 & 0.588 & 0.005 & $0.579,0.597$ \\
labor & 1707 & 0.246 & 0.002 & $0.242,0.250$ \\
intermediate & 1707 & 0.106 & 0.002 & $0.102,0.111$ \\
capital & 1707 & -0.004 & 0.002 & $-0.008,0.000$ \\
\hline
\end{tabular}

As for technical efficiency, the average technical efficiency is around 0.820 (see Table 4.5 in Appendix A). Overall, TE remains stable during 2004-2010, except for a reduction between 2004 and 2005, which is mainly caused by natural disasters. From 2004 to 2005, the disaster areas in Hubei Province increased by $66 \%$ and peaked at 2,580 thousand hectares in 2005, which irrefutably resulted in a decrease in TE. ${ }^{1}$

\subsubsection{Components of TFP change}

Table 4.6 provides statistical descriptive information about TFP components. The average decreasing rate of TFP is $2 \%$, which is a comprehensive outcome of all relevant components. Among all components, the effect of labor and intermediate and SE present positive effects on TFP change. The effect of labor (0.011) and intermediate input (0.003) indicate that average productivity increases due to the rise of labor and intermediate input. The positive SE (0.015) implies that it is beneficial to TFP growth if farmers adjust their size to achieve the most productive scale size (MPSS).

On the other hand, the negative impacts of effect of capital $(-0.017)$, the allocative effect of fertilizer nutrient $(-0.011)$ and technical regress $(-0.016)$ are the main reasons for the TFP decrease. The negative allocative effect of fertilizer nutrient $(-0.011)$ indicates that the observed nutrient share is larger than the efficient nutrient share when instant changes of fertilizer $\mathrm{N}$ contents are decreasing (see Table 4.8 in Appendix B), i.e. farmers use more

\footnotetext{
1 The disaster area data is from the National Bureau of Statistics (see http://www.stats.gov.cn/).
} 
fertilizer than they need. The overuse of $\mathrm{N}$ fertilizer can be reflected directly from the $\mathrm{N}$ surplus per unit land. The $\mathrm{N}$ surplus $\left(58 \mathrm{~kg} \mathrm{~N} \mathrm{ha}^{-1}\right)$ of current practices could be reduced to $16 \mathrm{~kg} \mathrm{~N} \mathrm{ha}^{-1}$ by using integrated soil crop practices that use advanced crop and implement nutrient management (Chen et al., 2014). The high nutrient share of fertilizer and excess use of $\mathrm{N}$ fertilizer would destroy the soil fertility and reduce productivity. To combat the overuse of chemical fertilizer and balance soil nutrient structure, the Chinese government has proposed to achieve zero-fertilizer and zero-pesticide growth in 2015. By 2020, the fertilizer application amount has declined for consecutive years, and NUE (40.2\%) has increased by $5 \%$ compared to 2015 . $^{1}$

The negative effect of capital suggests that rise of capital cannot lead to average productivity growth, because the effect of long-term input takes time to emerge. In the meantime, it is noteworthy that total nitrogen increases at an annual rate of $1.6 \%$. There are two reasons for this: one is the improvement of industrialization, and another is the low NUE. To satisfy the increasing material need and industrial growth, the rapid development of agriculture is usually associated with high energy consumption, high pollution, high waste and low efficiency. This agricultural development pattern inevitably leads to the consequence of excess fertilizer, pesticide, etc. In addition, due to the volatile and run-off nature of $\mathrm{N}$ fertilizer, NUE for grain crops is only $30-35 \%$ in China (Peng et al., 2015; Xu et al., 2012), which is much lower than in North-East Thailand (43.9\%) (Ohnishi et al., 1999). The low NUE causes the increasing amount of fertilizer application, and the excess $\mathrm{N}$ fertilizer application inhibits the absorption of other nutrients, which forms a vicious cycle.

\footnotetext{
${ }^{1}$ See http://www.gov.cn/xinwen/2021-01/17/content_5580552.htm.
} 
Table 4.6 Components of TFP

\begin{tabular}{lllll}
\hline & Mean & Std.Dev. & Min & Max \\
\hline TC & -0.016 & 0.002 & -0.019 & -0.014 \\
SE & 0.015 & 0.226 & -1.126 & 1.546 \\
TEC & -0.003 & 0.109 & -0.761 & 0.531 \\
allocative effect of land nutrient & -0.003 & 0.036 & -0.467 & 0.118 \\
allocative effect of fertilizer nutrient & -0.011 & 0.071 & -0.665 & 0.399 \\
effect of labor & 0.011 & 0.141 & -0.555 & 0.441 \\
effect of intermediate input & 0.003 & 0.106 & -0.505 & 0.606 \\
effect of capital & -0.017 & 0.263 & -0.903 & 0.706 \\
TFP & -0.020 & 0.347 & -1.363 & 1.670 \\
\hline
\end{tabular}

a There are 834 observations used to calculate TFP and its components, which is lower than the number of observations $(1,707)$ in the regression due to zero values of capital and the exclusion of first-year values when calculating instant changes of inputs and their $\mathrm{N}$ contents.

\subsection{Conclusion}

The main contribution of this paper is that we estimate total factor productivity within the framework of the stochastic nutrient frontier and further decompose it into technical efficiency change, technical change, allocative effect and quasi-fixed input effect based on the Divisia Index. The main findings of this paper are as follows. First, increases in fertilizer $\mathrm{N}$ contents, land $\mathrm{N}$ contents, rice output, labor and intermediate input could all lead to $\mathrm{N}$ growth. Second, compared to fertilizer $\mathrm{N}$ contents, land $\mathrm{N}$ contents significantly vary from plot to plot and could lead to a larger rise in total N. Third, due to the complementary relationship between fertilizer and quasi-fixed input, increases in labor and intermediate input can also lead to total $\mathrm{N}$ growth indirectly through fertilizer increase. Fourth, technical efficiency remains stable during 2004-2010, except for a reduction between 2004 and 2005, which is mainly caused by natural disasters. Fifth, TFP is decreasing with an average annual rate of $2 \%$, which is attributed to the negative impacts of the allocative effect of fertilizer nutrient (-0.011), the effect of capital $(-0.017)$ and technical regress $(-0.016)$. Sixth, the negative allocative effect of fertilizer $\mathrm{N}$ contents indicates that farmers use more fertilizer than they need. Seventh, due to the improvement of industrialization and low NUE, total N 
slightly increases at a rate of $1.6 \%$ every year. 


\subsection{Appendix}

\section{Appendix A}

Table 4.3 Parameter estimates

\begin{tabular}{|c|c|c|}
\hline 2003-2010 & Estimates & SE \\
\hline$\beta_{1}$ & $0.34 * * *$ & $(0.02)$ \\
\hline$\gamma_{1}$ & $0.53 * * *$ & $(0.02)$ \\
\hline$\varphi_{1}$ & $0.28 * * *$ & $(0.02)$ \\
\hline$\varphi_{2}$ & $0.13 * * *$ & $(0.02)$ \\
\hline$\varphi_{3}$ & $-0.02 *$ & $(0.01)$ \\
\hline$\beta_{11}$ & $0.17 * * *$ & $(0.03)$ \\
\hline$\gamma_{11}$ & $-0.16^{* * *}$ & $(0.04)$ \\
\hline$\varphi_{11}$ & -0.03 & $(0.02)$ \\
\hline$\varphi_{22}$ & $0.04 *$ & $(0.02)$ \\
\hline$\varphi_{33}$ & -0.00 & $(0.01)$ \\
\hline$\beta_{q 1}$ & $-0.12 * * *$ & $(0.03)$ \\
\hline$\rho_{11}$ & 0.01 & $(0.02)$ \\
\hline$\rho_{12}$ & $0.09^{* * *}$ & $(0.02)$ \\
\hline$\rho_{13}$ & -0.03 & $(0.02)$ \\
\hline$\varphi_{\mathrm{q} 1}$ & $0.09 * * *$ & $(0.02)$ \\
\hline$\varphi_{\mathrm{q} 2}$ & -0.03 & $(0.02)$ \\
\hline$\varphi_{\mathrm{q} 3}$ & $0.18 * * *$ & $(0.01)$ \\
\hline$\varphi_{12}$ & 0.01 & $(0.02)$ \\
\hline$\varphi_{13}$ & $-0.06^{* * *}$ & $(0.01)$ \\
\hline$\varphi_{23}$ & $-0.12 * * *$ & $(0.01)$ \\
\hline$\theta$ & $0.02 * * *$ & $(0.00)$ \\
\hline$\theta_{11}$ & -0.00 & $(0.00)$ \\
\hline$\alpha_{0}$ & $-0.04 * *$ & $(0.02)$ \\
\hline$\beta_{0}$ & $-0.05 * *$ & $(0.02)$ \\
\hline$\sigma_{u}^{2}$ & $-2.65 * * *$ & $(0.19)$ \\
\hline$\sigma_{v}^{2}$ & $-3.01 * * *$ & $(0.09)$ \\
\hline observations & 1,707 & 1,707 \\
\hline
\end{tabular}


Table 4.3 Test for different models

\begin{tabular}{lllll}
\hline model & loglikelihood value & df & AIC & BIC \\
\hline $\mathrm{M}_{1}$ : C-D function & -395.71 & 7 & 805.42 & 843.51 \\
$\mathrm{M}_{2}$ : time trend term & -382.02 & 9 & 782.04 & 831.03 \\
$\mathrm{M}_{3}$ : inefficiency term & -371.31 & 11 & 764.62 & 824.48 \\
$\mathrm{M}_{4}$ : translog function & -205.14 & 26 & 462.28 & 603.78 \\
\hline
\end{tabular}

Table 4.5 Levels of technical efficiency

\begin{tabular}{llll}
\hline Year & Mean & Std.Dev. & Freq. \\
\hline 2004 & 0.824 & 0.09 & 119 \\
2005 & 0.809 & 0.08 & 295 \\
2006 & 0.824 & 0.06 & 290 \\
2007 & 0.825 & 0.07 & 187 \\
2008 & 0.824 & 0.07 & 282 \\
2009 & 0.819 & 0.07 & 280 \\
2010 & 0.821 & 0.07 & 254 \\
average & 0.820 & 0.07 & 1707 \\
\hline
\end{tabular}




\section{Appendix B}

Table 4.7.1 OLS regression between fertilizer price and labor

\begin{tabular}{llllll}
\hline & Coef. & Std. Err. & $\mathrm{t}$ & $\mathrm{P}>\mathrm{t}$ & {$[95 \%$ Conf. Interval] } \\
\hline p_fertilizer & -1.71 & 0.91 & -1.89 & 0.06 & $-3.49,0.07$ \\
_cons & 25.22 & 1.37 & 18.43 & 0.00 & $22.54,27.91$ \\
\hline
\end{tabular}

Table 4.7.2 OLS regression between fertilizer price and intermediate input

\begin{tabular}{llllll}
\hline & Coef. & Std. Err. & $\mathrm{t}$ & $\mathrm{P}>\mathrm{t}$ & {$[95 \%$ Conf. Interval] } \\
\hline p_fertilizer & -9.90 & 5.66 & -1.75 & 0.08 & $-21.01,1.20$ \\
_cons & 184.99 & 8.54 & 21.66 & 0 & $168.24,201.73$ \\
\hline
\end{tabular}

Table 4.7.3 OLS regression between fertilizer price and capital

\begin{tabular}{llllll}
\hline & Coef. & Std. Err. & $\mathrm{t}$ & $\mathrm{P}>\mathrm{t}$ & {$[95 \%$ Conf. Interval] } \\
\hline p_fertilizer & -1.07 & 0.36 & -2.96 & 0.00 & $-1.78,-0.36$ \\
_cons & 3.31 & 0.55 & 6.06 & 0 & $2.24,4.38$ \\
\hline
\end{tabular}

Table 4.8 Instant changes of land $\mathbf{N}$ contents and fertilizer $\mathbf{N}$ contents

\begin{tabular}{llllll}
\hline Variable & Obs & Mean & Std. Dev. & Min & Max \\
\hline dot_land & 834 & -0.03 & 0.22 & -0.66 & 1.02 \\
dot_fertilizer & 834 & -0.04 & 0.38 & -1.22 & 1.75 \\
\hline
\end{tabular}

a The number of the observation is consistent with the number of observation used to calculate TFP and its components. 


\section{Chapter 5 General conclusion}

\subsection{Main findings}

There are three main objectives we try to achieve in this research. First, we try to measure the total factor productivity change in China's agricultural sector before and after China's entry to WTO, identify the decisive factors behind TFP change and find out the trade influence on technical efficiency. After measuring TFP change from 1995 to 2010 and decomposing it into TEC, TC, AE and SE in Chapter 2, we obtain following conclusions. First, land, labor, intermediate input and capital could all lead to output growth. Second, China's productivity increases during the whole research period, and TFP growth rate rises slightly after China's entry to WTO. Third, the main contributors to TFP growth are not the same for two sub-samples. Before China's accession to WTO, productivity growth majorly owes to allocative effect of pork and other meat and the considerable technical progress, while allocative effect of crop and land and technical progress are contributing factors after China's accession to WTO. Fourth, the development of technology achieves steady and substantial progress during the research period. Fifth, export has significant positive effect on technical efficiency before China's entry to WTO, while import presents negative effect on technical efficiency after China's entry to WTO.

Our second objective is measuring and decomposing China's environmental efficiency when production technology exhibits VRS. Based on the empirical research on rice production in Chapter 3, we obtain following findings. First, the annual INE scores experience a mild fluctuation in 2004-2010, and the average INE indicates there is large potential to reduce current $\mathrm{N}$ input by $39 \%$. Second, rice farmers in Hubei Province have already located at the most productive scale size. Third, RDTFP presents an annual decreasing rate owing to technical regress. Fourth, because of time lags and overestimation 
of inefficiency, the changing direction of TEC and TC are different. Fifth, rice farmers could decrease $19 \%$ of the nitrogen emissions based on the technical-efficient point on CRS frontier. Sixth, NASEC is found to be more strongly correlated with NTFPC. Seventh, the changing direction of NTFP is consistent with RDTFP.

The third objective is to measure current TFP in rice production using SFA, analyze factors behind environmental efficiency variation and provide possible approaches via which NUE can be improved and N pollution can be reduced. After our empirical research on rice production in Chapter 4, the main findings are as follows. First, increases in fertilizer N contents, land $\mathrm{N}$ contents, rice output, labor and intermediate input could all lead to $\mathrm{N}$ growth. Second, compared with fertilizer $\mathrm{N}$ contents, land $\mathrm{N}$ contents variation could lead to a larger rise in total N. Third, due to the complementary relationship between fertilizer and quasifixed input, increases in labor and intermediate input can also lead to total $\mathrm{N}$ growth indirectly through fertilizer increase. Fourth, technical efficiency in rice production remains stable in 2004-2010. Fifth, TFP is decreasing at an average annual rate of $2 \%$, which is attributed to the negative impacts of the allocative effect of fertilizer nutrient, the effect of capital and technical regress. Sixth, the negative allocative effect of fertilizer $\mathrm{N}$ contents indicates that farmers use more fertilizer than they need. Seventh, due to the improvement of industrialization and low NUE, total $\mathrm{N}$ slightly increases at a rate of $1.6 \%$ every year.

\subsection{Policy implications}

The empirical findings provide several policy implications. First, our results of Chapter 2 imply that technical progress could positively impact on China's productivity. Hence encouraging scientific and technological innovation and promoting agricultural management level are two promising aspects to achieve China's productivity growth in future. Second, government should reduce meat price or properly control meat export to eliminate meat allocative inefficiency. Third, to become crop production allocative-efficient, government 
could cut subsidies and national support concerning crop production. Fourth, enacting more proposals and regulations on perfecting the land circulation market and protecting arable land from using for commercial purpose could help reduce land allocative inefficiency.

Although we use different methods to measure environmental efficiency, the policy implications based on empirical findings are not contradictory. The implications based on empirical findings of Chapter 3 and Chapter 4 are as follows. First, to resolve the issue of agricultural waste and environmental pollution, policy makers should combine environmental and agricultural goal together when introducing regulations, since they are not contrary. Second, government's intervention and punishment on overuse of $\mathrm{N}$ fertilizer is necessary, due to the great potential of reducing $\mathrm{N}$ pollution by using less $\mathrm{N}$. Third, after satisfying the current minimum amount of $\mathrm{N}$ input to become technical-efficient and scaleefficient, policy makers could guide farmers to reallocate their input combination to become environmental-efficient, since it is the most effective way to prevent $\mathrm{N}$ pollution. Fourth, the overuse of $\mathrm{N}$ fertilizer may be counter-productive and deteriorate soil fertility, whereby balancing other $\mathrm{N}$ inputs (e.g. soil $\mathrm{N}$ ) against fertilizer $\mathrm{N}$ could achieve nutrient allocativeefficient and productivity growth at the same time. Fifth, since the excess use of land is inefficient and can lead to $\mathrm{N}$ growth, improving the land circulation market and integrating small fragmented arable land can be a solution to eliminate nutrient allocative inefficiency. Sixth, since technical regress is one of the main reasons for TFP decrease, encouraging technological innovation and developing an efficient fertilizer application approach may be a prior choice for promoting agricultural development and soil conservation in the future. Seventh, developing sustainable agriculture instead of high energy consumption, high waste and low efficiency agriculture could help to prevent $\mathrm{N}$ pollution growing over the years.

\subsection{Limitations and outlook for future research}

Although the decomposition of TFP and NTFP sheds light on the interpretation of TFP 
and NTFP variation, there are still some limitations in this study. First, we artificially aggregate some inputs as a whole, which neglects the heterogeneity among different inputs and may lead to a different estimation of the production frontier. Second, due to the restriction of dataset, we only explore some possible determinates of technical efficiency, which may be partial and biased. For future study, more extension related to technical efficiency should be taken into consideration to ensure a more accurate and comprehensive estimation. Third, since we only divide trade index into export index and import index, the specific trade effects of different kinds of products are still worth being explored in future studies to issue more practical and product-oriented regulations. Finally, more environmental extension should be involved to provide a more comprehensive and accurate analysis of the effects of agricultural production on the environment. Since the real ecological environment is much more complex, the calculation of nitrogen contents in soil and fertilizer inputted to agricultural production could only give us a preliminary idea of whether $\mathrm{N}$ excess exists. In practice, land and fertilizer $\mathrm{N}$ taken by plants is also affected by other nutrients and physical conditions, and thus additional environmental factors such as phosphorus contents, potassium contents, sunshine, temperature, rainfall, etc. should be taken into account to offer more comprehensive and constructive advice for scientific fertilizer application and agricultural productivity growth. 


\section{References}

Balk, B.M. (2001). Scale efficiency and productivity change. Journal of Productivity Analysis, 15(3), 159-183.

Battese, G.E. (1997). A Note on the Estimation of Cobb-Douglas Production Functions When Some Explanatory Variables Have Zero Values. Journal of Agricultural Economics, 48(1-3), 250-252.

Bauer, P.W. (1990). Decomposing TFP growth in the presence of cost inefficiency, nonconstant returns to scale, and technological progress. Journal of Productivity Analysis, 1(4), 287-299.

Bijay, S., Yadvinder, S., and Sekhon, G.S. (1995). Fertilizer-N use efficiency and nitrate pollution of groundwater in developing countries. Journal of Contaminant Hydrology, 20(3-4), 167-184.

Bohlool, B., Ladha, J., Garrity, D., and George, T. (1992). Biological nitrogen fixation for sustainable agriculture: A perspective. Plant and soil, 141(1-2), 1-11.

Brümmer, B., Glauben, T., and Lu, W. (2006). Policy reform and productivity change in Chinese agriculture: A distance function approach. Journal of Development Economics, 81(1), 61-79.

Brümmer, B., Glauben, T., and Thijssen, G. (2002). Decomposition of productivity growth using distance functions: the case of dairy farms in three European countries. American Journal of Agricultural Economics, 84(3), 628-644.

Burggraf, C., Kuhn, L., Zhao, Q.-r., Teuber, R., and Glauben, T. (2015). Economic growth and nutrition transition: an empirical analysis comparing demand elasticities for foods in China and Russia. Journal of Integrative Agriculture, 14(6), 1008-1022.

Callens, I., and Tyteca, D. (1999). Towards indicators of sustainable development for firms: a productive efficiency perspective. Ecological Economics, 28(1), 41-53. 
Cassman, K.G., Dobermann, A., and Walters, D.T. (2002). Agroecosystems, nitrogen-use efficiency, and nitrogen management. Ambio, 31(2), 132-140.

Cassman, K.G., Dobermann, A., Walters, D.T., and Yang, H. (2003). Meeting cereal demand while protecting natural resources And improving environmental quality. Annual Review of Environment and Resources, 28(1), 315-358.

Caves, D.W., Christensen, L.R., and Diewert, W.E. (1982). The economic theory of index numbers and the measurement of input, output, and productivity. Econometrica: Journal of the Econometric Society, 1393-1414.

Chaney, T. (2008). Distorted gravity: the intensive and extensive margins of international trade. American Economic Review, 98(4), 1707-1721.

Chen, X., Cui, Z., Fan, M., Vitousek, P., Zhao, M., Ma, W., Wang, Z., Zhang, W., Yan, X., Yang, J., Deng, X., Gao, Q., Zhang, Q., Guo, S., Ren, J., Li, S., Ye, Y., Wang, Z., Huang, J., Tang, Q., Sun, Y., Peng, X., Zhang, J., He, M., Zhu, Y., Xue, J., Wang, G., Wu, L., An, N., Wu, L., Ma, L., Zhang, W., and Zhang, F. (2014). Producing more grain with lower environmental costs. Nature, 514(7523), 486-489.

Cheng, S.H., Zhuang, J.Y., Fan, Y.Y., Du, J.H., and Cao, L.Y. (2007). Progress in research and development on hybrid rice: a super-domesticate in China. Ann Bot, 100(5), 959966.

Cho, J.-Y. (2003). Seasonal runoff estimation of $\mathrm{N}$ and $\mathrm{P}$ in a paddy field of central Korea. Nutrient Cycling in Agroecosystems, 65(1), 43-52.

Chung, Y.H., Färe, R., and Grosskopf, S. (1997). Productivity and undesirable outputs: a directional distance function approach. journal of Environmental Management, 51(3), 229-240.

Coelli, T., Lauwers, L., and Van Huylenbroeck, G. (2007). Environmental efficiency measurement and the materials balance condition. Journal of Productivity Analysis, $28(1-2), 3-12$.

Coelli, T., and Perelman, S. (1999). A comparison of parametric and non-parametric distance 
functions: With application to European railways. European Journal of Operational Research, 117(2), 326-339.

Cuesta, R.A., Lovell, C.K., and Zofío, J.L. (2009). Environmental efficiency measurement with translog distance functions: A parametric approach. Ecological Economics, 68(89), 2232-2242.

Faere, R., Grosskopf, S., Lovell, C.A.K., and Pasurka, C. (1989). Multilateral Productivity Comparisons When Some Outputs are Undesirable: A Nonparametric Approach. The Review of Economics and Statistics, 71(1), 90.

Fan, S. (1991). Effects of technological change and institutional reform on production growth in Chinese agriculture. American Journal of Agricultural Economics, 73(2), 266-275.

Fan, S., and Agcaoili-Sombilla, M. (1997). Why projections on China's future food supply and demand differ. Australian Journal of Agricultural and Resource Economics, 41(2), 169-190.

Färe, R. (1988). Fundamentals of production theory. Springer.

Farrell, M.J. (1957). The measurement of productive efficiency. Journal of the Royal Statistical Society, 120(3), 253-290.

Fleming, D.A., Abler, D.G., and Goetz, S.J. (2010). Agricultural trade and poverty in Chile: a spatial analysis of product tradability. Agricultural Economics, 41(6), 545-553.

Freney, J., Trevitt, A., De Datta, S., Obcemea, W., and Real, J. (1990). The interdependence of ammonia volatilization and denitrification as nitrogen loss processes in flooded rice fields in the Philippines. Biology and fertility of soils, 9(1), 31-36.

Fuentes, H.J., Grifell-Tatjé, E., and Perelman, S. (2001). A parametric distance function approach for Malmquist productivity index estimation. Journal of Productivity Analysis, 15(2), 79-94.

Gong, B. (2018). The Impact of Public Expenditure and International Trade on Agricultural Productivity in China. Emerging Markets Finance and Trade, 54(15), 3438-3453. 
Greene, W. (2005). Fixed and random effects in stochastic frontier models. Journal of Productivity Analysis, 23(1), 7-32.

Hoang, V.-N., and Coelli, T. (2011). Measurement of agricultural total factor productivity growth incorporating environmental factors: A nutrients balance approach. Journal of Environmental Economics and Management, 62(3), 462-474.

Hoang, V.-N., and Nguyen, T.T. (2013). Analysis of environmental efficiency variations: A nutrient balance approach. Ecological Economics, 86, 37-46.

Huang, J., Liu, Y., Martin, W., and Rozelle, S. (2009). Changes in trade and domestic distortions affecting China's agriculture. Food Policy, 34(5), 407-416.

Huang, W., Brümmer, B., and Huntsinger, L. (2014) "Technical Efficiency, Ecological Efficiency and Grassland Ecological Performance of Grazing in China." In the EAAE 2014 Congress: Agri-Food and Rural Innovations for Healthier Societies. Ljubljana, Slovenia August. 26-29.

Iram, R., Zhang, J., Erdogan, S., Abbas, Q., and Mohsin, M. (2020). Economics of energy and environmental efficiency: evidence from OECD countries. Environmental Science and Pollution Research, 27(4), 3858-3870.

Karagiannis, G., Midmore, P., and Tzouvelekas, V. (2004). Parametric decomposition of output growth using a stochastic input distance function. American Journal of Agricultural Economics, 86(4), 1044-1057.

Krugman, P. (1980). Scale economies, product differentiation, and the pattern of trade. The American economic review, 70(5), 950-959.

Kumbhakar, S.C., and Lovell, C.A.K. (2000). A Stochastic Frontier Analysis. Cambrige University Press, Cambrige.

Kuosmanen, T., and Kortelainen, M. (2005). Measuring eco-efficiency of production with data envelopment analysis. Journal of Industrial Ecology, 9(4), 59-72.

Ladha, J.K., Pathak, H., Krupnik, T.J., Six, J., and van Kessel, C. (2005). Efficiency of fertilizer nitrogen in cereal production: retrospects and prospects. Advances in 
agronomy, 87, 85-156.

Lin, J.Y. (1988). The household responsibility system in China's agricultural reform: a theoretical and empirical study. Economic Development and Cultural Change, 36(S3), S199-S224.

Linquist, B., Groenigen, K.J., Adviento-Borbe, M.A., Pittelkow, C., and Kessel, C. (2012). An agronomic assessment of greenhouse gas emissions from major cereal crops. Global Change Biology, 18(1), 194-209.

Melitz, M.J. (2003). The impact of trade on intra-industry reallocations and aggregate industry productivity. Econometrica, 71(6), 1695-1725.

Murty, S., Robert Russell, R., and Levkoff, S.B. (2012). On modeling pollution-generating technologies. Journal of Environmental Economics and Management, 64(1), 117-135.

Nin-Pratt, A., Yu, B., and Fan, S. (2009). Comparisons of agricultural productivity growth in China and India. Journal of Productivity Analysis, 33(3), 209-223.

Nin Pratt, A., Hertel, T.W., Foster, K.A., and Rae, A.N. Productivity Growth And CatchingUp: Implications For China'S Trade In Livestock Products.

Ohnishi, M., Horie, T., Homma, K., Supapoj, N., Takano, H., and Yamamoto, S. (1999). Nitrogen management and cultivar effects on rice yield and nitrogen use efficiency in Northeast Thailand. Field Crops Research, 64(1-2), 109-120.

Orea, L. (2002). Parametric decomposition of a generalized Malmquist productivity index. Journal of Productivity Analysis, 18(1), 5-22.

Peng, S., Buresh, R.J., Huang, J., Yang, J., Zou, Y., Zhong, X., Wang, G., and Zhang, F. (2006). Strategies for overcoming low agronomic nitrogen use efficiency in irrigated rice systems in China. Field Crops Research, 96(1), 37-47.

Peng, S., Tang, Q., and Zou, Y. (2015). Current Status and Challenges of Rice Production in China. Plant Production Science, 12(1), 3-8.

Phupaibul, P., Chinoim, N., and Matoh, T. (2002). Nitrate concentration in Chinese kale sold at markets around Bangkok, Thailand. Thai Journal of Agricultural Science (Thailand). 
Picazo-Tadeo, A.J., Beltrán-Esteve, M., and Gómez-Limón, J.A. (2012). Assessing ecoefficiency with directional distance functions. European Journal of Operational Research, 220(3), 798-809.

Picazo-Tadeo, A.J., Gomez-Limon, J.A., and Reig-Martinez, E. (2011). Assessing farming eco-efficiency: a Data Envelopment Analysis approach. J Environ Manage, 92(4), $1154-1164$.

Piot-Lepetit, I., and Le Moing, M. (2007). Productivity and environmental regulation: the effect of the nitrates directive in the French pig sector. Environmental and Resource Economics, 38(4), 433-446.

Ponnamperuma, F.N. (1972) "The chemistry of submerged soils." In Advances in agronomy. Elsevier, pp. 29-96.

Rae, A. (2008). China's agriculture, smallholders and trade: driven by the livestock revolution? Australian Journal of Agricultural and Resource Economics, 52(3), 283302.

Ray, S.C., and Desli, E. (1997). Productivity Growth, Technical Progress, and Efficiency Change in Industrialized Countries: Comment. The American economic review, 87(5), 1033-1039.

Reeves, T., Waddington, S., Ortiz-Monasterio, I., Bänziger, M., and Cassaday, K. (2002). Removing nutritional limits to maize and wheat production: A developing country perspective. Biofertilisers in Action. Rural Industries Research and Development Corporation, Canberra, 11-36.

Reinhard, S., Lovell, C.K., and Thijssen, G.J. (1999). Econometric estimation of technical and environmental efficiency: an application to Dutch dairy farms. American Journal of Agricultural Economics, 81(1), 44-60.

Reinhard, S., Lovell, C.K., and Thijssen, G.J. (2000). Environmental efficiency with multiple environmentally detrimental variables; estimated with SFA and DEA. European Journal of Operational Research, 121(2), 287-303. 
Shephard, R.W. (1970). Theory of cost and production functions Princeton University press, Princeton, New Jersey.

Turner, P.A., Griffis, T.J., Lee, X., Baker, J.M., Venterea, R.T., and Wood, J.D. (2015). Indirect nitrous oxide emissions from streams within the US Corn Belt scale with stream order. Proc Natl Acad Sci U S A, 112(32), 9839-9843.

Vitousek, P.M., Aber, J.D., Howarth, R.W., Likens, G.E., Matson, P.A., Schindler, D.W., Schlesinger, W.H., and Tilman, D.G. (1997). Human alteration of the global nitrogen cycle: sources and consequences. Ecological applications, 7(3), 737-750.

Vlontzos, G., Niavis, S., and Manos, B. (2014). A DEA approach for estimating the agricultural energy and environmental efficiency of EU countries. Renewable and Sustainable Energy Reviews, 40, 91-96.

Wang, H.-J., and Schmidt, P. (2002). One-step and two-step estimation of the effects of exogenous variables on technical efficiency levels. Journal of Productivity Analysis, $18(2), 129-144$.

Wu, G., and Zhu, J. (2014). The study of Chinese agricultural trade policy adjustment and comparative advantage change. Journal of Northwest A\&F University, 14(1), 47-63.

Xu, G., Fan, X., and Miller, A.J. (2012). Plant nitrogen assimilation and use efficiency. Annu Rev Plant Biol, 63, 153-182.

Zhang, Y., Wang, X., Glauben, T., and Brümmer, B. (2011). The impact of land reallocation on technical efficiency: evidence from China. Agricultural Economics, 42(4), 495-507.

Zhuang, P. (2011). International trade of agricultural products. 1 ed. University of International Business and Economics Press, Beijing, China. 